\title{
Phase Formation of Nanolaminated Transition Metal Carbide Thin Films
}

\author{
Chung-Chuan Lai
}

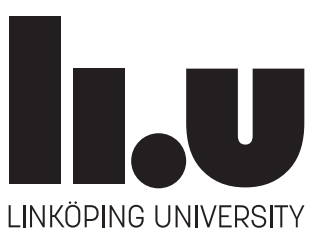

Thin Film Physics Division

Department of Physics, Chemistry and Biology (IFM)

Linköping University

Linköping 2017 
The cover image is a simple sketch of structural-chemical relation in between the metal layers in nanolaminated transition metal carbides: $\mathrm{Mo}_{2} \mathrm{GaC}, \mathrm{Mo}_{2} \mathrm{Ga}_{2} \mathrm{C}$, and $\mathrm{Mo}_{2}\left(\mathrm{Au}_{1-x} \mathrm{Ga}_{x}\right)_{2} \mathrm{C}$ with an in-plane order in the Au-Ga layers, where the last two phases were discovered in this thesis.

(C) Chung-Chuan Lai 2017

Printed in Sweden by LiU-Tryck 2017

ISSN 0345-7524

ISBN 978-91-7685-526-3 


\section{Abstract}

Research on inherently nanolaminated transition metal carbides is inspired by their unique properties combining metals and ceramics, such as higher damage tolerance, better machinability and lower brittleness compared to the binary counterparts, yet retaining the metallic conductivity. The interesting properties are related to their laminated structure, composed of transition-metal carbide layers interleaved by non-transition-metal (carbide) layers. These materials in thin-film form are particularly interesting for potential applications such as protective coatings and electrical contacts. The goal of this work is to explore nanolaminated transition metal carbides from the aspects of phase formation and crystal growth during thin-film synthesis. This was realized by studying phases in select material systems synthesized from two major approaches, namely, from direct-deposition and post-deposition treatment.

The first approach was used in studies on the Mo-Ga-C and Zr-Al-C systems. In the former system, intriguing properties have been predicted for the 3D phases and their 2D derivatives (so called MXenes), while in the latter system, the phases are interesting for nuclear applications. In this work, the discovery of a new Mo-based nanolaminated ternary carbide, $\mathrm{Mo}_{2} \mathrm{Ga}_{2} \mathrm{C}$, is evidenced from thin-film and bulk processes. Its structure was determined using theoretical and experimental techniques, showing that $\mathrm{Mo}_{2} \mathrm{Ga}_{2} \mathrm{C}$ has $\mathrm{Ga}$ double-layers in simple hexagonal stacking between adjacent $\mathrm{Mo}_{2} \mathrm{C}$ layers, and therefore is structurally very similar to $\mathrm{Mo}_{2} \mathrm{GaC}$, except for the additional Ga layers. For the Zr-Al-C system, the optimization of phase composition and structure of $\mathrm{Zr}_{2} \mathrm{Al}_{3} \mathrm{C}_{4}$ in a thin-film deposition process was studied by evaluating the effect of deposition parameters. I concluded that the formation of $\mathrm{Zr}_{2} \mathrm{Al}_{3} \mathrm{C}_{4}$ is favored with a plasma flux overstoichiometric in $\mathrm{Al}$, and with a minimum lattice-mismatch to the substrates. Consequently, epitaxial $\mathrm{Zr}_{2} \mathrm{Al}_{3} \mathrm{C}_{4}$ thin film of high quality were deposited on $4 \mathrm{H}-$ $\operatorname{SiC}(001)$ substrates at $800{ }^{\circ} \mathrm{C}$.

With the approach of post-deposition treatment, the studies were focused on a new method of thermally-induced selective substitution reaction of $\mathrm{Au}$ for the non-transition-metal layers in nanolaminated carbides. Here, the reaction mechanism has been explored in Al-containing ( $\mathrm{Ti}_{2} \mathrm{AlC}$ and $\left.\mathrm{Ti}_{3} \mathrm{AlC}_{2}\right)$ and Ga-containing $\left(\mathrm{Mo}_{2} \mathrm{GaC}\right.$ and $\left.\mathrm{Mo}_{2} \mathrm{Ga}_{2} \mathrm{C}\right)$ phases. The $\mathrm{Al}$ and $\mathrm{Ga}$ in 
these phases were selectively replaced by Au while the carbide layers remained intact, resulting in the formation of new layered phases, $\mathrm{Ti}_{2} \mathrm{Au}_{2} \mathrm{C}, \mathrm{Ti}_{3} \mathrm{Au}_{2} \mathrm{C}_{2}, \mathrm{Mo}_{2} \mathrm{AuC}$, and $\mathrm{Mo}_{2}\left(\mathrm{Au}_{1-x} \mathrm{Ga}_{x}\right)_{2} \mathrm{C}$, respectively. The substitution reaction was explained by fast outward diffusion of the $\mathrm{Al}$ or $\mathrm{Ga}$ being attracted to the surface $\mathrm{Au}$, in combination with back-filling of Au, which is chemically inert to the carbide layers, to the vacancies.

The substitution reaction was further applied to Ga-containing nanolaminated carbides, $\left(\mathrm{Cr}_{0.5} \mathrm{Mn}_{0.5}\right)_{2} \mathrm{GaC}$ and $\mathrm{Mo}_{2} \mathrm{GaC}$, motivated by development of novel magnetic nanolaminates. The former experiment resulted in the formation of $\left(\mathrm{Cr}_{0.5} \mathrm{Mn}_{0.5}\right)_{2} \mathrm{AuC}$, where the retained $\left(\mathrm{Cr}_{0.5} \mathrm{Mn}_{0.5}\right)_{2} \mathrm{C}$ layers allowed a comparative study on the magnetic properties under the exchange of $\mathrm{Ga}$ for $\mathrm{Au}$. After $\mathrm{Au}$ substitution, reduction in the Curie temperature and the saturation magnetization were observed, showing a weakened magnetic exchange interaction of the magnetic $\left(\mathrm{Cr}_{0.5} \mathrm{Mn}_{0.5}\right)_{2} \mathrm{C}$ layers across the $\mathrm{Au}$. In the $\mathrm{Mo}_{2} \mathrm{GaC}$ case, an Fe-containing MAX phase, $\mathrm{Mo}_{2} A \mathrm{C}$ with 50 at.\% of Fe on the $A$ site, was synthesized through selective substitution of Au-Fe alloy for the Ga layers, showing the first direct evidence for Fe in the MAX-phase structure. The substitution of Fe did not take place on another $\mathrm{Mo}_{2} \mathrm{GaC}_{\mathrm{Cample}}$ tested for Fe exchange only, indicating the essential role of $\mathrm{Au}$ in catalyzing the Fe-substitution reaction.

The knowledge gained from this thesis work contributes to improved approaches for attaining thin films of nanolaminated transition metal carbides with desired phase composition and crystal quality. The reports on the new nanolaminated phases through exchange interactions are likely to expand the family of nanolaminated carbides and advance their properties, and trigger more studies on related (quasi-) 2D materials. 


\section{Populärvetenskaplig Sammanfattning}

Övergångsmetallkarbider (förkortning på engelska, TMC) är keramiska material bestående av minst en övergångsmetall och kol (C). En binär TMC är alltså en TMC med bara två grundämnen: en övergångsmetall och kol, t.ex. titankarbid (TiC). Binära TMC är hårda, tåliga, kemiskt stabila, och leder värme och elektricitet. En känd användning av binära TMC är hårda ytbeläggningar som skyddar ytor av andra underliggande materialet mot te.x. nötning.

När binära TMC kombineras med en icke-övergångsmetall (ofta kallat för ett $A$-grundämne, t.ex. kisel (Si), aluminium (Al), eller gallium $(\mathrm{Ga})$ ) bildas en ny typ av material, nanolaminerade TMC. Dessa består av väldigt tunna TMC-lager (typisk tjocklek 3 - 7 atomlager) som separeras av $A$-lager. En känd familj av nanolaminerad TMC är 'MAX faser' vars $A$-lager består av endast ett atomlager. I vissa fall kan $A$-lagret ha en tjocklek av flera atomlager och innehålla kol också. Dessa nanolaminerade TMC behåller de flesta egenskaperna från den egna binära TMCn, men de är samtidigt mindre bräckliga och mer motståndskraftiga.

$A$-lagret i nanolaminerade TMC är kemiskt reaktivt och kan selektivt tas bort av syror när $A=$ Al. De återstående tvådimensionella TMC kallas för "MXener" för att betona att den har en 2Dkaraktär som liknar ett annat välkänt 2D-material, grafen. Tillverkning av MXener är lockande på grund av att deras stora ytor är användbara för applikationer inom t.ex. katalys och energilagring.

Forskning på nanolaminerade TMCs är motiverat bl.a. för tillverkning av MXener, men inte så många har tillverkats med ytbeläggningsprocesser. Tunna filmer är viktiga för kunna modifiera ytegenskaperna hos ett material, och för att tillverkning av vissa nanolaminerade TMC är besvärligt att göra i bulk-form.

Den här avhandlingen undersöker bildandet av nanolaminerade TMC både i ytbeläggningsprocesser och i kemiska reaktioner på ytor av tunna filmer. I det första fallet undersökte jag syntes av nanolaminerade TMC- filmer i två olika materialsystem; molybdengallium-kol (Mo-Ga-C) och zirkonium-aluminium-kol (Zr-Al-C). Jag upptäckte en ny fas, $\mathrm{Mo}_{2} \mathrm{Ga}_{2} \mathrm{C}$, som är den andra nanolaminerade fasen i Mo-Ga-C-systemet efter upptäckten av MAX-fasen $\mathrm{Mo}_{2} \mathrm{GaC}$ på 1960-talet. Faserna liknar varandra, förutom att $\mathrm{Mo}_{2} \mathrm{Ga}_{2} \mathrm{C}$ har två 
atomlager Ga mellan TMC-lagren istället bara ett Ga-lager för $\mathrm{Mo}_{2} \mathrm{GaC}$. Den skillnaden är en möjlig anledning till varför $\mathrm{Mo}_{2} \mathrm{C}$ MXener kan skapas från etsning av $\mathrm{Mo}_{2} \mathrm{Ga}_{2} \mathrm{C}$ även med $A=$ $\mathrm{Ga}$ men inte från etsning $\mathrm{av} \mathrm{Mo}_{2} \mathrm{GaC}$.

Jag undersökte också nanolaminerad $\mathrm{Zr}_{2} \mathrm{Al}_{3} \mathrm{C}_{4}$ i Zr-Al-C systemet, som är intressant för kärnkraftverk på grund av en låg neutron-absorbering. Jag optimerade tunnfilmskvaliteten av $\mathrm{Zr}_{2} \mathrm{Al}_{3} \mathrm{C}_{4}$ och drog slutsatsen att om den fasen ska förbättras bör den skapas vid höga temperaturer eller med extra tillskott av A1.

I andra delen av avhandlingen visar jag på kemiska reaktioner mellan nanolaminerade TMCtunnfilmer och guld $(\mathrm{Au})$-lager som lagts på dessa tunnfilmer. Det har bevisats tidigare att tunna filmer av $\mathrm{Ti}_{3} \mathrm{SiC}_{2} \mathrm{MAX}$-fas kan reagera med $\mathrm{Au}$, vilket resulterar i att $\mathrm{Au}$ ersätter Si i MAXfasen utan att påverka TMC-lagren. För att undersöka bakomliggande mekanismen för detta utförde jag samma studier på olika MAX-faser med $A=\mathrm{Al}$ och Ga, som sedan resulterade i fyra nya Au-innehållande nanolaminerade TMC. Från resultaten drog jag slutsatsen att $A$-elementen kan bege sig från MAX-fasen, attraherade av Au på ytan, och efterlämna vakanser i strukturen. Då Au har låg reaktivitet med TMC lagren fylls vakanserna med Au-atomer utan att förstöra den laminerade strukturen.

Kemiska reaktionen i $A$-lagren är känt sedan tidigare, men ett komplett byte av $A$-lagren utan att förstöra strukturen rapporterades inte förrän 2016. Detta kan användas för att ändra på nanolaminerade TMCs egenskaper med hjälp av att ändra $A$-elementen. Jag undersökte förändringen av egenskaperna genom att jämföra magnetiska MAX-fas tunnfilmer före och efter att Au ersätt $A$-lagren $(A=\mathrm{Ga})$. Resultaten visade en minskning i ferromagnetism efter Au-tillförseln som tyder på att egenskaper av nanolaminerade TMC kan trimmas med den här metoden.

Liknande metoder kan användas för att förändra egenskaper genom att föra in ett mer ovanligt element till $A$-lagren, t.ex. järn (Fe). Jag rapporterade en Fe-innehållande MAX-fas som bildades genom en reaktion i $A$-lagren med tillsättning av en Au-Fe blandning istället bara ren Au. Mer än hälften av Ga-innehållet byttes ut mot både Fe och Au. Ingen reaktion ägde rum om experimentet utfördes utan $\mathrm{Au}$, vilket bevisar dess viktiga roll i reaktionen.

Kunskapen som är ett resultat av den här avhandlingen kan hjälpa andra som forskar i detta fält att tillverka nanolaminerade TMC-tunnfilmer med önskad fas-sammansättning, kvalitet, och egenskaper. Därutöver kan de här nya nanolaminerade faserna inspirera till framtida syntes av 
ytterligare nya unika faser, samt till angränsande forskning kring syntes och egenskaper hos 2D eller kvasi-2D material, t.ex. $\mathrm{Mo}_{2} \mathrm{C}$ MXenes och enkel-lager av Fe. 


\section{Preface}

This thesis summarizes my research work in the Material Design Group, Thin Film Physics Division, Department of Physics, Chemistry and Biology (IFM), Linköping University, Sweden between January 2013 and June 2017 for my doctoral degree. The goal of my work is to assess the materials science in phase formation of nanolaminated transition metal carbides in thin-film form. Part of the work presented is inherited from my licentiate thesis published in October 2015 under the title "Thin Film Synthesis of New Nanolaminated Ternary Carbides" (Linköping Studies in Science and Technology, Licentiate Thesis No. 1728). During the course of research underlying this thesis, I was enrolled in Agora Materiae, a multidiciplinary doctoral program at Linköping University, Sweden.

This project is funded by the Swedish Foundation for Strategic Research (SSF) through the Synergy Grant FUNCASE.

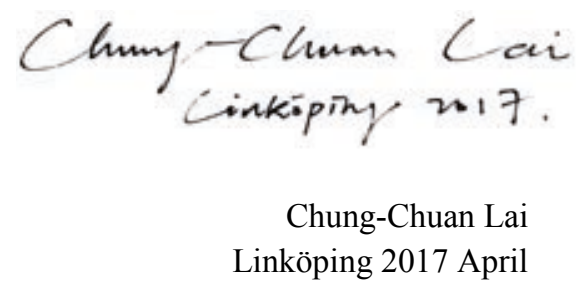




\section{Acknowledgement}

I am very grateful to my supervisor, Johanna Rosén, and my co-supervisors, Per Eklund and Lars Hultman, for all those nice advices and discussion, which made this thesis work possible. Without your guidance, it could have gone pretty wild and ended up in a mess. (Which might not totally be a bad thing though...)

I would like to thank our current and former Materials Design group members as well, who offered me many helps, ideas and conversations in- and outside the campus. Life is still tough, but it is a little bit easier because of you.

I would also like to thank all those friends in the department, for offering a very nice environment to work, and many other enjoyable activities than just work. I hope I did contribute the same thing to you as well.

Finally, I would like to give many appreciations to my beloved fiancée, Yi-Ping Liu, and our dearest families, for your endless supports and encouragement to me no matter when I was in Taiwan or in Sweden. I will always love you. 


\section{Appended Papers and Author's Contributions}

\section{Paper I}

\section{$\mathrm{Mo}_{2} \mathrm{Ga}_{2} \mathrm{C}$ : a New Ternary Nanolaminated Carbide}

C. Hu, C.-C. Lai, Q. Tao, J. Lu, J. Halim, L. Sun, J. Zhang, J. Yang, B. Anasori, J. Wang, Y. Sakka, L. Hultman, P. Eklund, J. Rosen, and M. W. Barsoum

Chem. Comm. 51 (2015) 6560-6563

In Paper I, I took a part in design of the experiments, and performed a major part of the thin film synthesis. I acquired and analyzed X-ray diffraction patterns on thin film samples, and took part in other characterizations. I wrote a part for the manuscript.

\section{Paper II}

\section{Structural and Chemical Determination of the New Nanolaminated Carbide $\mathrm{Mo}_{2} \mathrm{Ga}_{2} \mathrm{C}$ from First Principles and Materials Analysis}

C.-C. Lai, R. Meshkian, M. Dahlqvist, J. Lu, L.-Å. Näslund, O. Rivin, E. N. Caspi, O. Ozeri, L. Hultman, P. Eklund, M. W. Barsoum, and J. Rosen

Acta Mater. 99 (2015) 157-164

In Paper II, I took a part in designing of the experiments and in the thin film synthesis. I prepared thin film specimens for other experiments, and took part in other characterization. I wrote a major part of the manuscript. 


\title{
Paper III
}

\section{Synthesis and Characterization of $\mathrm{Zr}_{2} \mathrm{Al}_{3} \mathrm{C}_{4}$ Thin Films}

\author{
C.-C. Lai, M. D. Tucker, J. Lu, J. Jensen, G. Greczynski, P. Eklund, and J. Rosen
}

Thin Solid Films 595 (2015) 142-147

In Paper III, I took a part in design of the experiments, and performed a major part of the thin film synthesis. I acquired and analyzed X-ray diffraction patterns, and prepared specimen for other characterization. I wrote the manuscript.

\section{Paper IV}

\section{Phase Formation of Nanolaminated $\mathrm{Mo}_{2} \mathrm{AuC}$ and $\mathrm{Mo}_{2}\left(\mathrm{Au}_{1-x} \mathrm{Ga}_{x}\right)_{2} \mathrm{C}$ by Substitution Reaction within Au-capped $\mathrm{Mo}_{2} \mathrm{GaC}$ and $\mathrm{Mo}_{2} \mathrm{Ga}_{2} \mathrm{C}$ Thin Films}

C.-C. Lai, H. Fashandi, J. Lu, J. Palisaitis, P. O. Å. Persson, L. Hultman, P. Eklund, and J. Rosen

Manuscript in final preparation

In Paper IV, I designed and performed a major part of the experiments and the synthesis. I prepared specimens for electron microscope analysis, and carried out most part of the characterization. I wrote the manuscript.

\section{Paper V}

\section{Exchange-Intercalation of Gold into Thin Films of $\mathrm{Ti}_{2} \mathrm{AlC}$ and $\mathrm{Ti}_{3} \mathrm{AlC}_{2}$ Leading to the Synthesis of $\mathrm{Ti}_{2} \mathrm{Au}_{2} \mathrm{C}$ and $\mathrm{Ti}_{3} \mathrm{Au}_{2} \mathrm{C}_{2}$}

H. Fashandi, C.-C. Lai, M. Dahlqvist, J. Lu, J. Rosen, L. Hultman, M. Andersson, A. Lloyd Spetz, and P. Eklund

\section{Manuscript in final preparation}

In Paper V, I took a part in design of the experiments. I performed part of the sample characterization with X-ray diffraction, and part of the specimen preparation for electron microscope analysis. 


\section{Paper VI}

\section{Thin Film Synthesis and Characterization of a Magnetic MAX Phase $\left(\mathrm{Cr}_{\mathbf{0}_{.5}} \mathrm{Mn}_{0_{0.5}}\right)_{2} \mathrm{AuC}$ Obtained From Thermally-Induced Substitutional Reaction in $\left(\mathrm{Cr}_{\mathbf{0} .5} \mathrm{Mn}_{\text {o.5 }}\right)_{2} \mathrm{GaC}$}

C.-C. Lai, Q. Tao, H. Fashandi, U. Wiedwald, R. Salikhov, M. Farle, A. Petruhins, J. Lu, L. Hultman, P. Eklund, and J. Rosen

Manuscript in final preparation

In Paper VI, I designed and performed a major part of the experiments and the synthesis. I prepared specimens for electron microscope analysis and magnetic characterization, and carried out the phase and structural analysis. I wrote a major part of the manuscript.

\section{Paper VII}

\section{Thermally Induced Substitutional Reaction of Fe into $\mathrm{Mo}_{2} \mathrm{GaC}$ Thin} Films

C.-C. Lai, A. Petruhins, J. Lu, M. Farle, L. Hultman, P. Eklund, and J. Rosen

\section{Submitted}

In Paper VII, I designed and performed the experiments and the synthesis with helps from other authors. I prepared specimens for electron microscope analysis, and carried out most part of the characterization. I wrote the manuscript. 


\section{Related but not appended works}

\section{Paper VIII}

\section{Theoretical Prediction and Synthesis of $\mathrm{CS}_{x} \mathrm{~F}_{y}$ Thin Films}

C. Goyenola, C.-C. Lai, L.-Å. Näslund, J. Lu, H. Högberg, L. Hultman, J. Rosen, and G. K. Gueorguiev

J. Phys. Chem. C 120 (2016) 9527-9534

In paper VIII, I took a part in design of the experiments. I prepared and characterized the thin film samples and performed part of the specimen preparation for electron microscope analysis. I wrote a part for the paper.

\section{Paper IX}

\section{Synthesis and Properties of $\mathrm{CS}_{x} \mathrm{~F}_{y}$ Thin Films Deposited by Reactive} Magnetron Sputtering in an $\mathrm{Ar} / \mathrm{SF}_{6}$ Discharge

C.-C. Lai, C. Goyenola, E. Broitman, L.-Å. Näslund, H. Högberg, L. Hultman, G. K. Gueorguiev, and J. Rosen

J. Phys. Condens. Mat. 29 (2017) 195701

In paper IX, I took a part in design of the experiments. I prepared the thin film samples and performed part of the characterization. I wrote a major part of the paper.

\section{Paper X}

\section{Reactive Sputtering of $\mathrm{CS}_{x}$ Thin Solid Films Using $\mathrm{CS}_{2}$ as Precursor}

H. Högberg, C.-C. Lai, L.-Å. Näslund, C. Goyenola, E. Broitman, J. Lu, S. Schimdt, L. Hultman, J. Rosén, and G. K. Gueorguiev

\section{Manuscript in final preparation}

In paper X, I took a part in design of the experiments. I prepared the thin film samples and performed part of the characterization. I wrote a part for the paper. 


\section{Table of Contents}

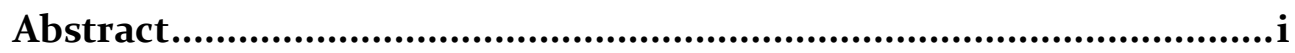

Populärvetenskaplig Sammanfattning .......................................... iii

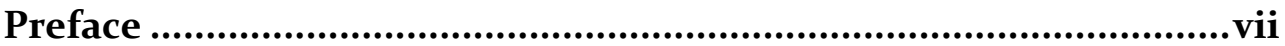

Acknowledgement .......................................................................

Appended Papers and Author's Contributions ................................xi

Table of Contents ...................................................................... Xv

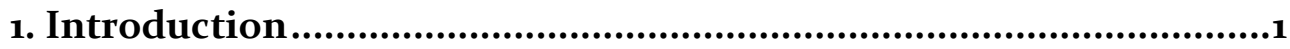

1.1 A Background of Transition Metal Carbides ............................................................. 1

1.2 Nanolaminated Transition Metal Carbides from Thin Film Perspectives ........................ 3

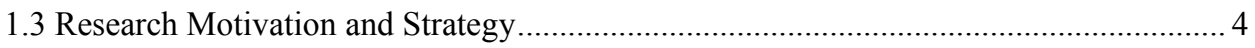

2. Transition-Metal Carbides ............................................................... 7

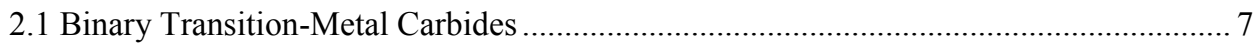

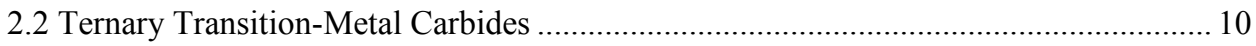

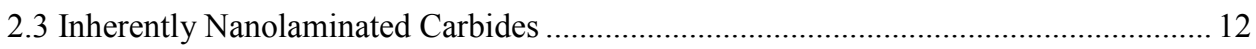

3. Chemical Reactions of the MAX Phases ........................................19

3.1 From Corrosion Behavior to MXene Production ...................................................... 19

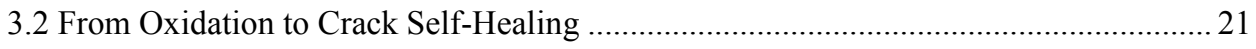

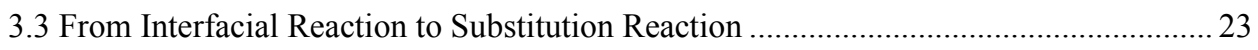

4. Thin Film Synthesis ...................................................................27

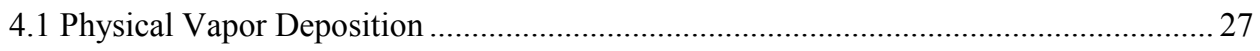

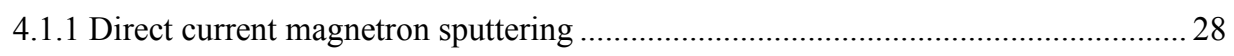




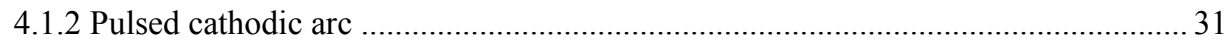

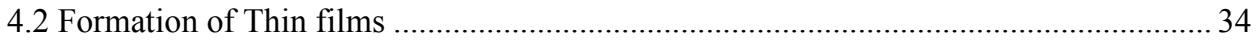

5. Thin Film Characterization Techniques ..................................... 39

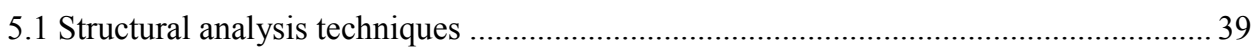

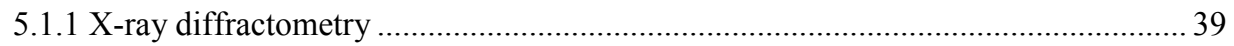

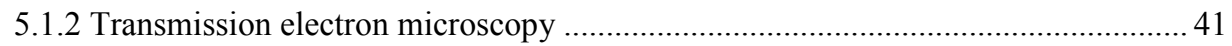

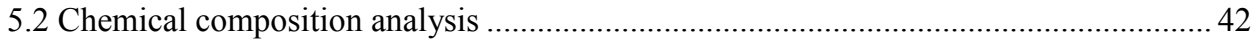

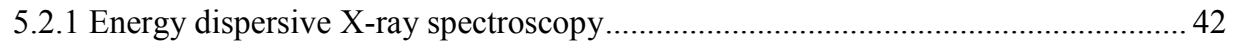

5.2.2 Time-of-flight elastic recoil detection analysis..................................................... 43

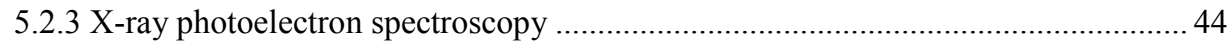

6. Summary and Contributions to the Field .................................... 47

Bibliography ............................................................................51

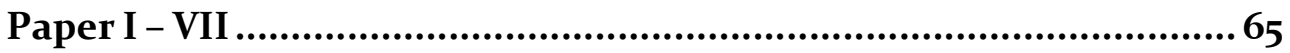




\section{Introduction}

\subsection{A Background of Transition Metal Carbides}

Transition-metal carbides (TMCs) are chemical compounds composed of at least one transition element (i.e. an element from group 3 - 13) and carbon. They share some general properties of ceramics, such as being hard, brittle, highly refractory, and chemically inert, in combination with some metallic behavior like being electrically and thermally conductive [1]. The combined properties show great potential of TMCs for applications in bulk and thin-film form, for example, as structural materials in molds, wire-drawing dies, and machine tools [2], as composite materials in hard coatings $[3,4]$, as electrical contacts for corrosive environments [4,5], and as chemical or electrochemical catalysts [6-9].

Research and production of most TMCs in history started from their binary systems, i.e. a single transition element and carbon system, though some of them were first identified in oxycarbide or carbonitride forms [1]. In the 1890's and 1900's, Henri Moissan synthesized a good number of refractory TMCs of group $4-6$ elements within an electric furnace originally designed for synthesizing artificial diamonds $[10,11]$. In the beginning of $20^{\text {th }}$ century, the attempts to apply pure TMCs, for example $\mathrm{WC}$ and $\mathrm{W}_{2} \mathrm{C}$, as refractory and abrasive tool materials were not very successful, due to their high brittleness and therefore low damage tolerance [12]. However, later in 1920's, the invention of cemented carbides, where WC act as reinforcement in relatively soft material matrices, has turned out to be a great success in production industry. Along with later research on improving the cemented carbide by making solid solutions with other transition metals, the TMCs started to attract more attention from the field and inspired series of careful examinations on the physics behind their properties [2,5].

Partly inspired by the idea of enhancing the high temperature performance of binary TMCs, which is crucial for applications in machine tools or protective coatings [5,13], extensive works have been carried out on synthesizing ternary carbides since 1960's, see examples in Ref. [14- 
17]. These then-newly reported carbides were mostly phases with a group $13-14$ elements as an additional third element, or solid solutions with boride, nitride and oxide.

In investigations of ternary TMC systems, many phases were identified with nanolaminated structures, for example $\mathrm{Ti}_{3} \mathrm{SiC}_{2}, \mathrm{Zr}_{3} \mathrm{Al}_{3} \mathrm{C}_{5}$, and $\mathrm{Mo}_{2} \mathrm{BC}$. A well-known example of the nanolaminated phases is the MAX phases, a family of $70+$ phases with a general formula $M_{n+1} A X_{n}$, where $M$ is a group $3-6$ element; $A$ is commonly a group $13-14$ element; $X$ is either $\mathrm{C}$ or $\mathrm{N} ; n=1,2$, or $3[18,19]$. Their crystal structures are formed by two different sets of layers repeatedly interleaved with each other: TMC layers and non-TMC layers, which contain the third element, e.g. the $A$ element in a MAX phase. As compared to their binary TMC counterparts, these materials are also electrically and thermally conductive, and they are often more damage tolerant and stiffer, yet slightly softer. More interestingly, because of their unique layered structure, they can be machined more easily into desired shapes without cracking like most other ceramics [19]. Some MAX phases are already commercially available on the market as, e.g. powders, heating elements, and $\mathrm{Ti}_{3} \mathrm{SiC}_{2}$ electrical contact with $\mathrm{SiC}$, because of their outstanding combination of properties [20].

Recent research on the MAX and related nanolaminated phases remark on the achievement of producing "2D TMCs" by selectively etching away the non-TMC layers from the structure [21]. These materials have been referred to as "MXenes" in order to emphasize their relation with the MAX phases and the similarity with another 2D material, graphene, since the first report in 2011, where exfoliated $\mathrm{Ti}_{3} \mathrm{C}_{2}$ was produced from $\mathrm{Ti}_{3} \mathrm{AlC}_{2}$ MAX phase [22]. Soon in 2012, six more MXenes was reported by the same authors, showing the production for a larger group of the 2D TMCs with the same method [23]. Later on, MXenes made from phases other than the MAX phases [24-26], as well as synthesized by direct growth as 'ultra-thin films', have also been published [27], which overcome the restriction of producing MXenes only by etching the MAX phases.

As a 2D material by itself, the MXenes have attract increasing attention after its discovery on the topics of, e.g., surface functionalization, molecule and ion intercalation, energy storage, and electrocatalysis [21,28,29]. The MXenes benefit from the wide variety in the chemical composition of the MAX and related nanolaminated phases, allowing the possibility of tuning the properties by alloying/replacing on the $M$ and/or $X$ sites [21]. Theoretical calculations have also been performed for the MXenes, predicting interesting electrical, thermoelectric, 
superconducting, optical, and magnetic properties controlled by different chemical compositions and terminating groups on the surface [30,31].

\subsection{Nanolaminated Transition Metal Carbides from Thin Film Perspectives}

Nanolaminated TMCs have been reported for more than 50 years with increasing attention paid to the unique properties and their $2 \mathrm{D}$ derivatives. However, the studies related to thin film processes are still in minority compared to the ones related to bulk synthesis $[29,32,33]$. Understanding the phase formation of nanolaminated TMCs in thin film processes is important for the development of studies on properties and applications in thin film form. It is also crucial for controlling the synthesis, and possibly the alloying, of desired MAX phases [32].

Meanwhile, as anisotropic properties can naturally be expected from a layered structure, epitaxial thin films or single crystals are desired for detailed characterization of nanolaminated phases on, e.g., electrical/thermal transport and magnetism [34,35]. Thin film synthesis complement the field with lower synthesis temperature and a far-from-equilibrium synthesis condition in general, benefiting the formation of phases with elements that are tricky to handle in bulk synthesis, for example, $M=\mathrm{Mn}, A=\mathrm{Ga}$, or $X=\mathrm{N}$ in the MAX and related phases [36].

Studying phase formation of nanolaminated TMCs in thin films can be separated into two parts [32]. One is more concerned about the synthesis during a deposition process, which is referred to as direct synthesis and aims for a specific phase, preferably grown with desired crystal quality and texture at the same time. The direct synthesis is a more common method of synthesizing MAX and related phases, yet it requires more efforts on the optimization of the deposition parameters in the process in order to deposit reproducible, high quality thin films [33]. In modern cases, reliable theoretical guidance can greatly help the optimization by investigating the relative phase stability and the crystal structure of the phases in the material system of interest [37-41].

The other is more focusing on post-deposition modification of the phases, which studies the changes in the phase composition of deposited thin films due to various external factors, e.g. elevated temperature [42] and oxidizing atmosphere [43]. It can also be an alternative method of synthesizing the MAX and related phases by annealing amorphous thin films [44-46] or artificial multilayers [47-52] with an overall chemical composition close to the desired phase. Most recently, Fashandi et al. have reported on new MAX and related nanolaminated phases, $\mathrm{Ti}_{3} \mathrm{AuC}_{2}$ and $\mathrm{Ti}_{3} \mathrm{Au}_{2} \mathrm{C}_{2}$, synthesized by thermally induced exchange reaction of $\mathrm{Au}$ into the $\mathrm{Si}$ 
layers of $\mathrm{Ti}_{3} \mathrm{SiC}_{2}$ thin films [53]. The authors reported that the Au-containing phases retained the nanolaminated structures and served as a high-temperature-stable Ohmic electrical contact with the underlying SiC substrate [53].

\subsection{Research Motivation and Strategy}

A broad scope of my work is to assess the materials science of these nanolaminated carbide systems from the aspect of their phase formation and crystal growth during the synthesis in thin film form. This is realized by studies on following topics,

(1) Phase and structural determination of $\mathrm{Mo}_{2} \mathrm{Ga}_{2} \mathrm{C}$ thin films prepared by magnetron sputtering deposition: Mo-based materials have attracted increasing attention because of their diverse properties, such as the superconducting properties in the carbides [54,55], low friction characteristic of $\mathrm{MoS}_{2}$ [56,57], and photochromic and catalytic properties in the oxides [58,59]. Despite the research interests on the properties of the Mo-based nanolaminated carbides, and of the 2D derivatives of $\mathrm{Mo}_{2} \mathrm{C}$ [30,31], there was only one $\mathrm{MAX}$ phase, $\mathrm{Mo}_{2} \mathrm{GaC}$, reported in literature $[54,60]$. In this work, a new Mo-based nanolaminated phase, $\mathrm{Mo}_{2} \mathrm{Ga}_{2} \mathrm{C}$, is reported, along with detailed investigation on its structure using theoretical calculations and various experimental techniques (See Paper I and II).

(2) Effect of deposition parameters on $\mathrm{Zr}_{2} \mathrm{Al}_{3} \mathrm{C}_{4}$ thin films prepared by cathodic arc deposition: Zirconium carbides in ternary forms have been suggested as protective coatings for zirconiumalloy claddings of nuclear fuel tube [61-63]. They have improved high temperature chemical stability and mechanical properties compared to the binary counterpart, $\mathrm{ZrC}$, as well as a low neutron absorption cross-section among TMCs [64]. While several nanolaminated phases in the Zr-Al-C system have been experimentally synthesized in bulk, none has been reported by thin film processing $[14,65,66]$. Here, as a step towards thin film optimization, the phase composition and the crystal quality of $\mathrm{Zr}_{2} \mathrm{Al}_{3} \mathrm{C}_{4}$ thin films were studied in relations with deposition parameters applied to the synthesis process (See Paper III).

(3) Post-deposition synthesis of Au- and Fe-containing nanolaminated carbides by thermally induced exchange reaction: Many works have been done previously on chemical reactions of the MAX phases in contact with metals or oxidizing atmosphere for potential applications as protective coatings or electrical contacts. Most of the combinations show either very local substitution on the $M$ and $A$ sites [67,68] or mobile $A$ elements out-diffusion following with the decomposition of the MAX phase [42,43,69-73]. However, the reaction of $\mathrm{Ti}_{3} \mathrm{SiC}_{2}$ with $\mathrm{Au}$ 
results in formation of nanolaminated $\mathrm{Ti}_{3} \mathrm{AuC}_{2}$ and $\mathrm{Ti}_{3} \mathrm{Au}_{2} \mathrm{C}_{2}$ phases with retained $\mathrm{Ti}_{3} \mathrm{C}_{2}$ layers, showing a new route of modifying the MAX phases with noble metals. Here, the formation of Au-containing phases was explored on the MAX and related phases with $A=\mathrm{Al}$ and $\mathrm{Ga}$, resulting in new nanolaminated phases $\mathrm{Ti}_{n+1} \mathrm{Au}_{2} \mathrm{C}_{n}$ (Paper IV), $\mathrm{Mo}_{2} \mathrm{AuC}$, and $\mathrm{Mo}_{2}\left(\mathrm{Au}_{1-x} \mathrm{Ga}_{x}\right)_{2} \mathrm{C}$ (Paper V). The Au exchange reaction for Ga in the MAX phase was further investigated by a comparative study on the magnetic properties of $\left(\mathrm{Cr}_{0.5} \mathrm{Mn}_{0.5}\right)_{2} \mathrm{GaC}$ and $\left(\mathrm{Cr}_{0.5} \mathrm{Mn}_{0.5}\right)_{2} \mathrm{AuC}$ (Paper VI), and another study on the exchange reaction using Au-Fe alloy instead of pure Au (Paper VII). 


\section{Transition-Metal Carbides}

A carbide is a compound formed with a carbon atom chemically bonded to other elements with lower electronegativity. Where solid-state carbide phases can be found in, for example, the group $1-2$ metals [74,75], the transition metals [1,5,75], the rare-earth metals [75,76], the actinide metals [75,77], and some group 13 - 15 elements (B, Al, Si, Ge, and P). These carbideforming elements can be roughly sorted by three classes depending on the bonding nature. For example, the carbides formed with larger differences in the electronegativity between $\mathrm{C}$ and, e.g. the group 1 - 2 metal, the rare-earth metal, the actinide metals, and Al, exhibit stronger ionic bonding condition and salt-like properties, i.e. can decompose more easily in water. When the difference is small, e.g. with $\mathrm{B}, \mathrm{Si}, \mathrm{Ge}$, and $\mathrm{P}$, the carbides normally formed with a more covalent-type bonding condition. The transition-metal carbides (TMCs) exhibit a mixing-type of bonds between ionic-covalent bonding and metallic bonding due to the intermediate difference in electronegativity and the interstitial crystal structure [78]. In this thesis, TMCs will be restricted to only the carbides of the $d$-block transition metals, and more explicitly on the group $4-7$ carbides. An introduction is given in this chapter to crystal structures of these TMCs in they binary and ternary phases.

\subsection{Binary Transition-Metal Carbides}

The formation of the binary TMCs and their properties follow certain periodic trends, which can be extrapolated to their ternary phases, due to the electron configurations and the atomic size of transition metals [79]. As a general rule of thumb, TMCs between group 4-12 reduce in thermodynamic stability when increasing the number of $d$-orbit valence electrons in the transition metal, i.e., moving towards the right in the periodic table of chemical elements. Evidently, at normal pressure, the standard enthalpy of formation for $3 d$-orbit TMCs becomes less negative in the value when moving from Ti to Fe. Only metastable carbide phases have 
been reported for group $8-10$ (e.g. $\mathrm{Fe}_{3} \mathrm{C}, \mathrm{Co}_{2} \mathrm{C}$ and $\mathrm{Ni}_{3} \mathrm{C}$ ), while no stable phase has been reported in group $11-12$ (e.g. $\mathrm{Cu}, \mathrm{Zn})$ [80].

Notably, at thermodynamic equilibrium of group 3-7 metal and carbon binary system, their most C-rich carbides form in structures that can only accommodate less carbon atoms, e.g. $\mathrm{Sc}_{3} \mathrm{C}_{4}, \mathrm{TiC}, \mathrm{VC}, \mathrm{Cr}_{3} \mathrm{C}_{2}$ and $\mathrm{Mn}_{7} \mathrm{C}_{3}$, when increasing atomic number. In addition, the $\mathrm{Cr}-\mathrm{C}, \mathrm{Mn}-$ $\mathrm{C}$ and $\mathrm{Fe}-\mathrm{C}$ system are often discussed with low carbon-concentration $(<10$ at.\%) and at high temperature $\left(>500{ }^{\circ} \mathrm{C}\right)$, where most of their metastable carbides can be produced [81].

The group 3 - 6 elements can form carbide phases in a common rock-salt ( $\mathrm{NaCl}$-type) structure (space group $F m \overline{3} m$ (225)), which has a face-centered cubic lattice of transition metal atoms with carbon atoms sitting in each octahedral interstitial site, forming $M_{6} \mathrm{C}$ octahedrons, where $M$ is a transition metal, as shown in Fig. 2-1(a). The NaCl-type carbide is the only stable phase for the group 4 elements ( $\mathrm{Ti}, \mathrm{Zr}$ and $\mathrm{Hf}$ ), and is a metastable phase for the group 6 elements $(\mathrm{Cr}$, Mo and $\mathrm{W}$ ) at room temperature. This is explained by the average number of valence electron filling in the bonding-, antibonding-, and non-bonding states of the carbide. When the average number is 4, like in TiC, the Fermi level is right in between the bonding- and antibonding-states, and hence both increasing and decreasing the atomic number in the $d$-block reduces the thermodynamic stability of the compound $[82,83]$. As the average number increases and the anti-bonding states start to be filled, the TMC will try to lower its formation enthalpy by distorting the crystal structure to accommodate less C. Eventually in group $8-10$, the nonbonding states are filled, and consequently the stability is less affected by the average number of valence electron [84], resulting in very similar phase diagrams in, e.g., Fe-C, Co-C, and Ni-

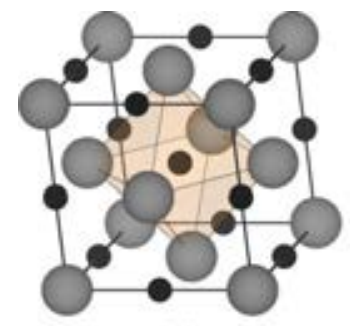

(a)

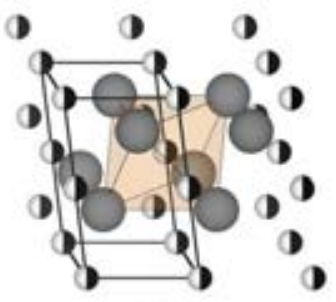

(b)

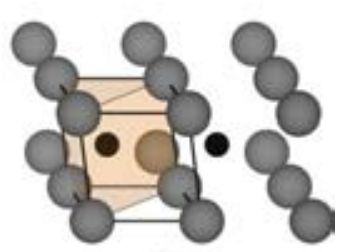

(c)

Figure 2-1. Crystal structure of binary TMCs in (a) the NaCl-type structure, (b) the $\beta-M_{2} \mathrm{C}$ structure, and (c) the hexagonal monocarbide structure. The $M_{6} \mathrm{C}$ octahedron and trigonal prism are highlighted in respective structure. Note that (b) and (c) are expanded to $2 \times 2 \times 1$ unit cells, and the C occupancy in (b) is half. 
$\mathrm{C}$ systems. The same trend is observed in $3 d-, 4 d$-, and $5 d$-blocks, where $\mathrm{ZrC}$ and $\mathrm{HfC}$ are the most stable carbide in the rock-salt structure.

The carbide phases in the rock-salt structure are often written as $M \mathrm{C}_{x}$, where $M$ is a transition metal and $x \leq 1$, to show the fact that the occupancy of the $\mathrm{C}$ interstitial sites are often less than 1. In group 4 carbides, $x$ is usually $0.6-0.95$ but it becomes narrower in range in group 5 and even narrower in group 6. For the group 5 elements $(\mathrm{V}, \mathrm{Nb}$ and $\mathrm{Ta})$, non-stoichiometric rocksalt cubic phase tends to undertake order transformation during cooling from higher temperature, leading to the formation of chemically ordered phases, such as $\mathrm{V}_{8} \mathrm{C}_{7}, \mathrm{~V}_{6} \mathrm{C}_{5}, \mathrm{Nb}_{6} \mathrm{C}_{5}$ and possibly $\mathrm{V}_{4} \mathrm{C}_{3}$ and $\mathrm{Ta}_{6} \mathrm{C}_{5}$, depending on the composition [85-87]. These ordered phases retain a basis of the rock-salt structure with ordered vacancies on the $\mathrm{C}$-interstitial sites, resulting in a reduced symmetry of the entire crystal. The C stoichiometry of the NaCl-type TMCs can affect their properties, but not with the same trend in different groups. For example when increasing the $\mathrm{C}$ occupancy, the hardness increases for $\mathrm{Ti}, \mathrm{Zr}$ and $\mathrm{Hf}$, but decreases for $\mathrm{Nb}$ and $\mathrm{Ta}[16]$.

The group 5 - 6 metals, except $\mathrm{Cr}$, can also form stable $\mathrm{M}_{2} \mathrm{C}$ carbide (space group $P 6_{3} / \mathrm{mmc}$ (194)), where $M$ forms a hexagonal close-packed sublattice with $C$ filling into $1 / 2$ of the octahedral interstitial sites, as shown in Fig. 2-1(b). The hexagonal $M_{2} \mathrm{C}$ phase is often recognized in literature as $\beta$-phase, and sometimes written as $\beta-M_{2} \mathrm{C}_{x}$ to emphasize its homogeneity region, e.g., $x=0.88-1.00$ for $\beta$ - $\mathrm{V}_{2} \mathrm{C}_{x}$. Structurally, the metal atoms in the $\beta$ phase can be described in an ' $A B A B A B \ldots$..' stacking sequence along the $c$-axis of the hexagonal lattice, as compared to an ' $A B C A B C \ldots$ '.. stacking sequence along the [111]-direction of the NaCl-type TMCs $[85,88,89]$.

The $\beta$-phase undergoes order transformation on the $\mathrm{C}$ sites during cooling as well. Two ordered phases were reported in earlier studies: an orthorhombic phase (space group Pbcn (60)) and a hexagonal phase (space group $P \overline{3} m 1$ (164)). However, these two phases has not been observed in neutron diffraction studies of quenched tungsten carbides, while instead another ordered $\varepsilon$ phase in trigonal structure (space group $P \overline{3} 1 \mathrm{~m}$ (162)) was reported as the result of order transformation, which is now broadly accepted [88-90]. Notice that sometimes in literature these disordered and ordered phases are written in different ways, such as $\beta$ and $\beta^{\prime}$, or $\beta$ and $\alpha$, respectively.

For Mo and W, their monocarbide phases in hexagonal structure $(\gamma$-MoC and $\delta$-WC, space group $P \overline{6} m 1$ (187)) are thermodynamically stable at low temperature, and it is the only lowtemperature $(<1500 \mathrm{~K})$ stable phase for $\mathrm{W}[89]$. The metal atoms here are packed in simple 
hexagon, and hence can be described in an 'AAAA...' stacking sequence. Unlike the NaCl-type and the $\beta$-phase TMCs, the $\mathrm{C}$ atoms in the hexagonal monocarbide structure are sitting at the center of trigonal prism interstitial sites with full occupancy, as shown in Fig. 2-1(c). A reduced stability of $\gamma$-MoC has been theoretically demonstrated by increasing the amount of C-vacancies [88]. In addition to the NaCl-type carbide and $\gamma$-MoC, two other Mo-based monocarbide phases have been identified in literature. One is a high-temperature phase in hexagonal structure, denoted as $\eta$-MoC $\mathrm{M}_{x}$ and $x \sim 0.67$ (space group $P 6_{3} / \mathrm{mmc}$ (194)), whose metal atoms are stacked in ' $A B C A C B \ldots$ ' sequence along the $c$-axis and the $\mathrm{C}$ atoms randomly reside in $2 / 3$ of the octahedral interstitial sites. The other is a metastable phase, $\gamma^{\prime}-\mathrm{MoC}_{x}$ (space group $\mathrm{Pb}_{3} / \mathrm{mmc}$ (194)), which needs to be stabilized by oxygen inclusion on the $\mathrm{C}$ sites [88]. The metal atoms in $\gamma^{\prime}-\mathrm{MoC}_{x}$ are stacked in ' $A A B B \ldots$ '. sequence and the $\mathrm{C}$ and $\mathrm{O}$ atoms are randomly distributed on both octahedral and trigonal prism interstitial sites respectively in between the ' $A B$ ' and the ' $A A$ (or $B B$ )' metal stacking.

The formation of Cr-based binary carbides behaves somewhat differently as compared to Mo and $\mathrm{W}$ in the same group, but more close to those weaker carbide-formers in $3 d$-block, i.e. $\mathrm{Mn}$, $\mathrm{Fe}, \mathrm{Co}$, and Ni. There are three low-temperature stable phases reported for $\mathrm{Cr}$ : $\mathrm{Cr}_{3} \mathrm{C}_{2}$ (space group Pnma (62)) and $\mathrm{Cr}_{7} \mathrm{C}_{3}$ (space group Pnma (62)), where the $\mathrm{C}$ atoms sitting in trigonal prism interstitial sites, and $\mathrm{Cr}_{23} \mathrm{C}_{6}$ (space group $F m \overline{3} m$ (225)), where the $\mathrm{C}$ atoms sitting at the center of square anti-prism [81]. Cr also forms a metastable $\mathrm{Cr}_{3} \mathrm{C}$ phase upon rapid quenching, which is isostructure with $\mathrm{Fe}_{3} \mathrm{C}$ (cementite) [91,92]. In fact, all of the above structures are stable phases for $\mathrm{Mn}$ and most of them are metastable phases for $\mathrm{Fe}, \mathrm{Co}$, and $\mathrm{Ni}$, allowing carbide solid solutions composed of these elements to be made, e.g. $(\mathrm{Cr}, \mathrm{Fe})_{3} \mathrm{C}$ and $(\mathrm{Cr}, \mathrm{Fe})_{7} \mathrm{C}_{3}$ [93]. The dissimilarity between the carbide formation behavior of $\mathrm{Cr}$ and of $\mathrm{Mo}$ or $\mathrm{W}$ is mainly explained by a smaller difference in atomic radius with $\mathrm{C}$, which is unfavorable to the formation of interstitial-type compounds like most other TMCs.

\subsection{Ternary Transition-Metal Carbides}

Research on ternary TMC phase diagrams is triggered by interactions of applied TMCs with surrounding materials, such as diffusion barriers [94,95], composites [96], and other applications with existence of oxygen [97,98], as well as by the needs of improvements on the cemented carbides [2]. A ternary (or higher order) TMC can either be a solid solution, where atoms of the original system are substituted by a third element, or an ordered phase, where atoms of a third element join the crystal structure with a spatial periodicity. 
Solid solutions on the $\mathrm{C}$ sites form normally with elements in the same period around $\mathrm{C}$, such as $\mathrm{B}, \mathrm{N}$, and $\mathrm{O}$, while a possible $\mathrm{Si}$-substitution for $\mathrm{C}$ in $\mathrm{TiC}_{x}$ has also been reported [69]. Except $\mathrm{Si}$, these elements have similar atomic size with $\mathrm{C}$, which allows substitution for $\mathrm{C}$ in the interstitial sites of the metal lattice. For example, the group-4 TMCs can form a full-range solid solution with $\mathrm{N}$ in the $\mathrm{NaCl}$-type structure, and solid solutions with $\mathrm{B}$ and $\mathrm{O}$ with a much narrower solution-range due to the lack of isostructural phases in $M$-B and $M$-O systems $(M=$ $\mathrm{Ti}, \mathrm{Zr}$, and Hf) [99-101]. Many studies on TMC solid-solutions on their C sites are regarding with improving properties for cemented carbides, such as a higher hardness and improved oxidation-resistance of $\mathrm{Ti}(\mathrm{C}, \mathrm{N})$ than $\mathrm{TiC}$ alone $[99,100]$. Another relevant subject is regarding with the TMCs formed in Fe-based alloys (e.g. steel), where the carbides can be more stable with the incorporation of $\mathrm{N}$ and/or $\mathrm{O}$ on the $\mathrm{C}$ sites [81].

TMC also forms ternary solid-solutions with two transition metal species on the $M$ sites, as shown previously in the case of $\mathrm{Cr}-\mathrm{Mn}-\mathrm{C}$ and $\mathrm{Cr}-\mathrm{Fe}-\mathrm{C}$ systems [81,93]. At higher temperature, the NaCl-type TMCs forms solid solutions with a wide miscibility range among group $4-5$ metals, while the $\beta$-phase carbide solid-solution are found in group $5-6$, e.g. $(\mathrm{V}, \mathrm{Nb})_{2} \mathrm{C}$ or $(\mathrm{Mo}, \mathrm{W})_{2} \mathrm{C}[16,102,103]$. The NaCl-type solid-solutions even exist between binary carbides and nitrides with different transition metals, which consequently results into the formation of a quaternary solid solution such as $(\mathrm{Ti}, \mathrm{V})(\mathrm{C}, \mathrm{N})$ from $\mathrm{TiC}-\mathrm{VN}[16,104]$. The solid solutions are mostly studied on improved mechanical performances of TMC composites or hard coatings, for example in W-Ti-C and W-Hf-C systems [16,105]. However, in most systems, the mutual solubility decreases at lower temperature, leading to separation and precipitation of the binary phases. The precipitated minority phase can hinder the growth and reduce the grain size of the majority phase, and thus be applied to provide extra material hardening, for example in $\mathrm{W}-\mathrm{V}$ $\mathrm{C}$ and W-Cr-C systems [106].

On the other hand, ordered ternary TMCs are commonly formed with an element from group 13 - 17, denoted as $A$, or an additional transition metal, denoted as $M^{\prime}$ [ $[16,107]$, but only a few ternary TMCs have been put into practical applications since they are generally very brittle. The ternary TMCs with $A=\mathrm{Al}$ and $\mathrm{Si}$ are usually reported with enhanced oxidation resistance due to formation of denser $A$-based oxide products compared to transition metal oxides, preventing further oxygen penetration. Some commonly encountered phases of this type are $M_{3} \mathrm{AlC}$ (inverse perovskite structure), $M_{3} \mathrm{Al}_{2} \mathrm{C}, M_{5} \mathrm{Al}_{3} \mathrm{C}$ and $M_{5} \mathrm{Si}_{3} \mathrm{C}_{1-x}$ with the $M$ element from group $3-6$ [108]. Note that the TMCs in the inverse perovskite structure has also been reported 
on the systems with $M=\mathrm{Mn}, \mathrm{Fe}, \mathrm{Co}$, and $\mathrm{Ni}$, and $\mathrm{Al}$ is replaced by $\mathrm{Mg}, \mathrm{Zn}, \mathrm{Ge}, \mathrm{Sn}$, and $\mathrm{Ga}$, which have been studied for their magnetic properties $[109,110]$.

The ordered ternary TMCs composed of an additional transition metal $M$ ' have mostly been studied on the so-called $\kappa$-phase (kappa) and $\eta$-phase (eta). The $\kappa$-phase carbides have a general chemical formula $M_{9} M_{3}^{\prime} C_{4}$, where $M^{\prime}=\mathrm{Cr}, \mathrm{Mn}, \mathrm{Fe}, \mathrm{Co}$, or $\mathrm{Ni}$ when $M=\mathrm{W}$ and $M^{\prime}=(\mathrm{Mn}, \mathrm{Al})$, (Fe,Al), $(\mathrm{Co}, \mathrm{Al}),(\mathrm{Ni}, \mathrm{Al})$, or $(\mathrm{Cu}, \mathrm{Al})$ when $M=\mathrm{Mo}$, while other $\kappa$-phases can be found when $\mathrm{C}$ is replaced by, e.g., $\mathrm{B}, \mathrm{Si}$, and $\mathrm{O}[111,112]$. On the other hand, the $\eta$-phase carbides have two variations in the chemical formulae: $M_{4} M^{\prime}{ }_{2} \mathrm{C}$ and $M_{6} M_{6}{ }_{6} \mathrm{C}_{n}$, where $M=\mathrm{Zr}, \mathrm{Nb}, \mathrm{Mo}$, or $\mathrm{W} ; M^{\prime}$ $=3 d$-block transition-metals but mostly between Mn $-\mathrm{Ni} ; n=1-3$ [81,113,114]. Both $\kappa$-phase and $\eta$-phase have very complex and large crystal structure, and they are often mentioned in material systems related to steel [81].

\subsection{Inherently Nanolaminated Carbides}

Among the ordered ternary TMCs composed of an $A$ element (see section 2.2), some are identified with ordered repetition of atomically defined crystalline layers along one crystal axis, and therefore are sometimes described as inherently nanolaminated phases or inherently layered phases. The term inherently emphasizes the fact that the nanolaminated structures of these carbides are not only thermodynamically stable or metastable, but also spontaneously ordered themselves into layered structure at the occurrence of the phases. This is in distinction to artificial nanostructures, which are not included as inherently nanolaminated phases, though they can still be thermodynamically stable [32]. Examples can be found in Ref. [47-50], where artificial carbide- or nitride-nanolaminates were deposited for the synthesis of inherently nanolaminated phases by post-deposition annealing.

The MAX phases are a family of inherently nanolaminated phases with a general chemical formula $M_{n+1} A X_{n}$ (space group $P 6_{3} / m m c$ (194)), where $M$ is primarily a transition metal from group $4-6$ but also Sc and $\mathrm{Mn} ; A$ is commonly a group $13-15$ element but also $\mathrm{Cd}$ and $\mathrm{S} ; X$ is either $\mathrm{C}$ or $\mathrm{N} ; n$ is an integer between $1-3$ [29]. Hence, the MAX-phase family has a large number of combinations on the $M, A, X$, and $n$, where over 70 phases have been experimentally reported so far, excluding the MAX-phase solid solutions on one or more of the $M, A$, and $X$ sites [32].

The structure of MAX phases can be described as layers of transition-metal carbides or nitrides (the $M_{n+1} X_{n}$ blocks) interleaved by atomic monolayers of the $A$ elements, see Fig. 2-2. The 
carbide and nitride layers are formed by edge-sharing $M_{6} X$ octahedrons, which is identical to the binary $\mathrm{NaCl}$-type TMCs, while the $A$ atoms are located at the center of trigonal prisms between two twinned $M_{n+1} X_{n}$ layers, which are also edge-sharing with each other and with $M_{6} X$ octahedrons. By increasing $n$, the total number of $X$ layers between two $A$ layers increases respectively, i.e. one $X$ layer for $n=1$ (usually referred to as '211 phase'); two for $n=2$ ('312 phase'); three for $n=3$ ('413 phase'), and therefore the size of the unit cell increases along the $c$-axis $[18,19]$.

There are two polymorphs reported for the 312 and 413 phases, $\alpha-\mathrm{Ti}_{3} \mathrm{SiC}_{2}$ and $\beta-\mathrm{Ti}_{3} \mathrm{SiC}_{2}$ $[115,116]$, and $\alpha-\mathrm{Ta}_{4} \mathrm{AlC}_{3}$ and $\beta-\mathrm{Ta}_{4} \mathrm{AlC}_{3}$ [117], respectively, where experimentally the $\alpha$ polymorphs are dominant in most cases. This is explained by theoretical calculations showing that in these systems the $\alpha$-polymorph has a lower ground-state total energy than the $\beta$ polymorph, though both structures are thermodynamically stable [118,119]. The structural difference between the polymorphs in the 312 phase is changing the stacking sequence of the $A$ layers, which can be expressed by the stacking of the $M$ and $A$ elements along the $c$-axis as " $B C \underline{B} C B A \underline{B} A B \ldots$.." for the $\alpha$-polymorph and " $B C \underline{A} C B A \underline{C} A \ldots$.." for the $\beta$-polymorph, where the $A$ layers are underlined. Consequently, the $M_{6} A$ trigonal prism from the $A$ layers is now face-

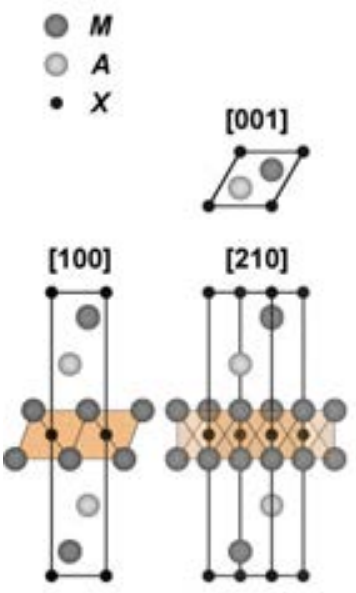

(a) $n=1$

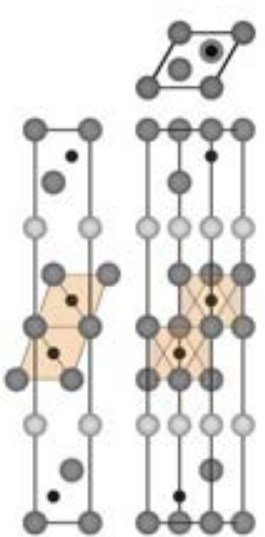

(b) $n=2$

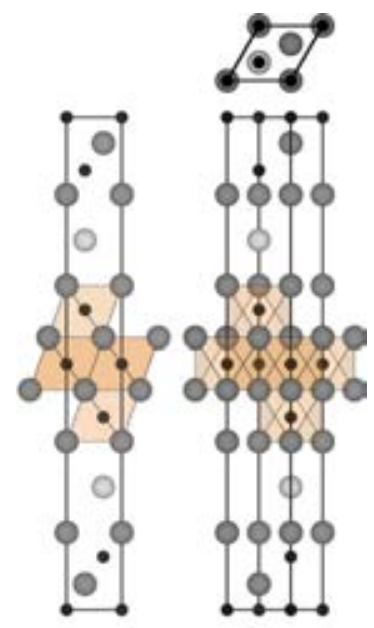

(c) $n=3$

Figure 2-2. (a) - (c) Crystal structures of $M_{n+1} A X_{n}$ phases with $n=1,2$, and 3 and along the [100], [210], and [001] zone axes. The $M_{6} X$ octahedrons in the carbide/nitride layers are highlighted. 
sharing with the adjacent $M_{6} X$ octahedrons. See Fig. 2-3(a). However in the 413 phase, the stacking sequence is changed in the $M_{4} X_{3}$ layers from " $B C \underline{B} C B A C \underline{A} C A \ldots$. for $\alpha$-polymorph into " $B A \underline{B} A B A B \underline{A} B A \ldots$... for the $\beta$-polymorph, where the $M_{4} X_{3}$ layers in the former is more alike to the NaCl-type structure and in the latter is more alike to hexagonal close-packed structure. See Fig. 2-3(b). The formation mechanism for $\beta$-polymorph is not yet clear, but it has been shown that the transition between the two polymorphs does not solely depend on the temperature [120].

MAX phases can form solid solutions on the $M$ sites (e.g., $(\mathrm{Ti}, \mathrm{V})_{3} \mathrm{AlC}_{2},(\mathrm{Nb}, \mathrm{V})_{2} \mathrm{AlC}$, $\left.(\mathrm{Nb}, \mathrm{V})_{4} \mathrm{AlC}_{3},(\mathrm{Nb}, \mathrm{Zr})_{2} \mathrm{AlC}[121]\right)$, on the $A$ sites (e.g., $\mathrm{Ti}_{3}(\mathrm{Si}, \mathrm{Ge}) \mathrm{C}_{2}$ [122], $\mathrm{Ti}_{3}(\mathrm{Al}, \mathrm{Sn}) \mathrm{C}_{2}$ [123], $\mathrm{V}_{2}(\mathrm{Ga}, \mathrm{Al}) \mathrm{C}$ [124]), and on the $X$ sites (e.g., $\mathrm{Ti}_{3} \mathrm{Al}(\mathrm{C}, \mathrm{N})_{2}$ [123], $\mathrm{Ti}_{2} \mathrm{Al}(\mathrm{C}, \mathrm{N})$ [125]). This allows further tailoring the properties of the MAX phases, such as hardness [126-129], magnetism [130-135], thermal expansion [129,136-138], and oxidation resistance [139-140]. However, there are some reports showing no prominent solution-hardening of MAX-phase solid solutions [141-144], which is explained by a reduced solution-effect in fine-grain MAX-phase samples, where high density of grain boundaries can limit the dislocation glide and deformation of the MAX phases [129]. For the electrical properties, the solution effect is also less noticeable when

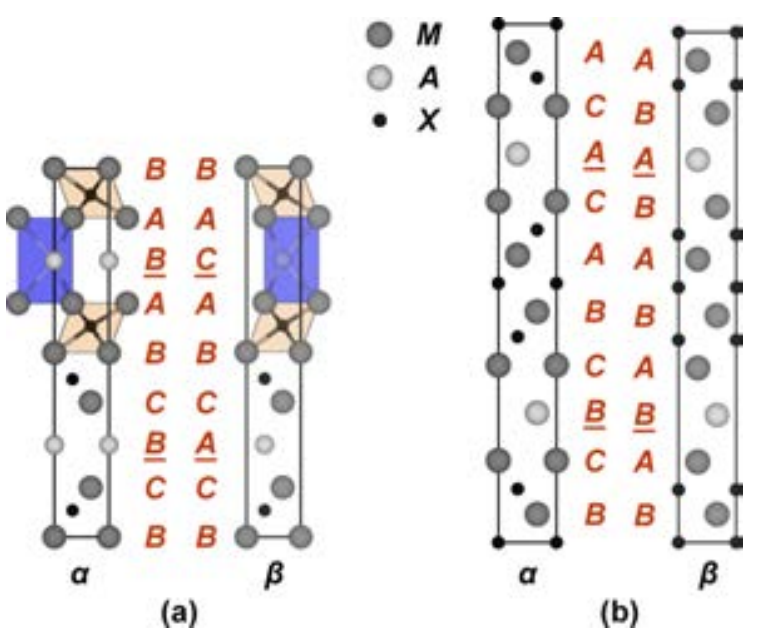

Figure 2-3. Crystal structures of (a) $\alpha$ - and $\beta$ - $\mathrm{Ti}_{3} \mathrm{SiC}_{2}$, and (b) $\alpha$ - and $\beta$ - $\mathrm{Ta}_{4} \mathrm{AlC}_{3}$ along the [100] zone axis. Few of the $M_{6} X$ octahedrons and the $M_{6} A$ trigonal prism in (a) are highlighted for comparison. The stacking sequence of the $M$ and the $A$ elements are also labelled. 
the solution is on the $A$ or the $X$ sites than on the $M$ sites [145-147] due to that the electrical conduction in MAX phases is mainly contributed from the $d$-orbits of the transition metals on the $M$ sites [148]. Moreover, formation of solid solutions can help in stabilizing the MAX phases when either or both of the end-point phases are less stable and tricky to synthesize [149$152]$.

In addition to the conventional MAX-phase structure described above, there are at least three groups of nanolaminated phases that are closely related to the MAX-phase structure, which are often referred to as the intergrown MAX-phases, the out-of-plane ordered MAX-phases, and the 221 phase. The intergrown phase got its name because it is structurally a half-lattice 211 phase regularly intergrown with a half-lattice 312 phase, or a half-lattice 312 phase intergrown with a half-lattice 413 phase, and they are often refered to as the 523 and 725 phases, respectively. In these phases, the $A$ layers are now sandwiched by twinned $M_{2} X$ and $M_{3} X_{2}$ blocks, or by twinned $M_{3} X_{2}$ and $M_{4} X_{3}$ blocks, as the $\mathrm{Ti}_{5} \mathrm{Al}_{2} \mathrm{C}_{3}$ shown in Fig. 2-4(a). Notice that the twinned $\mathrm{Ti}_{n+1} \mathrm{C}_{n}$ blocks are asymmetric with respect to the $A$-layers now, as compared to the conventional MAX-phases, and therefore the unit cell are extended along the $c$-axis and the space group is adjusted to $R \overline{3} m$ (166) [153]. The intergrown phases are commonly observed in

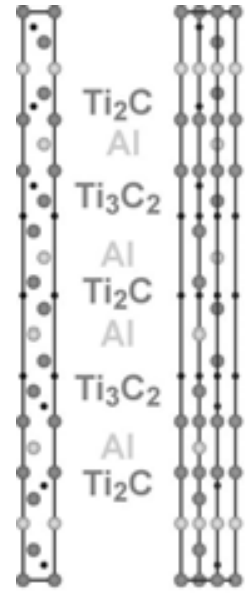

(a)

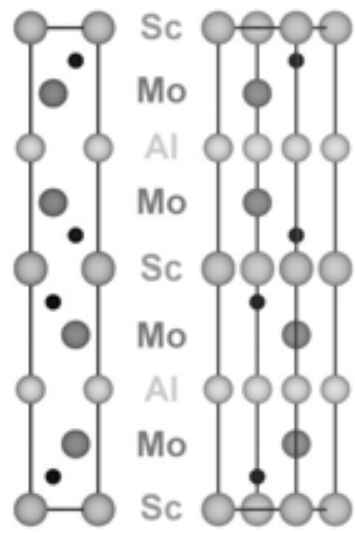

(b)

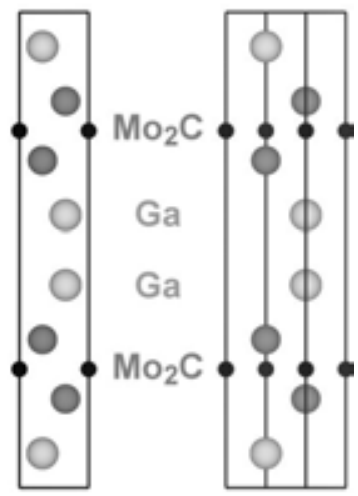

(c)

Figure 2-4. Crystal structures of (a) the intergorwn phase, $\mathrm{Ti}_{5} \mathrm{Al}_{2} \mathrm{C}_{3}$, (b) the outof-plane ordered phase, $\mathrm{Mo}_{2} \mathrm{ScAlC}_{2}$, and (c) the 221 phase, $\mathrm{Mo}_{2} \mathrm{Ga}_{2} \mathrm{C}$, along their [100] and [210] zone axes. The atomic layers or the $M_{n+1} X_{n}$ layers are labelled. (a) is shrunk to fit in the figure and not to the scale of (b) and (c). 
MAX-phase samples of various material systems, synthesized in thin film [149,154-156] or in bulk $[153,157]$, but only $\mathrm{Ti}_{7} \mathrm{Si}_{2} \mathrm{C}_{5}$ has been prepared in phase pure form [156].

The out-of-plane ordered MAX phases are quaternary phases with chemical formulae $M_{2} M^{\prime} A X_{2}$ and $M_{2} M_{2}^{\prime} A X_{3}$ and are isostructural to the 312 and 413 phases, respectively, with two transition metal species, $M$ and $M^{\prime}$, e.g., $\mathrm{Cr}_{2} \mathrm{TiAlC}_{2}$ [158], $\mathrm{Cr}_{2} \mathrm{VAlC}_{2}$ [159], $\mathrm{Mo}_{2} \mathrm{TiAlC}_{2}$ [160], $\mathrm{Mo}_{2} \mathrm{ScAlC}_{2}$ [161], and $\mathrm{Mo}_{2} \mathrm{Ti}_{2} \mathrm{AlC}_{3}$ [162]. See $\mathrm{Mo}_{2} \mathrm{ScAlC}_{2}$ in Fig. 2-4(b) as an example, where in the carbide blocks, Mo occupies only the atomic layers adjacent to the $A$ layer $(A=\mathrm{Al})$, and Sc occupies the atomic layers adjacent only to the Mo layers. The stacking sequence of the $M$, $M$ ', and $A$ (underlined) elements are therefore described as "Sc-Mo-Al-Mo-Sc-Mo-Al-Mo..." along the $c$-axis, which, in order words, shows a chemical order of the atomic layers along the out-of-plane directions of the basal planes. Although theoretical calculations indicate a tendency for the $M$ and $M$ ' elements to completely separate into different atomic layers $[161,163]$, the experimental results often show a small amount of intermixing in each atomic layer. Formation of such chemical order between the layers is explained by different chemical tendency of the transition-metal bonding to $\mathrm{C}$ and to $\mathrm{Al}$, where the interfacial transition-metal sites are mostly occupied by the transition metals that does not form stable binary NaCl-type carbide [162].

The 221 phase, as shown by its name, is a nanolaminated TMC with twice amount of the $A$ element compared to the conventional $211 \mathrm{MAX}$-phase, where $\mathrm{Mo}_{2} \mathrm{Ga}_{2} \mathrm{C}$ is the only phase discovered [164]. The $\mathrm{Mo}_{2} \mathrm{Ga}_{2} \mathrm{C}$ is the second nanolaminated phase reported in Mo-Ga-C system after the $\mathrm{Mo}_{2} \mathrm{GaC}$ MAX-phase, and both phases are thermodynamically the most stable phases in their respective stoichiometry, as shown by theoretical calculations $[60,165]$. Comparing $\mathrm{Mo}_{2} \mathrm{Ga}_{2} \mathrm{C}$ to $\mathrm{Mo}_{2} \mathrm{GaC}$, the twinned $\mathrm{Mo}_{2} \mathrm{C}$ layers are interleaved by $\mathrm{Ga}$ double-layers, instead of Ga monolayers in the 211 phase, where the Ga double-layers are directly stacked on top of each other forming a simple-hexagon stacking, as shown in Fig. 2-4(c). The 221 phase has also been observed in the intergrowth with the 211 phase in both in-plane and out-of-plane directions with respect to the basal planes, showing a close relation in both structure and chemistry [165]. The formation of the 221 phase is partly explained by the dimetric bonding nature of $\mathrm{Ga}$ [166], which also implies that 221 phase with other $M$ element in the $M_{2} \mathrm{C}$ layers can possibly form.

Other nanolaminated TMCs other than the MAX- and related phases are found in the cases where the $A$ element is bonded to $\mathrm{C}$ other than bonded only to the $M$ element. For example, the 
$M_{n} \mathrm{Al}_{3} \mathrm{C}_{n+2}$ and $M_{n} \mathrm{Al}_{4} \mathrm{C}_{n+3}$ families, where $M=\mathrm{Zr}$ and $\mathrm{Hf} ; n=2-4$, have $\mathrm{Al}_{3} \mathrm{C}_{2}$ and $\mathrm{Al}_{4} \mathrm{C}_{3}$ layers, respectively, between two twinned $(M C)_{n}$-layers instead of the $A$ monolayers in MAX phases, as shown in Fig. 2-5 [167,168]. They are in different space groups, $P 6_{3} / m m c$ (194) and $R \overline{3} m$ (164) respectively, and are sometimes written as $(M \mathrm{C})_{n}\left(\mathrm{Al}_{3} \mathrm{C}_{2}\right)$ and $(M \mathrm{C})_{n}\left(\mathrm{Al}_{4} \mathrm{C}_{3}\right)$ to emphasize the different building blocks and the nanolaminated structure. The metallic bonding sequence $M-A$ in the MAX phases is now replaced by a more ionic-covalent bonding sequence $M$-C-Al in these phases [61]. In addition, the structures of the $\mathrm{Al}_{3} \mathrm{C}_{2}$ and $\mathrm{Al}_{4} \mathrm{C}_{3}$ layers are analogue to partial structure of $\mathrm{Al}_{4} \mathrm{C}_{3}$ phase (space group $R \overline{3} m(164)$ ), while the $(M C)_{n}$ layers are structured similarly as in MAX phases [169]. The $\mathrm{Al}_{4} \mathrm{C}_{3}$-type family can form solid solutions with $\mathrm{Si}$ and $\mathrm{Ge}$ on the $\mathrm{Al}$ sites, e.g., $\mathrm{Zr}_{2}(\mathrm{Al}, \mathrm{Si})_{4} \mathrm{C}_{5}$ and $\mathrm{Zr}_{3}(\mathrm{Al}, \mathrm{Si})_{4} \mathrm{C}_{6}$, which has shown to improve the oxidation resistance by formation of Al- and Si-oxide mixture [61].
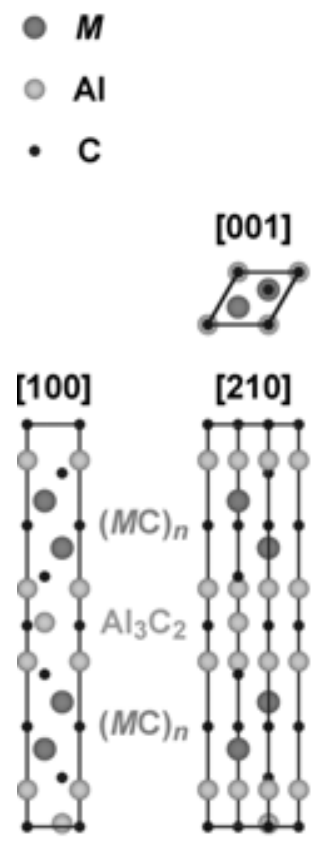

(a)

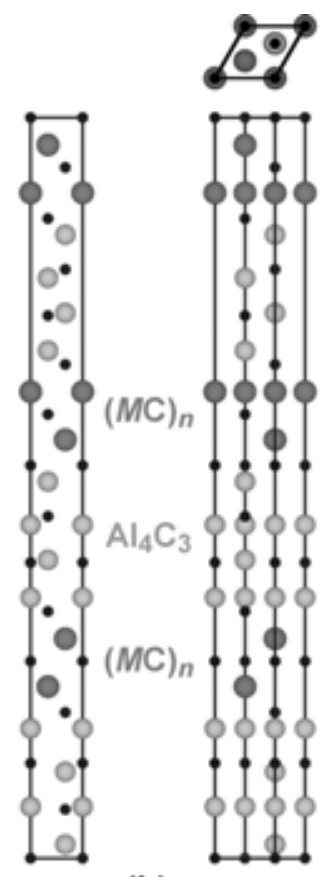

(b)

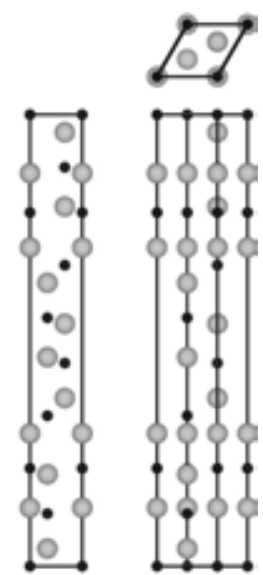

(c)

Figure 2-5. Crystal structures of (a) $M_{n} \mathrm{Al}_{3} \mathrm{C}_{n+2}$ and (b) $M_{n} \mathrm{Al}_{4} \mathrm{C}_{n+3}$ with $n=2$ and along the [100], [210], and [001] zone axes. The $(M C)_{n}$ and the $\mathrm{Al}_{3} \mathrm{C}_{2} / \mathrm{Al}_{4} \mathrm{C}_{3}$ layers are labelled in order to show the partial similarity with crystal structure of (c) the $\mathrm{Al}_{4} \mathrm{C}_{3}$ phase. 
The $M \mathrm{Al}_{3} \mathrm{C}_{3}$ and $M \mathrm{Al}_{4} \mathrm{C}_{4}$ phases, i.e. $n=1$ cases, are considered to be different from the other members since, when $n=1$, the characteristic structure of the $M_{6} X$ octahedrons vanishes from the TMC layers. Moreover, the $\mathrm{MAl}_{3} \mathrm{C}_{3}$ phase has only been experimentally discovered when $M$ is a group 3 or $f$-block transition metal (e.g. $\mathrm{ScAl}_{3} \mathrm{C}_{3}$ [169], $\mathrm{YAl}_{3} \mathrm{C}_{3}$ [167], $\mathrm{UAl}_{3} \mathrm{C}_{3}$ and $\left.\mathrm{YbAl}_{3} \mathrm{C}_{3}[170]\right)$, while the $M \mathrm{Al}_{4} \mathrm{C}_{4}$ phase $(M=\mathrm{Zr}$ and $\mathrm{Hf})$ was identified in a different space group P3m1 (156) than the other members [171,172]. Interestingly, the tendency of forming nanolaminated phases with $\mathrm{Al}_{3} \mathrm{C}_{2}$ or $\mathrm{Al}_{4} \mathrm{C}_{3}$ blocks is restricted to group 3 - 4 transition metals, except $\mathrm{Ti}$, which compete with the formation of conventional MAX phases, e.g. $\mathrm{Zr}_{2} \mathrm{AlC}$ or $\mathrm{Hf}_{2} \mathrm{AlC}$. This creates difficulties in producing MAX phases in above systems, which explains the scarcity of the experimental works despite of their relatively late discovery, and the high amount of impurity phases in the samples $[62,63,173]$.

Another example of nanolaminated TMCs with the $A$ element bonded to $\mathrm{C}$ is the $\mathrm{Mo}_{2} \mathrm{BC}$ phases (space group $\mathrm{Cmcm}(63)$ ) and its solid solution $(\mathrm{Mo}, \mathrm{W})_{2} \mathrm{BC}$. The $\mathrm{C}$ and $\mathrm{B}$ atoms are located at the interstitial sites forming $M_{6} \mathrm{C}$ octahedrons and $M_{6} \mathrm{~B}$ trigonal prisms, respectively, where the octahedrons are edge-sharing with each other and corner-sharing with the trigonal prisms [174]. The studies on the Mo-based nanolaminated phases are mostly focusing on the superconducting properties [54,175], where a recent study also shows a combined property of high stiffness and moderate ductility for $\mathrm{Mo}_{2} \mathrm{BC}$, suggesting potential applications in as protective coatings for cutting tools [174]. 


\section{Chemical Reactions of the MAX Phases}

The nanolaminated structure of the MAX phases, composed of ceramic $M-X$ slabs interleaved by more metallic $A$ layers, makes the overall properties a mixture of those of ceramics and metals. The interesting metallic-ceramic duality has triggered many works studying the chemical behavior of the MAX phases when in contact with another chemical element or compound. A general conclusion can be made from the results that the $M-X$ slabs retain their chemical inertness as ceramics, while the $A$ layers are more reactive to the surrounding. The metallic bonding between the $M$ and $A$ elements also allows higher mobility of the $A$ elements than the other elements in the structure. Hence in presence of an chemical attraction, the $A$ elements can easily out-diffuse from the bulk region of the structure to the surface, and subsequently react with the attracting surrounding by, e.g., evaporation, oxidation, or dissolution. Such high reactivity of the $A$ layers can sometimes be desired for, e.g. producing 2D TMCs (MXenes), while in some other applications it can be troublesome, as the nanolaminated structure tends to collapse and decompose when it is heavily substoichiometric. In this chapter, the chemical reaction of the MAX phases is introduced from the aspects of three major research topics.

\subsection{From Corrosion Behavior to MXene Production}

Some studies have been done on the chemical and electrochemical corrosion behaviors of the MAX phases, especially for the most studied $\mathrm{Ti}_{3} \mathrm{SiC}_{2}$ and $\mathrm{Ti}_{3} \mathrm{AlC}_{2}$ phases, by immersing the materials in aqueous solutions of acids, bases, or salts. Travaglini et al. showed that $\mathrm{Ti}_{3} \mathrm{SiC}_{2}$ is much more resistive to hydrochloric acid $(\mathrm{HCl})$, sulfuric acid $\left(\mathrm{H}_{2} \mathrm{SO}_{4}\right)$, diluted hydrofluoric acid $(\mathrm{HF})$, and sodium hydroxide $(\mathrm{NaOH})$ solution in chemical bath than commercially pure $\mathrm{Ti}$, which is widely used in corrosion resistive components [176]. This can be related to the general chemical inertness of the binary TMCs, with the only exception of vanadium carbide, which explains the results that V-based MAX phases dissolve easily in electrochemical test using the 
above solutions [177]. The other MAX phases that have been studied, e.g. $\mathrm{Cr}_{2} \mathrm{AlC}, \mathrm{Ti}_{3} \mathrm{GeC}_{2}$, and $\mathrm{Ti}_{n+1} \mathrm{AlN}_{n}(n=1$ and 3$)$ exhibit passive or trans-passive behaviors in electrochemical tests [176-180]. The passivation of the MAX phases in aqueous solutions is mainly due to the formation of a thin oxide-based passivating layer from the out-diffusing $A$ element during corrosion, such as $\mathrm{SiO}_{2}$ [181] or $\mathrm{GeO}_{2}$ [178]. Yet the effect of passivation is depending on the combination of the $A$ element and the chemical environment, for example, the phases with $A=$ $\mathrm{Al}$ are reported to be more resistive to $\mathrm{H}_{2} \mathrm{SO}_{4}$ solutions, but much less to $\mathrm{HCl}$ or $\mathrm{NaCl}$ solutions compared to the phases with $A=\mathrm{Si}$ or Ge $[180,182,183]$.

Due to the toxicity of HF solution, less has been reported on the chemical reaction between HF and the MAX phases before the first discovery of layered $\mathrm{Ti}_{3} \mathrm{C}_{2}$ by selectively etching Al layers away from $\mathrm{Ti}_{3} \mathrm{AlC}_{2}$ using $50 \%$ concentrated HF [22]. See Fig. 3-1. This new material, along with many other layer carbides, $M_{n+1} C_{n}(n=1-3)$, made by the same method, are therefore referred to as "MXenes" to emphasize the origin of removing the $A$ element from the MAX phases and the structural similarity with a well-known 2D material, graphene [22]. MXenes are shown to be electrically conductive and transparent to visible light [184]. Meanwhile, in order to passivate the dangling bonds created by removal of the $A$ elements, the surface of MXenes is often terminated by a combination of oxygen (-O), hydroxyl group (-OH), or fluorine (-F) [185], making MXenes to exhibit hydrophilic properties [23]. This makes the interaction between the MXene layers become weak van der Waals force, and consequently allows the MXene layers to be further delaminated and intercalated [186-188].

To date, more than 20 MXenes have been experimentally reported, including those with different $n$-numbers (the thickness of $M_{n+1} \mathrm{C}_{n}$ layer), with solid solution on the $M$ or the $X$ sites, and with out-of-plane chemical orders [29]. The etching process has also been developed from only using concentrated $\mathrm{HF}$ to, for example, the usage of bifluoride solutions (e.g., $\mathrm{NH}_{4} \mathrm{HF}_{2}$, $\mathrm{NaHF}_{2}$, and $\mathrm{KHF}_{2}$ ), and of $\mathrm{HCl}$ or $\mathrm{H}_{2} \mathrm{SO}_{4}$ solution with lithium fluoride (LiF) [28]. It is also noteworthy that so far no pure nitride-based MXenes, i.e. $M_{n+1} \mathrm{~N}_{n}$, has been reported, despite that several attempts has been done $[189,190]$. The difficulty of producing pure nitride-based MXenes from, e.g., $\mathrm{Ti}_{n+1} \mathrm{AlN}_{n}$, is explained by a combined effect of the stronger Ti-Al bonding and the less stable $\mathrm{Ti}_{n+1} \mathrm{~N}_{n}$ blocks, as compared to $\mathrm{Ti}_{n+1} \mathrm{AlC}_{n}[189,191]$.

However, the experimental reports on producing $\mathrm{Mo}_{2} \mathrm{C} T_{x}, \mathrm{Zr}_{3} \mathrm{C}_{2} T_{x}$, and $\mathrm{Hf}_{3} \mathrm{C}_{2} T_{x}(T=$ termination groups) show that the MXene production can also be done by selective etching of other nanolaminated TMCs than the MAX phases, for example in these cases, $\mathrm{Mo}_{2} \mathrm{Ga}_{2} \mathrm{C}$ [24], 


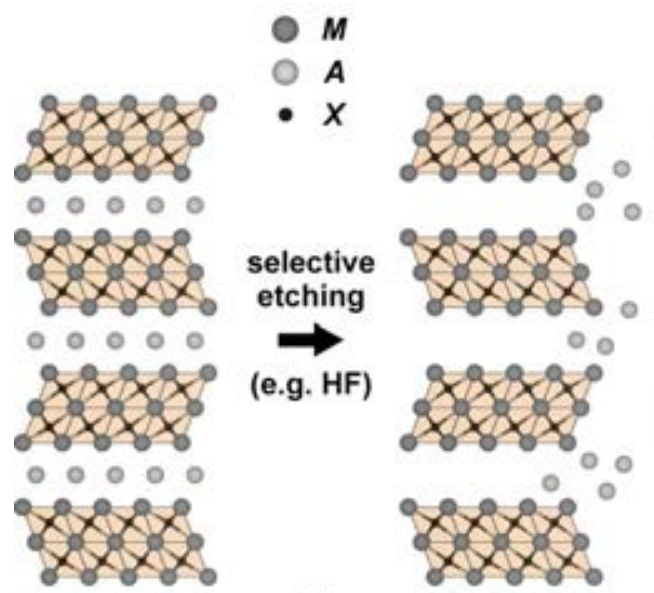

(a)

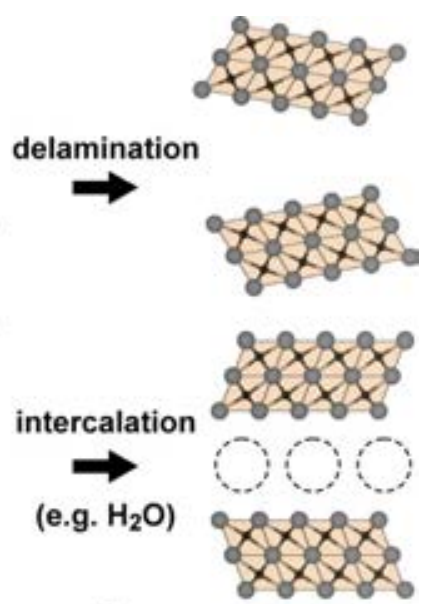

(b)

Figure 3-1. Schematic illustration of MXene production by (a) selective etching of the $A$ layers from a MAX-phase structure, followed by (b) intercalation and delamination of the remaining $M_{n+1} X_{n}$ layers. The intercalant are indicated by the circles with dash-line.

$\mathrm{Zr}_{3} \mathrm{Al}_{3} \mathrm{C}_{5}$ [25], and $\mathrm{Hf}_{3} \mathrm{Al}_{3} \mathrm{C}_{5}$ [26], respectively. The $\mathrm{Mo}_{2} \mathrm{Ga}_{2} \mathrm{C}$ case is explained by the dimeric nature of $\mathrm{Ga}$ atoms [166] that strengthens the Ga-Ga interaction but weakens the Ga-Mo interaction (see Fig. 2-4(c)), making the double-Ga layers easier to be selectively etched as compared to the single-Ga layers of $\mathrm{Mo}_{2} \mathrm{GaC}$, for which the MXene production has not been reported. The $\mathrm{Zr}_{3} \mathrm{Al}_{3} \mathrm{C}_{5}$ and $\mathrm{Hf}_{3} \mathrm{Al}_{3} \mathrm{C}_{5}$ case, on the other hand, are explained by easily hydrolyzed nature of $\mathrm{Al}_{4} \mathrm{C}_{3}$, which is structurally-chemically similar to the $\mathrm{Al}_{3} \mathrm{C}_{2}$-building block in $\mathrm{Zr}_{3} \mathrm{Al}_{3} \mathrm{C}_{5}$ and $\mathrm{Hf}_{3} \mathrm{Al}_{3} \mathrm{C}_{5}$ [25,26]. Overall, the MXene production follows the general trend that the non-TMC building blocks in nanolaminated TMCs, i.e., the $A$-containing layers, are prone to be attacked in aggressive environments.

\subsection{From Oxidation to Crack Self-Healing}

Little have been done on the oxidation behavior of the MAX phases before the first high purity $\mathrm{Ti}_{3} \mathrm{SiC}_{2}$ bulk sample was reported by Barsoum and El-Raghy, as the primary impurities resulting from the synthesis, e.g., $\mathrm{TiC}_{x}$ and $\mathrm{SiC}$, can deteriorate the oxidation resistance of the entire sample $[192,193]$. In 2000, Barsoum reviewed the preliminary oxidation properties of several MAX phases, showing that the oxides of the $A$ element are one of the primary products 
from the oxidation reaction [18] due to the faster out-diffusion of the $A$ element. This general concept holds in later studies of most other MAX phases, e.g., with $A=\mathrm{Si}, \mathrm{Al}, \mathrm{In}, \mathrm{Sn}$, and $\mathrm{S}$, but so far with one exception, $A=\mathrm{Ge}$, which can stay as elemental precipitates during the oxidation of $\mathrm{Ti}_{3} \mathrm{GeC}_{2}$ and $\mathrm{Ti}_{3}(\mathrm{Ge}, \mathrm{Si}) \mathrm{C}_{2}[194,195]$. As a result, the main kinetic of the oxidation is governed by either inward diffusion of oxygen or outward diffusion of the $M$ and $X$ elements through the oxide scale, or both factors.

The oxide scale is formed when the $M$ and $A$ elements are oxidized, as the oxidation of the $X$ elements normally results in volatile species, e.g., $\mathrm{CO}$ and $\mathrm{CO}_{2}$ when $X=\mathrm{C}[196]$ and $\mathrm{N}_{2}$ and $\mathrm{N}_{2} \mathrm{O}$ when $X=\mathrm{N}$ [197]. Therefore, the oxidation behavior of the MAX phases is significantly depending on whether or not the scale is capable of retarding $\mathrm{O}$ penetration and $M / A$-element out-diffusion at a given temperature. Most combinations of the $M$ and $A$ elements are oxidation protective only up to a temperature range of $400-500{ }^{\circ} \mathrm{C}$, such as $M_{2} \mathrm{O}_{5}-\mathrm{Al}_{2} \mathrm{O}_{3}$ in $M_{2} \mathrm{AlC}(M$ $=\mathrm{Nb}, \mathrm{Ta})[198,199], \mathrm{Ti}_{2} \mathrm{O}_{3}-\mathrm{In}_{2} \mathrm{O}_{3}$ in $\mathrm{Ti}_{2} \mathrm{InC}$ [200], $\mathrm{Nb}_{2} \mathrm{O}_{5}-\mathrm{SnO} / \mathrm{SnO}_{2}$ in $\mathrm{Nb}_{2} \mathrm{SnC}$ [201], and rutile $\mathrm{TiO}_{2}$ in $\mathrm{Ti}_{2} \mathrm{SC}$ [202]. Further increase the temperature or the time interval result in linear oxidizing kinetics and the oxidation in the bulk materials due to, e.g., formation of nonprotective oxide species [198-200], microcracks/pores [198-202], and volatile oxide species [202], or spallation of the scale [202]. Contrarily, $\mathrm{Ti}_{2} \mathrm{AlC}$ and $\mathrm{Ti}_{3} \mathrm{AlC}_{2}$ exhibits less oxidation resistance at temperature lower than $\sim 700{ }^{\circ} \mathrm{C}$ [18,203-205] but an improved oxidation resistance at temperature higher than $1000{ }^{\circ} \mathrm{C}$, which can be described with cubic oxidation kinetics [206]. This is explained by a slower kinetic for the formation of protective $\mathrm{Al}_{2} \mathrm{O}_{3}$ species than the formation of rutile $\left(\mathrm{Ti}_{1-x} \mathrm{Al}_{x}\right) \mathrm{O}_{2-x}$ with $x<0.05$, which is poor in preventing $\mathrm{O}$ penetration $[43,203,206]$.

The oxidation of the MAX phases has been reported for introducing crack self-healing to the damaged materials by sealing the cracks with, primarily, oxides of the $A$ element $[43,207]$. The oxidation-induced crack-healing has been realized in $\mathrm{Ti}_{2} \mathrm{AlC}$ [208-211], $\mathrm{Ti}_{3} \mathrm{AlC}_{2}$ [207], $\mathrm{Cr}_{2} \mathrm{AlC}$ [212-214], $\mathrm{Ti}_{2}(\mathrm{Sn}, \mathrm{Al}) \mathrm{C}$ [215], and $\mathrm{Ti}_{2} \mathrm{SnC}$ [216], by exposing the pre-notched or cracked samples to oxidizing atmosphere (air) for several hours at elevated temperature. After the oxidation process, the microcracks filling with mainly $\mathrm{Al}_{2} \mathrm{O}_{3}$ or $\mathrm{SnO}_{2}$, but also rutile $\mathrm{TiO}_{2}$ and $\mathrm{Cr}_{7} \mathrm{C}_{3}$, were observed, while nearly fully recovered, or in some cases, even higher values of the flexural strength were measured [209,212,216]. The results indicate that the oxides filling in the cracks can hinder the fast crack propagation as can be observed from most brittle materials, and hence prevent the fracture. 
The crack-healing mechanism is explained by the fast out-diffusion of the $A$ element along the basal planes and, therefore, faster accumulation of the oxides in the valleys or the cracks, where the surface area is larger and more a layers are exposed $[43,208]$. It has also been reported that MAX phases with crack healing property need to withstand a substoichiometry of the $A$ element before decomposition, since the decomposition can introduce more pores, cracks, and $M$-based phases (e.g. $\mathrm{TiO}_{2}$ and $\mathrm{Cr}_{7} \mathrm{C}_{3}$ ) that deteriorate the strength of the material [208,217]. For example, $\mathrm{Ti}_{2} \mathrm{Al}_{x} \mathrm{C}$ has been predicted to be stable with $\mathrm{Al}$ vacancy up to $x \sim 0.5$, while substoichiometric $\mathrm{Ti}_{2} \mathrm{Sn}_{x} \mathrm{C}$ has been shown to be able to withstand electron beam radiation [218,219]. Farle et al. listed primary criteria for selecting self-healing MAX phases, including that the $A$ element needs to have high diffusivity; the oxide of the $A$ element needs to be stable, oxidizing protective, adhesive to the surface, and have sufficient volume expansion to fill the cracks; the oxide and the MAX phase need to have comparable thermal expansion and Young's modulus to avoid stress-induced cracks [220]. The authors later performed tests on $\mathrm{Ta}_{2} \mathrm{AlC}$, which exhibited no crack healing behavior, to show that the oxidation kinetics also needs to be considered [221].

Despite higher stoichiometry of $\mathrm{Al}$ in $(M \mathrm{C})_{n}\left(\mathrm{Al}_{3} \mathrm{C}_{2}\right)$ and $(M \mathrm{C})_{n}\left(\mathrm{Al}_{4} \mathrm{C}_{3}\right)$, where $M=\mathrm{Zr}$ and $\mathrm{Hf}$ and $n=1-3$, types of nanolamianted carbides compared to the Al-based MAX phases, they are not particularly resistant to oxidation. Zhou et al. have reviewed that they generally show an parabolic-linear transition in oxidation kinetics at around $600{ }^{\circ} \mathrm{C}-700{ }^{\circ} \mathrm{C}$ [61]. This is due to stronger Al-C bonds, and consequently lower $\mathrm{Al}$ diffusivity, in the $\left(\mathrm{Al}_{3} \mathrm{C}_{2}\right)$ and $\left(\mathrm{Al}_{4} \mathrm{C}_{3}\right)$ building blocks compared to the mostly metallic $A$ layer in MAX phases. As a result, the $\mathrm{Al}$ in the Al-C slabs is not selectively oxidized to form the oxidizing protective scale, and the $\mathrm{Zr}$ or $\mathrm{Hf}$ become more vulnerable to oxygen. Alloying $\mathrm{Si}$ on the Al-sites, e.g., $\mathrm{Zr}_{2}[\mathrm{Al}(\mathrm{Si})]_{4} \mathrm{C}_{5}$ and $\mathrm{Zr}_{3}[\mathrm{Al}(\mathrm{Si})]_{4} \mathrm{C}_{6}$, can improve the oxidation resistance due to the formation of more protective species, such as aluminoscilicate $\left(\mathrm{Al}_{2} \mathrm{SiO}_{5}\right)$ and mullite $\left(3 \mathrm{Al}_{2} \mathrm{O}_{3} \cdot 2 \mathrm{SiO}_{2}\right)[61]$.

\subsection{From Interfacial Reaction to Substitution Reaction}

It has been pointed out that MAX phases do not melt, but rather decompose congruently at elevated temperature as following $[18,32]$ :

$$
M_{n+1} A X_{n} \rightarrow M_{n+1} X_{n}+A
$$

In absence of oxidizing atmosphere, the $M-X$ block may not maintain the nanolaminated structure and further transform into porous binary carbides $[42,69]$. The porous binary carbide crystal and the out-diffusing $A$ element are both prone to react with metals or ceramics in contact, 
leading to the formation of binary or ternary intermediate phases. In some occasion, such interfacial reaction is desired, as the products at the interaction layer can provide a mechanically stronger joint in between a MAX phase and a counter surface. But in the case where too high temperature or too long reaction time is allowed, the MAX-phase bulk can decompose entirely and consequently the preferred properties form the nanolaminated phase is lost. Thus, the assessment on interfacial reaction of MAX phases in contact with metals or ceramics are crucial for potential applications that usually involve large contact area and elevated temperature.

For example, the MAX phases are often applied to composites as a reinforcing material to another relatively softer material, e.g. $\mathrm{Cu}$ [73,222-224], Al [71,225,226], Ni-Al alloys [228229], Ni-Ti alloys [230], and Mg [231,232], like WC particles to a Ni-based matrix in the cemented carbide. The composites are heat-treated to increase the interfacial strength between the MAX phases and the soft materials, as shown in $\mathrm{Ti}_{3} \mathrm{SiC}_{2}$ reinforced $\mathrm{Cu}$ composites, where the mechanical properties were improved after annealing and the reaction products $\mathrm{TiC}_{0.67}$ and $\mathrm{Cu}_{3} \mathrm{Si}$ were observed [72]. The fast dissolution of the $A$ element into the material of the counter surface is commonly identified in the composites of the alloys listed above except $\mathrm{Mg}$, where thick interaction layer was not observed at the interface of $\mathrm{Ti}_{2} \mathrm{AlC}$ reinforced $\mathrm{Mg}$ composites $[231,232]$. The authors found out that the $\mathrm{Mg}$ can dissolve in $\mathrm{Ti}_{2} \mathrm{AlC}$, forming $\left(\mathrm{Ti}_{1-x} \mathrm{Mg}_{x}\right)_{2} \mathrm{AlC}$ with $x \leq 0.2$, while the out-diffusing Al can wet and strengthen the interface.

Similar to the composites, a well-controlled interfacial reaction can be used in diffusion-bonded joints of MAX phases and other structural components, with or without a filler metal. This type of joints utilizes the reaction between MAX phases and, e.g., Ti- [233], Zr- [234], Al- [235,236] and Ni-based alloys [237-240]. In addition, an interesting example has been demonstrated on direct diffusion-bonded joints of two MAX phases, $\mathrm{Ti}_{3} \mathrm{SiC}_{2}$ and $\mathrm{Ti}_{3} \mathrm{AlC}_{2}$, resulting in continuous gradients of the $\mathrm{Si}$ and $\mathrm{Al}$ contents at the interface [241].

The interfacial reaction of MAX phase has also been studied on the interfaces with semiconductor substrates and with oxidation barrier for long-term high-temperature applications. This topic is originated from the discovery of heteroepitaxial $\mathrm{Ti}_{3} \mathrm{SiC}_{2}$ formation at the interface of $\mathrm{Ti} / \mathrm{Al} / 4 \mathrm{H}-\mathrm{SiC}$ and $\mathrm{Ni} / \mathrm{Ti} / \mathrm{Al} / 4 \mathrm{H}-\mathrm{SiC}$ after annealing at $1000{ }^{\circ} \mathrm{C}$ and $800{ }^{\circ} \mathrm{C}$, respectively, which exhibited electrical Ohmic-contact behavior with low specific contact resistance [242]. Later, it has been reported that the Si-C-Si structure between the surface of $\mathrm{SiC}$ and the interfacial $\mathrm{Ti}_{3} \mathrm{SiC}_{2}$ has an important role of lowering Schottky barrier by intermediating the barrier height between the SiC substrate and the metal contact [243,244]. 
The electrical Ohmic-contact behavior has also been reported on directly synthesized epitaxial $\mathrm{Ti}_{3} \mathrm{SiC}_{2}$ and $\mathrm{Ti}_{3} \mathrm{GeC}_{2}$ on $4 \mathrm{H}-\mathrm{SiC}$ followed by a subsequent annealing $[245,246]$. However, the electron micrographs showed an atomically sharp MAX/SiC interfaces, indicating no interfacial reaction between the MAX phases and the SiC.

In 2015, Fashandi et al. reported a single-step process of producing $\mathrm{Ti}_{3} \mathrm{SiC}_{2}$ electrical $\mathrm{Ohmic}$ contact with $4 \mathrm{H}-\mathrm{SiC}$ by directly depositing $\mathrm{Ti}$ on $\mathrm{SiC}$ substrates while applying substrate temperature above $900{ }^{\circ} \mathrm{C}$ [247]. In order to explore the long-term high-temperature stability of previous $\mathrm{Ti}_{3} \mathrm{SiC}_{2} / \mathrm{SiC}$ contact in air, the authors deposited four different Au- and Ir-based capping layers $\left(\mathrm{Au}, \mathrm{Ir} / \mathrm{Au}, \mathrm{Ir}\right.$, and $\left.\mathrm{IrO}_{x} / \mathrm{Au}\right)$ as an electrically conductive oxidation barrier for the underlying $\mathrm{Ti}_{3} \mathrm{SiC}_{2} / \mathrm{SiC}$ structure. Subsequent annealing of the samples showed that $\mathrm{Au}$ can react with $\mathrm{Ti}_{3} \mathrm{SiC}_{2}$ through a thermal-induced substitution reaction for $\mathrm{Si}$, as shown in Fig. 3-2, resulting in formation of new nanolaminated carbides, $\mathrm{Ti}_{3} \mathrm{AuC}_{2}$ and $\mathrm{Ti}_{3} \mathrm{Au}_{2} \mathrm{C}_{2}$. $\mathrm{The} \mathrm{Ti}_{3} \mathrm{Au}_{2} \mathrm{C}_{2}$ phase can further react with Ir through the same reaction and form another new nanolaminated phase, $\mathrm{Ti}_{3} \mathrm{IrC}_{2}$. Both Ir-capped $\mathrm{Ti}_{3} \mathrm{Au}_{2} \mathrm{C}_{2}$ and $\mathrm{Ti}_{3} \mathrm{IrC}_{2}$ decomposed after prolonged anneal in air

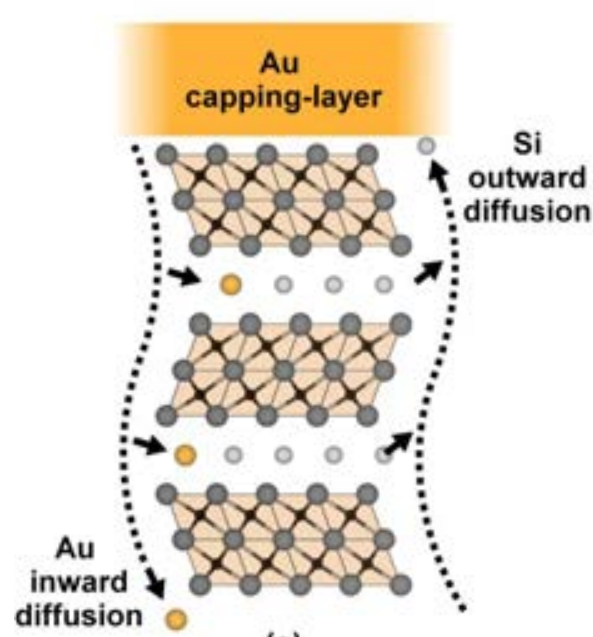

(a)

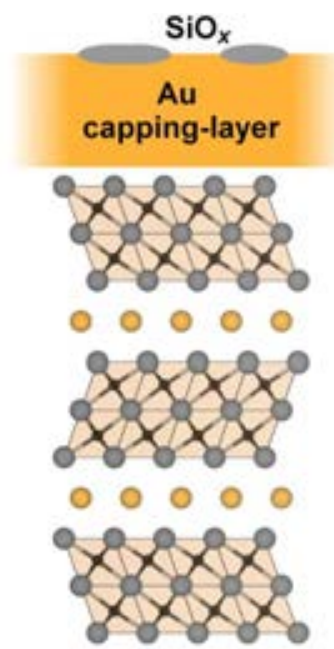

(b)

Figure 3-2. Schematic illustration of (a) thermally-induced substitution reaction of $\mathrm{Au}$ for $\mathrm{Si}$ in $\mathrm{Ti}_{3} \mathrm{SiC}_{2}$, resulting in (b) formation of nanolaminated $\mathrm{Ti}_{3} \mathrm{AuC}_{2}$ phase and $\mathrm{SiO}_{x}$ on the sample surface. 
at $600{ }^{\circ} \mathrm{C}$, while $\mathrm{IrO}_{x} / \mathrm{Au}$-capped $\mathrm{Ti}_{3} \mathrm{AuC}_{2}$ remained structurally intact and electrical Ohmiccontact behavior after $1000 \mathrm{~h}$ anneal in air at $600{ }^{\circ} \mathrm{C}[53]$.

Besides the remarkable long-term high-temperature stability of the $\mathrm{IrO}_{x} / \mathrm{Au} / \mathrm{Ti}_{3} \mathrm{AuC}_{2} / \mathrm{SiC}$ structure, the discovery of the new phases is highly noteworthy in the research of nanolaminated materials by following aspects:

(1) The complete $\mathrm{Au}$ substitution for the $\mathrm{Si}$ layers in $\mathrm{Ti}_{3} \mathrm{SiC}_{2}$ and the subsequent complete $\mathrm{Ir}$ substitution for the $\mathrm{Au}$ layers in $\mathrm{Ti}_{3} \mathrm{Au}_{2} \mathrm{C}_{2}$ show an intercalation behavior of $\mathrm{Au}$ in between carbide nanolaminae without destroying the carbide structure. Such reaction can be potentially be applied to modify nanolaminated phases.

(2) The formation of inherently nanolamianted phase with noble metals, Au and Ir, which indicates the possibility of expanding the method to other intercalant/substituent, e.g. the coinage group $(\mathrm{Cu}, \mathrm{Ag}, \mathrm{Au})$ and the platinum group $(\mathrm{Ru}, \mathrm{Rh}, \mathrm{Pd}, \mathrm{Os}, \mathrm{Ir}, \mathrm{Pt})$, and their alloys. Note that there are reports showing $\mathrm{Cu}$ and $\mathrm{Ag}$ local substitution on the $M$ and $A$ sites of MAX phases $[67,68]$, where further increase the substituted content can result in decomposition of the nanolaminated phase [68].

(3) The complete substitution for $\mathrm{Si}$ monolayer in $\mathrm{Ti}_{3} \mathrm{SiC}_{2}$ by $\mathrm{Au}$ monolayer $\left(\mathrm{Ti}_{3} \mathrm{AuC}_{2}\right)$ or $\mathrm{Au}$ double-layer $\left(\mathrm{Ti}_{3} \mathrm{Au}_{2} \mathrm{C}_{2}\right)$ results in lattice expansion along $c$-axis by $+5.3 \%$ and $+31.3 \%$, showing high tolerance of the $\mathrm{Ti}_{3} \mathrm{C}_{2}$ nanolaminates in such deformation. 


\section{Thin Film Synthesis}

A thin film is a layer of materials with a thickness ranging from few atomic layers up to few micrometers, depending on the scope of application or analysis. Applying thin films is an important method to modify the surface or interfacial properties of an underlying material, which is called a substrate. Products with combined properties can, therefore, be fabricated by depositing thin films on top of substrates, such as a light-weighted plastic-ware decoratively coated with a metallic thin-film, or a metallic structural component coated with a chemically inert ceramic thin film. In some applications, multiple thin films can be stacked on top of each other, for example in electronic devices or in optical components, where multi-layered thin films are done in regular basis.

\subsection{Physical Vapor Deposition}

In thin film deposition processes, desired starting materials are normally transformed into a more mobile form for the sake of delivery on to substrates and of phase formation (see Section 4.2). For example, the materials can be evaporated to form plasma and neutral species as in vapor deposition processes, be dissolved to form ions as in electrochemical plating, be melted into molten states as in thermal spray techniques, or be dispersed in volatile solutions as used in spin coating. The choice of the most suitable process depends on limitations and requirements of the final product, for example temperature tolerance, impurity level, thickness and uniformity [248].

In which, the vapor processes involves two major variations, namely physical vapor deposition (PVD) and chemical vapor deposition (CVD). CVD relies on chemical reactions of the starting materials (the precursors) taking places in the gas phase usually at or near the substrate surface, where the products will either condense as thin films or be evacuated from the system [249]. PVD processes, on the other hand, have no chemical reactions involved in the main deposition mechanism, where the materials are vaporized from the sources (or the targets) and directly 
condensed on substrate surface as thin films. Therefore, PVD processes are less limited by generation of chemical by-products and thermal equilibrium. In practice, they are commonly employed for depositing thin films with low impurity level and/or thermodynamically metastable phases [248].

However, the 'reaction-less' condensation also sets a limitation to PVD processes, compared to CVD processes, that the efficiency of deposition (or the deposition rate) is significantly reduced when a substrate is not in the 'line-of-sight' of the target. Hence, depositions on complexshaped substrates are usually challenging for PVD processes, which can be seen from the differences of microstructure, density and growth rate from on-axis and off-axis deposited thin films [250]. In the following subsections, a brief introduction is presented for the PVD methods used in this work, namely the direct current magnetron sputtering and the pulsed cathodic arc deposition processes.

\subsubsection{Direct current magnetron sputtering}

A magnetron sputtering process is normally initiated with ionization of gas molecules inside the system by accelerating stray electrons with a negative bias (in order of $10^{2}-10^{3} \mathrm{~V}$ ) on the target surface. The energized electrons can consequently ionize gas molecules via collisions under certain probability. Due to the target bias, the positive ions from the ionization are accelerated toward, and eventually impinge on the target surface. The incident ions transfer the momentum and the energy to the target material, creating series of collisions, or collision cascades, between target atoms. Such collision cascades may return part of the momentum and the energy back to the surface, causing surface atoms or molecules to be ejected from the surface. The above process of removing materials from a surface by impingement of energetic particles is referred to as sputtering. Thereafter, deposition begins when the ejected target species arrive at the substrate surface, nucleate and grow into a thin film [251]. See Fig. 4-1 for a brief illustration of the sputtering process on a target surface.

In order to reduce the impurity level in thin films, the deposition system is normally evacuated to a vacuum typically below $10^{-4} \mathrm{~Pa}$, and then back-filled with sputtering gas up to a certain working pressure, normally of the order of $10^{0}-10^{-1} \mathrm{~Pa}$, during deposition. The sputtering gas molecules will be ionized to ignite plasma as the main source of the positive ions in the sputtering process. Hence, such gas species are ideally easily ionized and chemically inert to reduce unwanted chemical reactions [251]. Ar is currently the most popular sputtering gas due to an optimal combination of its abundance, ionization energy, and chemical inertness 


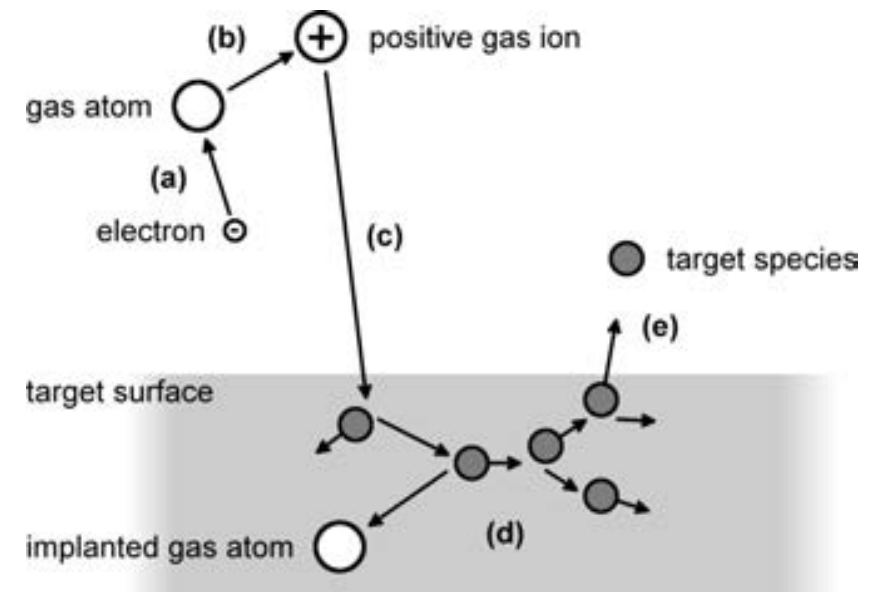

Figure 4-1. Schematic illustration of sputtering process starting by (a) electron acceleration, (b) gas ionization, (c) acceleration of gas ion towards a target surface, (d) collision cascade in the target, and (e) ejection of target species. See text in subsection 4.1.1.

compared to other noble gases and atmospheric gases such as $\mathrm{N}_{2}$ or $\mathrm{O}_{2}$. It also has a similar atomic mass to many common depositing materials from period $2-4$, which benefits the sputtering yield at the target surface. Other noble gas species, e.g. $\mathrm{Ne}$ and $\mathrm{Kr}$, and mixtures of these gas species can also be utilized in sputtering-processes to enhance the yield of lighter or heavier target elements, such as $\mathrm{B} / \mathrm{C}$ or $\mathrm{Hf} / \mathrm{Ta} / \mathrm{W}$, respectively $[252,253]$.

The emission of secondary electrons induced by sputtering on the target surface is the most important effect for sustaining the plasma and the sputtering deposition process. In contrast to the positive ions, the emitted secondary electron are expelled away from the target by the negative bias, and they can consequently ionize or excite more gas molecules upon collision. The ionized or excited gas molecules can further complete the cycle by creating positive ions for the sputtering deposition and the secondary electron emission [251]. However, without sufficient confinement to the emitted secondary electrons, the electrons can easily escape from the plasma and be lost to an anode (usually the chamber wall), leading to a diode sputtering process with a low ionization efficiency. Usually in this case, a high target-bias is constantly required to sustain the plasma, but the electrons expelled or the positive ions recoiled by the 
high voltage can easily reach the substrate, causing unwanted damage to the substrate and even the deposited films [254].

Therefore, a magnetron sputtering process solves the problems in diode sputtering by confining electrons close to the target with a magnetic field. A magnetic field of a few hundred gauss (100 $\mathrm{G}=0.01 \mathrm{~T}$ ) is commonly applied by permanent magnets placed behind a planar target like in this work, but it can also be provided by, for example, an electromagnetic coil surrounding a cylindrical target [255]. See Fig. 4-2. With the confinement, the electrons travel prolonged trajectories to increase the collision events with the sputtering gas before they escape to an anode. The densified plasma above the cathode can increase the sputtering rate of the target and the deposition rate on the substrate compared to a diode sputtering deposition process. Moreover, since the secondary electron emission is more efficient in such confinement, the applied voltage on the target is normally lower compared to diode sputtering [254].

Last, the term direct current is used to state the contrast to a pulsed magnetron sputtering process, where in the latter case the amplitude of the target voltage is pulsed instead of constant

(a)

(b)

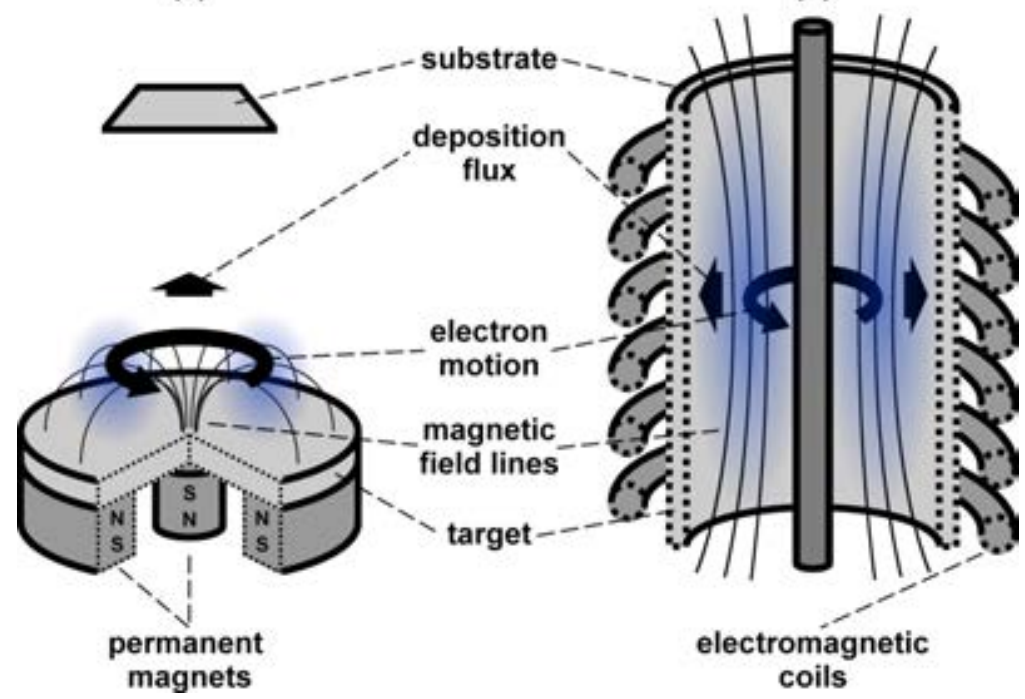

Figure 4-2. Schematic illustrations of magnetron sputtering processes using (a) a planar target on permanent magnets and (b) a cylindrical target surrounded by electromagnetic coils. Some components are partially removed along the dotted lines for a better view of the interior structure. 
as in direct current magnetron sputtering (DCMS). The pulsed magnetron sputtering technique is often used in so-called reactive sputtering processes, where reactive species, usually in gas state, is additionally introduced into the system during deposition to form desired compounds in thin films by chemical reactions with the target materials. For example, $\mathrm{N}_{2}$ can be used for depositing $\mathrm{TiN}$ thin films and $\mathrm{O}_{2}$ for $\mathrm{TiO}_{2}$ thin films together with a Ti target. Utilizing the pulsed magnetron sputtering technique in a reactive process can reduced the deficiency of low plasma density and the high tendency of target arcing, which lower the production throughput and/or the quality of thin films, as compared to non-reactive magnetron sputtering [256]. In addition, a specialized pulsed process has been developed to provide a higher ionization degree in the deposition flux by applying high peak power (in the order of $10^{3}-10^{4} \mathrm{~W}$ ) on the target, which is therefore referred to as a high-power impulse magnetron sputtering (HiPIMS) process. In order not to exceed the thermal loadability of the target materials, a typical HiPIMS process has a pulsing frequency in the range of $10^{2}-10^{3} \mathrm{~Hz}$, leading to a time-averaged power similar to DCMS (in the order of $10^{1}-10^{2} \mathrm{~W}$ ). Hence in HiPIMS, an ionization degree above $90 \%$ can be achieved for e.g., Ti, compared to less than 1\% in DCMS [257]. The effect of ionization degree on deposited films will be elaborated in Section 4.2.

\subsubsection{Pulsed cathodic arc}

In a cathodic arc process, a plasma of the target material is generated in a cathodic arc discharge on the surface of a negatively biased target, which serves as a cathode in the process. Cathodic arc and thermionic arc are two types of collective electron emission processes, or arc discharges, where a large amount of electrons are emitted in a confined area, or a cathode spot, when a certain condition is fulfilled. In a thermionic arc discharge, a surface is heated until electrons are sufficiently thermalized to overcome the working potential of the surface material and escape into vacuum. On the other hand, a cathodic arc discharge relies on an external electric field to enable the surface electrons to overcome the potential via quantum-tunneling at the places with lower work function or higher electric field locally. A collective electron emission is very different from individual electron emission as in, e.g., glow discharge and sputtering, whose emission yield (the number of electrons emitted per incident particle) can reasonably be calculated $[258,259]$.

During an arc discharge, a high density of electrons (in the order of $10^{12} \mathrm{~A} / \mathrm{m}^{2}$ ) is emitted from each of $\mu \mathrm{m}$-sized cathode spots, where the target material at the surface is resistively heated up by such high flow of electrons. For metal targets, the raised temperature at the cathode spots normally has a positive effect to further increase the thermionic electron emission and the local 
electric resistivity, which in return further increase the local temperature and the emission. Consequently, the local temperature can reach several thousands of kelvin in a time frame of few nanoseconds before a cathode spot extinct (after few tens of nanoseconds), where the temperature is high enough to transform almost all metals into plasma state at the emission center [260]. This rapid transformation in a confined volume pushes the plasma away from the target surface into the vacuum with a supersonic ion velocity (in the order of $10^{3}-10^{4} \mathrm{~m} / \mathrm{s}$ ). The ions can then travel through the system and reach the substrate with a higher direct ion kinetic energy (ranging from $20-160 \mathrm{eV}$ ) and a nearly $100 \%$ ionization degree $[261,262]$.

As mentioned above, the ignition of a cathodic arc discharge requires a sufficiently high electric field, at least locally, across a cathode and an anode. In modern cathodic arc deposition processes, this is mostly done by various triggering methods, where the arc is first initiated by an auxiliary triggering component [262]. For example in a mechanically drawn arc, a triggering electrode is repeatedly connecting and disconnecting against the target surface, where it increases the electric field by shortening the distance between the electrodes. Another method is utilizing a focused laser beam to locally increase the temperature on the target surface and, hence, trigger cathodic arc via thermionic arc discharge. In Paper III, the arc was ignited by a triggering method involving a surface voltage flashover, where the arc can be established more

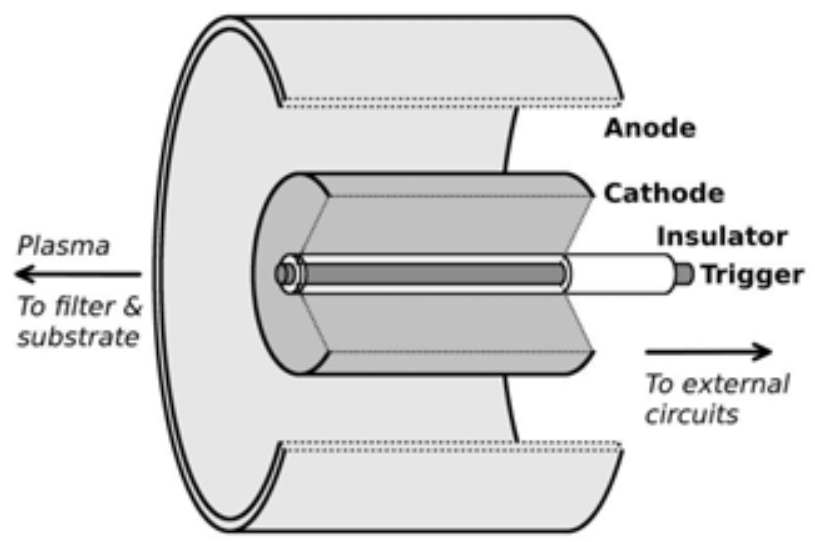

Figure 4-3. Schematic illustration of the cathodic arc source used in Paper III, where the trigger, the insulator, the cathode, and the anode are concentric. Some components are partially removed along the dotted lines for a better view of the interior structure. 


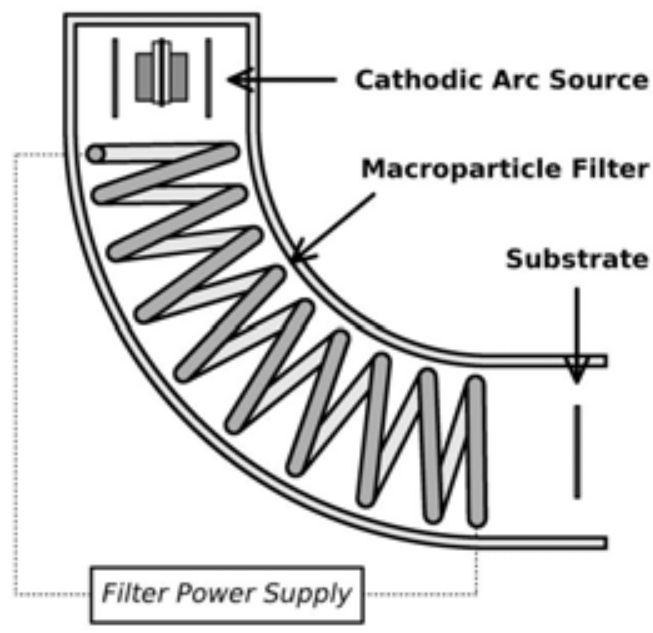

Figure 4-4. Schematic illustration of the arrangement of the cathodic arc source, the magnetic macroparticle filter and the substrate in Paper III. For simplicity, only one cathode and only 9 out of 30 turns are shown for the solenoid. Dotted lines indicate electrical connections from the filter to the filter power supply.

easily between the cathode and the triggering electrode through surface states of an insulating surface. Fig. 4-3 shows a schematic illustration of the cathode used in this work. Also see Ref. [263] for more detailed descriptions for the system.

Cathodic arc processes are developed into DC arc and pulsed arc processes. In a DC arc process, the bias on all components are constant in contrast to the pulsed bias on the trigger and the target in a pulsed arc process. DC arc processes are often applied in industry since dense films with good adhesion can normally be deposited at a high deposition rate. Pulsed cathodic arc deposition, on the other hand, is often found in small-scale or laboratory-sized system, where a wide range of research can be done with improved control of the deposition parameters, e.g. pulse frequency and pulse length. In addition, the pulsed arc processes can achieve higher peak currents (close to or more than $1 \mathrm{kA}$ ) compared to DC process (normally less than $0.5 \mathrm{kA}$ ) because of better cathode spot stability and less target-cooling limitation [264,265]. Moreover, the pulsed processes allow better adjustments on the chemical composition of the plasma and the deposited films by adjusting the relative numbers of pulses ignited from multiple targets of different materials. 
Cathodic arc deposition processes typically result in inclusion of nanometer- and micrometersized clusters composed of the target materials in the deposited films, whose chemical and structural homogeneity can largely be affected. These clusters are often referred to as macroparticles or 'droplets' to stress on their significant size. However in the deposition flux, there is in fact a continuous size-distribution from single atom/ion (as in the plasma) up to particles of micrometers. The formation of droplets is often explained by molten target materials around an emission center (roughly the center of a cathode spot) being pushed out by the fast expanded plasma. The droplets in the deposition flux can be removed by a droplet filter installed between the arc source and the substrates. The filter works either to enhance the plasma-todroplet ratio or to remove the majority of the droplets from the plasma [266]. In Paper III, a $90^{\circ}$-bent solenoid, installed between the pulsed cathodic arc source and substrates as shown in Fig. 4-4, was operated as a magnetic macroparticle filter during depositions by dispersing the deposition flux with respect to the charge-to-mass ratio of the particles. The removal of droplets usually causes significant reduction in the deposition rate and therefore is not necessary for the applications where inclusion of macroparticles has detrimental effects on the properties.

\subsection{Formation of Thin films}

Formation of thin films is a part of the deposition process which concerns the formation of phases and microstructure in the thin films after condensation of the target species at the substrates. The main driving force for the formation of thin films is the difference between the chemical thermodynamic equilibrium and the system's free energy. In order to minimize the difference, the condensed species (or adatoms) tend to look for energetically favorable sites on the surface by diffusion. That is, the adatoms adjust their chemical bonding conditions by moving around the condensed positions to lower the free energy of the system under a given set of composition, temperature and pressure. The ability of diffusion, or the mobility, for the adatoms is also governed by the kinetic energy of the adatoms, where the higher the kinetic energy, the further away they can move from the condensed position. When an adatom moves into an energetically favorable sites, it thus become less mobile and the growth of a thin film can thus be initiated.

The so-called three primary growth modes [267], namely the Volmer-Weber (island) growth, the Frank-van der Merwe (layer-by-layer) growth, and the Stranski-Krastanov (layer-intoisland) growth, illustrate, in a simplified manner, the initial stage of thin-film growth in three different conditions. They assume only one metal species is deposited on the substrate, while 
the adatoms have high mobility to diffuse on the surface, i.e. the kinetic effect is less concerned. Hence, the major reason of exhibiting different growth behavior is the adatoms' preference in interacting with the surroundings, i.e., with the substrate species, with other adatoms, and with vacuum.

In the island growth, the bonding between adatoms is more energetically favored and therefore they tend to form 3D clusters to minimize the non-self-bonding surface area, resulting in a low wettability between the adatoms and the substrate species, as shown in Fig. 4-5(a). This growth mode is often observed when depositing coinage metals $(\mathrm{Cu}, \mathrm{Ag}, \mathrm{Au})$ on amorphous silicon oxides, where a high thickness is required in order to form a continuous film. In contract to the island growth, the adatoms in the layer-by-layer growth are energetically more favorable to maximize the surface bonded to the substrate species or left unbonded. Hence, the adatoms tend to grow in 2D atomic layers, resulting in a high wettability to the substrate and a low roughness in the thin film, as shown in Fig. 4-5(b) [248]. This growth mode is desired in most semiconductor applications utilizing multilayer structures for the production of electronic devices, where smoother interfaces between the layers are required to ensure the performances.

In the third growth mode, or the layer-into-island growth, the adatoms initially favor the layer growth and then transformed into the island growth after first one or few monolayers has formed, as shown in Fig. 4-5(c). This is commonly seen when the adatoms favor the bonding to the substrate, but the lattice mismatch between the deposited monolayers and the substrate causes accumulation of the strain energy along with the growing film. When the energy is released, it can cause the island growth above the critical thickness of the thin film [248]. This has been observed in the deposition of $\mathrm{Mo}_{2} \mathrm{Ga}_{2} \mathrm{C}$ on $\mathrm{MgO}(111)$ and $(\mathrm{Cr}, \mathrm{Mn})_{2} \mathrm{GaC}_{\text {on }} \mathrm{Al}_{2} \mathrm{O}_{3}(001)$ during this work, where tilted grains and rough surfaces can be found after the layer-by-layer growth of $\sim 50 \mathrm{~nm}$.

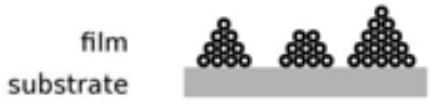

(a)

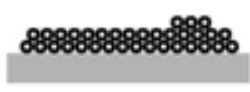

(b)

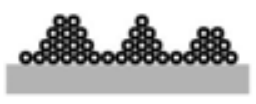

(c)

Figure 4-5. Schematic illustrations of the three primary growth modes: (a) Volmer-Weber (island) growth, (b) Frank-van der Merwe (layer-by-layer) growth, and (c) Stranski-Krastanov (layer-into-island) growth. 
However in a condition where the chemical potential is close to the local equilibrium or the kinetic energy of the adatoms is low, certain types of diffusion might not be enable, e.g. bulk diffusions or long-range diffusions. Hence, the long-range equilibrium cannot be reached in this diffusion-limited condition, resulting in the formation of metastable phases. For example, a metastable $(\mathrm{Ti}, \mathrm{Al}) \mathrm{N}$ solid solution in cubic structure, whose stable phase-composition is separated cubic TiN plus hexagonal AlN, can be synthesized when applying low substrate temperature [268]. At the same time, microstructures with reduced grain-size and high porosity can be introduced in such condition, as shown in Fig. 4-6 where the vacancies cannot be removed when adatom diffusion is prevented. In this case, the three primary growth modes alone might not be sufficient to elucidate the observed microstructure [269].

In some cases where the metastable phases and/or the porous microstructures are not desired, the adatom mobility can be enhanced by supplying additional energy to the substrate surface and the growing film. Commonly, the additional energy is provided by increasing growth temperature (i.e. substrate temperature) or by enhancing incident ion energy (i.e. ion bombardment) [269]. Notice that the method of changing the growth temperature can also lead to changes of the equilibrium condition. However, if a desired phase has large equilibrium range with respect to temperature, increasing the growth temperature often leads to deposition of denser films with larger grain size.

On the other hand, increasing the incident ion energy increases the adatom mobility by transferring kinetic energy through collision cascades (as in sputtering), which not only mobilize surface diffusions but also introduce short-range intermixing under the surface. The kinetic energy of the incident species is normally enhanced by applying a negative bias on or behind a substrate to accelerate the ions towards the substrate [270]. This is one reason for

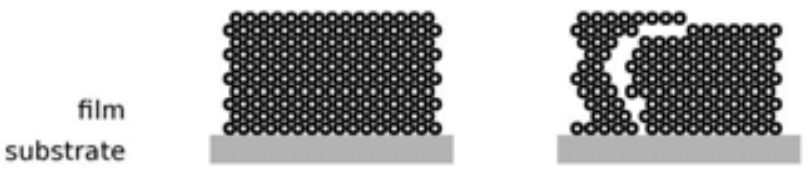

Figure 4-6. Schematic illustration of an ideal layer-by-layer growth (left) and an underdense microstructure introduced by diffusion-limited condition (right), where incomplete atomic layers are formed. 
developing various PVD processes with high ionization degree of the target species, such as cathodic arc deposition and HiPIMS, to maximize the control over incident ions $[271,272]$. In DCMS processes, where the ionization degree of target species is low, an unbalanced magnetron with a reduced confinement to the electrons and the plasma can be used to allow part of the sputtering gas ion to escape from the plasma and to impinge on to the substrate [254].

To illustrate the effects of adatom mobility on the microstructure of the deposited films, a simplified empirical model, called structure zone diagram (SZD), is often introduced. The SZD modified by Anders [273] shows differences in the microstructure evolution by controlling the adatom mobility through the growth temperature or the incident ion energy. This difference is explained by extra defects and ion implantation (e.g. sputtering gas) introduced by high energy ion bombardment, which disrupt the crystal growth and lead to smaller grain sizes. Moreover, the deposition rate can also decrease upon increasing the incident ion energy due to resputtering on the deposited films, which eventually leads to erosion and a negative deposition rate when further increase the incident energy.

In practice, the formation of thin films involves control of many parameters other than just applied substrate temperature and/or bias in a deposition process, e.g. selection of substrate material, deposition flux ratio, and working pressure. The complexity of attaining desired phase composition, crystal quality (e.g. epitaxy), and materials properties (e.g. magnetism) at the same time increases substantially along with the number of element in a material system. For example, the optimization of the MAX-phase thin films is very sensitive to applied temperature, material, and surface quality of the substrates [33,274]. In the case of $\mathrm{Mo}_{2} \mathrm{GaC}$, the MAX phase can grow on $\mathrm{MgO}(111)$ but not on $\mathrm{Al}_{2} \mathrm{O}_{3}(001)$ while using the same deposition parameters [60]. In Paper III, a similar observation was reported on the optimization of $\mathrm{Zr}_{2} \mathrm{Al}_{3} \mathrm{C}_{4}$ thin films in a pulsed cathodic arc process, where the ternary carbide only grows on $\mathrm{SiC}(001)$ and $\mathrm{Al}_{2} \mathrm{O}_{3}(001)$ substrates. 


\section{Thin Film Characterization Techniques}

\subsection{Structural analysis techniques}

\subsubsection{X-ray diffractometry}

$\mathrm{X}$-ray diffractometry (XRD) is a technique where information about a sample is interpreted from the diffraction from the sample when irradiated by X-rays. It is a widely used method to characterize the phase composition and the structural information of crystalline samples, since it generally requires no complex sample preparation, no vacuum systems, and is able to be integrated for in situ experiments in non-ambient pressure and temperature. With the help of Rietveld analysis (or Rietveld refinement), where measured diffraction patterns are fitted and compared with theoretical patterns of built models, quantitative phase and structural information can also be obtained. In Paper I and II, the Rietveld analysis was done on XRD and neutron diffraction patterns of $\mathrm{Mo}_{2} \mathrm{Ga}_{2} \mathrm{C}$ powder samples.

The X-ray diffraction comes from elastic scattering between the incident X-ray and electrons surrounding the sampled atoms, where the elastically scattered X-ray photons have the same wavelength $\lambda$ with the incident and are in phase with each other. When interference occurs between the X-rays scattered from different atoms, a diffraction pattern is thus created with an angularly distributed photon intensity, $I(2 \theta)$, on the scattering plane, i.e. the plane spanned by both incident and scattered beams, as shown in Fig. 5-1. The argument $\theta$ is referred to as the scattering angle, and is specified as the half-angle between the incident and the scattered beam.

The diffraction pattern can be recorded to extract phase and structural information from the angular position of the constructive interference spots, or diffraction peaks. Bragg's equation relates the angular position of the $n$th diffraction peak to an interplanar spacing, $d$, from a group of periodic crystal planes as following:

$$
2 \cdot d \cdot \sin \theta=n \cdot \lambda
$$




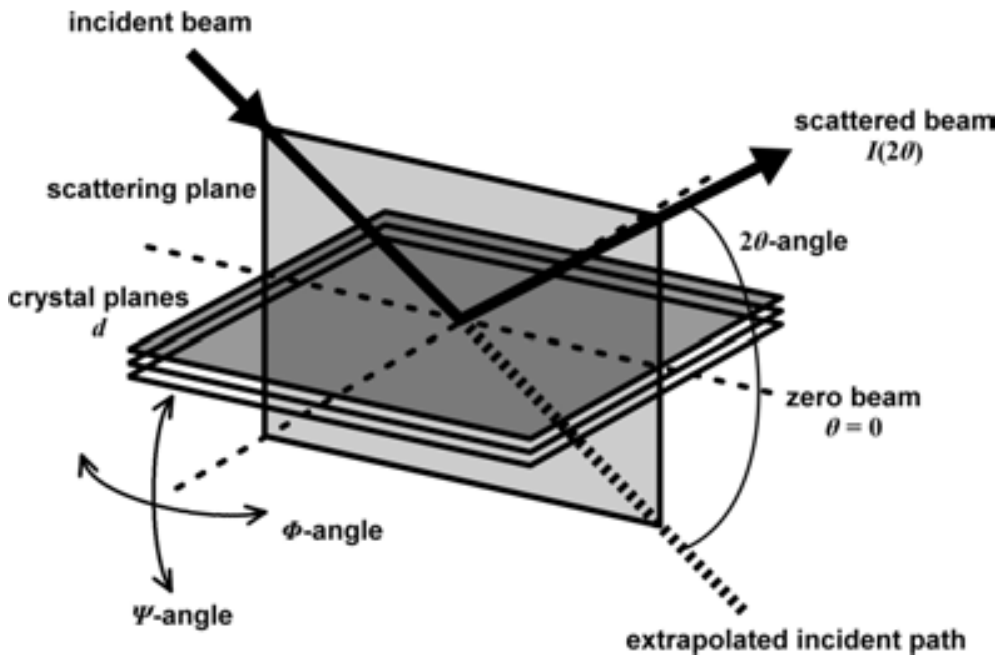

Figure 5-1. Schematic illustration of the XRD geometry.

Notice that $d$ is in the scattering plane and perpendicular to the path of zero beam (the path of the incident beam when $\theta=0$ ), and usually only $n=1$ has enough intensity to be visible.

For a crystalline phase, the relative intensity of its diffraction pattern can be calculated by its structure factor, which is function depending on the scattering angle, the chemical stoichiometry, and the crystal structure. Some diffraction peaks can turn out with zero intensity according to the structure factor of a material and are therefore referred to as forbidden peaks. Because of the structure factor, every crystalline phase has its own unique XRD pattern, where a diffraction pattern from a sample with multiple crystalline phases will be a superposition of all individual patterns. In the latter case, a database that collects diffraction data of various materials can be helpful in identifying the phase composition in an acquired XRD pattern.

In the practice of thin-film characterization, diffraction patterns of a sample can also be acquired using extra sample-motions with respect to other two rotation angles, $\Phi$ - and $\Psi$-angles, as shown in Fig. 5-1. These diffraction patterns can provide information such as texture and strain/stress of crystalline thin films and symmetry of crystals. See the XRD pole figures in Paper I and the $I(\Phi)$ plots with given $\Psi$-angles in Paper III for examples. 


\subsubsection{Transmission electron microscopy}

Transmission electron microscopy (TEM) utilizes interactions between incident electrons and sampling materials to form images. To some extent, this is analogous to the photon-material interaction used in optical microscopy. The main advantage of using electrons as imaging source is to obtain a higher resolution with the shorter wavelength, which is related to the kinetic energy of electrons and, therefore, to the accelerating voltage of the source.

For example, an electron source with $200 \mathrm{kV}$ acceleration voltage, which is generally used in TEM, can yield electrons with wavelength less than $3 \mathrm{pm}$, which is about 5 order less than the lower limit (say, $300 \mathrm{~nm}$ ) of visible light. The very high energy electron source used in TEM allows acquiring micro- and nanometer scale images, electron diffraction patterns, as well as possible electron or photon emission spectra from the specimen, as shown in Fig. 5-2, which is not feasible in normal optical microscopy. However, such high voltage electron source also makes the technique more costly (in terms of money and time) and more restrictive compared to many other analytical methods.

When electrons in TEM are transmitted through a very thin specimen (normally less than 200 $\mathrm{nm}$ depending on the experiment), they create contrasts in intensity due to variation of properties in a region of interest (ROI), such as crystal structure, specimen thickness, and

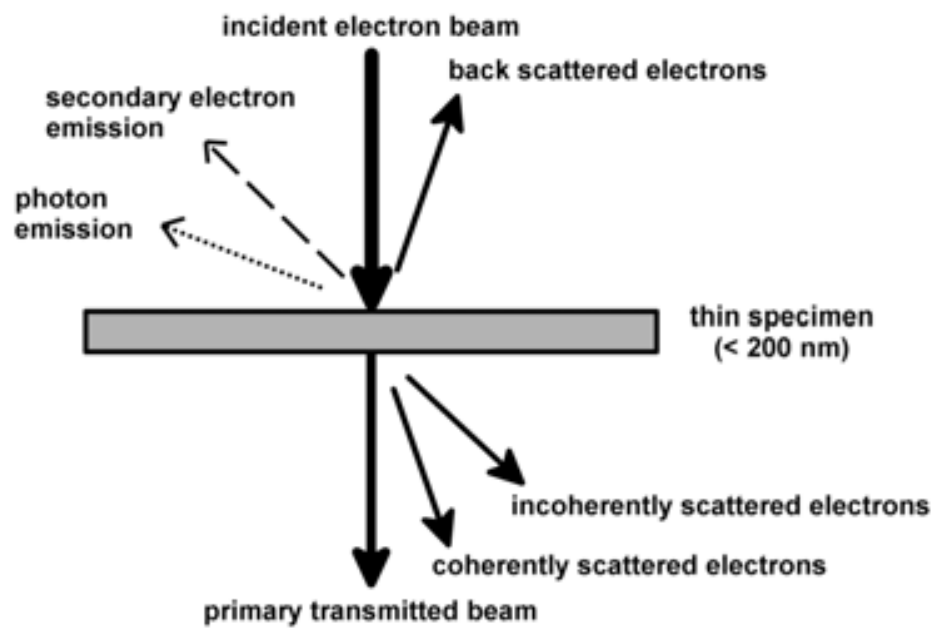

Figure 5-2. Possible electron beam interactions from an irradiated specimen. 
chemical composition, which diffract, absorb and scatter electrons differently. Since all contrast mechanisms can overlap in the same ROI, one challenge in analyzing TEM images is to identify the origin of the contrast in order to obtain useful information.

Electron diffraction patterns in TEM, formed by elastically scattered electrons, can be obtained at the back focal plane of the object lens. It is common to use an extra aperture to select a ROI to take the diffraction pattern, and therefore this technique is also referred to as selected area electron diffraction (SAED). The SAED patterns contain structural information of the specimen in two dimensions that helps in interpretation of crystal symmetry.

High resolution TEM (HR-TEM) is a TEM operation in where lattice-resolved, or even atomicscale, images can be obtained. The HR-TEM images form mainly by phase contrast, in which the incident electrons are coherent and the specimen thickness is small and uniform. Hence, ideally, the only contrast observed is due to the phase shift introduced when incident electrons are transmitted through different atomic potentials of the specimen. However, since it is not easy to guarantee all ideal set-ups, addressing one-to-one atomic position is still very difficult in HR-TEM. In Paper III, a HR-TEM image is shown to compare with the periodic interplanar spacing observed in the XRD pattern of the same thin film sample, which is then assigned to $\mathrm{Zr}_{2} \mathrm{Al}_{3} \mathrm{C}_{4}$ phase.

Another specialized technique is scanning transmission electron microscopy (STEM), in which the incoherently scattered electrons at high scattering-angle (the angle between incident path and scattering path) are collected by an annular detector and the direct transmitted beam is left out. Due to low intensity of the incoherently scattered electrons, STEM is operated with a convergent beam source, which scans through the ROI, to increase the current density of the incoming beam. The contrasts in STEM imaging is mainly affected by differences in atomic number of the irradiated atoms and in thickness of the specimen. In an optimal condition, images with atomic resolution can be acquired, as shown in Paper I, II, and IV-VII for the atomic layers in nanolaminated phases.

\subsection{Chemical composition analysis}

\subsubsection{Energy dispersive X-ray spectroscopy}

Energy dispersive X-ray spectroscopy (EDS or EDX) is an analytical technique mainly used for obtaining the chemical composition of a sample. It requires an energetic electron beam to excite inner-shell electrons of the atoms in a sampling volume to higher unoccupied states. 
When electrons from outer shells of these atoms relax to the unoccupied states in the inner shells, X-ray photons can be emitted from these transitions.

Such photons possess a certain amount of energy released from their respective transitions, whose transition energy is determined by the electron configuration of each element, i.e. it is characteristic for elements. Hence, by acquiring an energy spectrum of these photons, qualitative information about the chemical composition can be obtained. If the characteristic Xray emission cross-section is taken into account, quantitative analysis can further be done. However due to smaller emission cross-sections for light elements, say the elements with an atomic number less than 10, EDX analysis is normally not suitable for quantifying these elements, especially for some EDX detectors equipped with Be-windows.

An EDX detector is often integrated into an electron microscope, including scanning electron microscope (SEM) and TEM, where high energy electron beams $(>5 \mathrm{keV}$ in SEM and $>100$ $\mathrm{keV}$ in TEM) are utilized as the excitation sources. This provides a major benefit on acquiring micrographs and chemical information, possibly at the same ROI, in one operating session. Moreover, with an electron beam source that is capable of sweeping the ROI, e.g. SEM and STEM, a distribution map of chemical composition can be acquired. See Paper I and II for examples, where Mo (in red) and Ga (in green) distributions are shown in the images.

\subsubsection{Time-of-flight elastic recoil detection analysis}

Elastic recoil detection analysis (ERDA) is an ion beam analysis technique, where a sample is irradiated by a mono-energy ion beam to extract information such as chemical composition and elemental depth profile. The incident (primary) ions are commonly ${ }^{35} \mathrm{Cl},{ }^{79} \mathrm{Br},{ }^{127} \mathrm{I},{ }^{63} \mathrm{Cu}$ and ${ }^{197} \mathrm{Au}$ with an incident energy from few tens up to few hundreds of $\mathrm{MeV}$. ERDA is capable of detecting and quantifying all elements lighter than incident ion species, and is also possible to detect heavier elements with special detectors.

The basic principle for ERDA can be explained by the classical kinematics of two-body elastic collision, see Fig. 5-3, where the kinetic energy of the recoiled species, $E_{\mathrm{r}}$, after the collision can be described by

$$
E_{\mathrm{r}}=\left(\frac{4 M_{\mathrm{i}} M_{\mathrm{r}} \cdot \cos ^{2} \beta}{\left(M_{\mathrm{i}}+M_{\mathrm{r}}\right)^{2}}\right) E_{\mathrm{i} 0},
$$

where $M_{\mathrm{i}}$ and $M_{\mathrm{r}}$ are the masses of the incident ion and the recoiled species, respectively; $E_{\mathrm{i} 0}$ is the initial kinetic energy of the incident ion, and $\beta$ is the recoil angle. Given known values for 


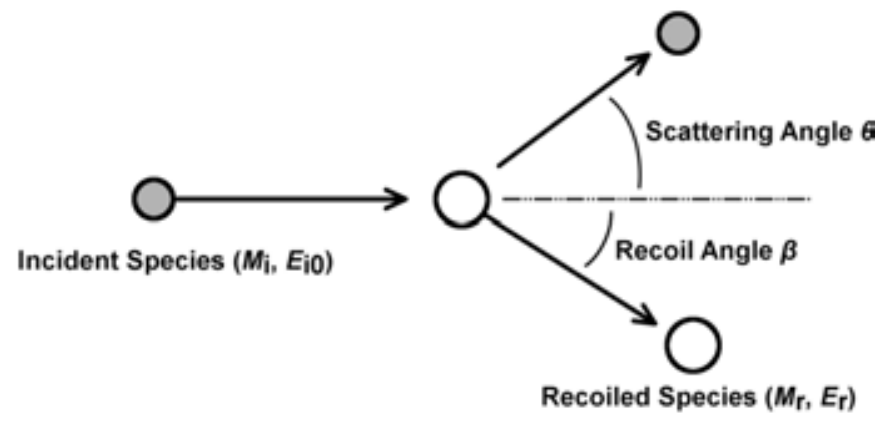

Figure 5-3. Schematic illustration of a classical two-body elastic collision.

$E_{\mathrm{i} 0}$ and $M_{\mathrm{i}}$ as well as a fixed detection angle $\beta$ to collect recoiled species, $M_{\mathrm{r}}$ can be calculated from Equation (2) with detected $E_{\mathrm{r}}$.

Time-of-flight ERDA (ToF-ERDA) is a setup with two ToF gates before the energy detector in order to measure the velocity of the recoiled species. This technique is developed to improve the energy resolution for the analysis, since the recoiled energy, $E_{\mathrm{r}}$, can also be determined by several factors other than just Equation (2), such as the roughness of the sample surface, the depth of the recoiled species into the sample and possible multiple scattering (collision) in the sample. However, due to the ToF gates introduced between the sample and the energy detector, the ToF-ERDA usually trades off its detection efficiency for lighter elements.

\subsubsection{X-ray photoelectron spectroscopy}

X-ray photoelectron spectroscopy (XPS) is an analytical technique which obtains information about the chemical composition and the chemical bonding condition of atoms in a sample by studying the binding energy of their shell electrons. In XPS, the sample is irradiated by X-ray photons, which can excite the shell electrons from the atoms into vacuum state with a certain amount of kinetic energy. Hence, the photon energy, $E_{\mathrm{ph}}$, can be related to the excited electrons' previous binding energy $\left(E_{\mathrm{B}}\right)$ and detected kinetic energy $\left(E_{\mathrm{K}}\right)$ by following equation,

$$
E_{\mathrm{ph}}=E_{\mathrm{B}}+E_{\mathrm{K}}+\phi_{\mathrm{W}}
$$

Where $\phi_{\mathrm{W}}$ is the work function of the detecting material. Given known values of $E_{\mathrm{ph}}$ and $\phi_{\mathrm{W}}$, $E_{\mathrm{B}}$ of the electrons can therefore be extracted for the reading of $E_{\mathrm{K}}$. Commonly, the XPS readout from the detector is plotted into a spectrum with electron intensity against $E_{\mathrm{B}}$. The intensity 
increases in the spectrum when the corresponding energy position represents a certain shell electron's binding energy. Since the binding energy depends on the electron configuration, which is element-specific, the chemical composition of a sample can qualitatively be interpreted from the peak position of the detected spectrum.

The binding energy of shell electrons can change according to the chemical environment of an atom, i.e. the element or the group bonded to an atom, and therefore a chemical shift can be observed on the respective peak(s). Studying the chemical shift can give additional information about the bonding condition between the elements consisted in a sample, but it is also possible that different elements are bonded without introducing chemical shift. It is usually challenging work to properly calibrate a XPS spectrum and resolve differently shifted components (peaks) from electrons of the same shell in order to draw correct conclusions.

The quantification of the chemical composition or between chemically shifted components can also be obtained from the acquired spectrum by comparing areas under the peaks and applying a proper relative sensitivity factor (RSF) for each element. Briefly speaking, the former represents the population of electrons with certain binding energy, while the RSF is to compensate the different electron emission cross-sections from various electron states of different elements. 


\section{Summary and Contributions to the Field}

My work investigates the materials science of nanolaminated TMCs, in particular the aspects of phase formation and crystal growth during the synthesis process in thin-film form. This was achieved by studying nanolaminated TMCs synthesized in selected material systems using the two different approaches of direct-deposition synthesis and post-deposition modification. In this chapter, the discoveries and the conclusions drawn from my work are summarized, followed by the contributions that I bring to the field through the work.

The studies using direct-deposition synthesis were carried out on two materials systems, MoGa-C and Zr-Al-C. Nanolaminated phases consisting of $\mathrm{Mo}_{2} \mathrm{C}$ building blocks, and their 2D derivatives, exhibit interesting physical and catalytic properties. In this work, both thin-film and bulk form of $\mathrm{Mo}_{2} \mathrm{Ga}_{2} \mathrm{C}$ were synthesized. This is a new Mo-based nanolaminated ternary carbide discovered in this material system, where the only previous such phase, $\mathrm{Mo}_{2} \mathrm{GaC}$, was reported in 1963 . The atomic structure and the phase stability of $\mathrm{Mo}_{2} \mathrm{Ga}_{2} \mathrm{C}$ were determined by a comprehensive study using theoretical calculations and experimental methods. $\mathrm{Mo}_{2} \mathrm{Ga}_{2} \mathrm{C}$ is structurally and chemically similar to $\mathrm{Mo}_{2} \mathrm{GaC}$, a so-called MAX phase, except that the $\mathrm{Ga}$ layers in $\mathrm{Mo}_{2} \mathrm{Ga}_{2} \mathrm{C}$ are not monolayers but double-layers in simple hexagonal stacking. The two phases can even transition into each other in the same crystal along the $c$-axis or on the basal plane without interrupting the adjacent $\mathrm{Mo}_{2} \mathrm{C}$-layers. The observation of $\mathrm{Ga}$-double layers in a nanolaminated phase is reported for the first time, while the structural similarity between $\mathrm{Mo}_{2} \mathrm{Ga}_{2} \mathrm{C}$ and MAX phases indicates another possible family of nanolaminated phase with double layers of the $A$ element. The discovery of $\mathrm{Mo}_{2} \mathrm{Ga}_{2} \mathrm{C}$ became even more important later on, because of the first report of $\mathrm{Mo}_{2} \mathrm{C}$ MXene production, which is also the first report on selective etching of a Ga-containing nanolaminated carbide.

Nanolaminated phases in Zr-Al-C system, on the other hand, have been suggested for a potential application as protective coatings on the claddings of nuclear fuel rods, but studies on these 
phases in thin-film form were not reported. Here, I have studied optimization of a nanolaminated carbide, $\mathrm{Zr}_{2} \mathrm{Al}_{3} \mathrm{C}_{4}$, in filtered cathodic arc deposition process. The phase composition and the crystal quality of $\mathrm{Zr}_{2} \mathrm{Al}_{3} \mathrm{C}_{4}$ thin films were studied to evaluate the effect of deposition parameters, including elemental flux ratio, substrate temperature, and selection of the substrate material. It was concluded that the formation of $\mathrm{Zr}_{2} \mathrm{Al}_{3} \mathrm{C}_{4}$ is favored with higher Al plasma flux concentration than the resulting film stoichiometry, but not as sensitive to the $\mathrm{Zr} / \mathrm{C}$ flux ratio. $\mathrm{Zr}_{2} \mathrm{Al}_{3} \mathrm{C}_{4}$ does not grow on substrates when the temperature is lower than 700 ${ }^{\circ} \mathrm{C}$, or when the lattice mismatch is too large. Phase-pure epitaxial $\mathrm{Zr}_{2} \mathrm{Al}_{3} \mathrm{C}_{4}$ thin film were deposited on $4 \mathrm{H}-\mathrm{SiC}(001)$ substrates at $800{ }^{\circ} \mathrm{C}$ or a $\mathrm{Al}_{2} \mathrm{O}_{3}(001)$ at $900{ }^{\circ} \mathrm{C}$, but the crystal quality was much higher on $\mathrm{SiC}$ substrates than $\mathrm{Al}_{2} \mathrm{O}_{3}$ substrate due to a smaller lattice mismatch.

The other part of the work, which used post-deposition modification of the material, focused on new Au-containing nanolaminated carbides synthesized by thermally-induced substitution/exchange reaction. As introduced in section 3.2, this reaction is a method to modify the properties of nanolaminated carbides. However, the reaction mechanism has not yet been elucidated, nor has its applicability on other phases. This requires further assessments on the reaction applied to other nanolaminated carbides than just $\mathrm{Ti}_{3} \mathrm{SiC}_{2}$ [53]. Here, the $\mathrm{Au}$ substitution/exchange reaction for $\mathrm{Al}$ in $\mathrm{Ti}_{2} \mathrm{AlC}$ and $\mathrm{Ti}_{3} \mathrm{AlC}_{2}$ and for $\mathrm{Ga}$ in $\mathrm{Mo}_{2} \mathrm{GaC}$ and $\mathrm{Mo}_{2} \mathrm{Ga}_{2} \mathrm{C}$ has been studied, resulting in the formation of $\mathrm{Ti}_{2} \mathrm{Au}_{2} \mathrm{C}, \mathrm{Ti}_{3} \mathrm{Au}_{2} \mathrm{C}_{2}, \mathrm{Mo}_{2} \mathrm{AuC}$, and $\mathrm{Mo}_{2}\left(\mathrm{Au}_{1-x} \mathrm{Ga}_{x}\right)_{2} \mathrm{C}$, respectively. Similar to $\mathrm{Si}$, all phases underwent $\mathrm{Au}$ selective replacement for the majority of their $A$ elements, while the carbide building blocks remained intact. However, both Al-containing phases transformed into double Au-layer phases after the Au exchange reaction, without single-Au-layer phases, e.g. $\mathrm{Ti}_{2} \mathrm{AuC}$ or $\mathrm{Ti}_{3} \mathrm{AuC}_{2}$, as observed in $\mathrm{Au}-\mathrm{Ti}_{3} \mathrm{SiC}_{2}$ reaction. Moreover, an in-plane order was observed in the double (Au,Ga)-layers in $\mathrm{Mo}_{2}\left(\mathrm{Au}_{1}\right.$ $\left.{ }_{x} \mathrm{Ga}_{x}\right)_{2} \mathrm{C}$ with nine $\mathrm{Au}$ atoms to one $\mathrm{Ga}$ atom along the basal plane direction, i.e., $x \sim 0.1$.

The results above showed that the Au substitution/exchange reaction can be applied to modify Al- and Ga-containing nanolaminated carbides, resulting in a new group of Au-containing nanolaminated phases. The mechanism for the reaction is explained by fast out-diffusion of the original $A$-element ( $\mathrm{Si}, \mathrm{Al}$, or $\mathrm{Ga}$ ) attracted by the Au matrix in the diffusion couple in order to balance the chemical potential, followed by an inward diffusion of Au back-filling into the vacancies in the $A$ layers. Since Au is chemically inert to the carbide blocks in our cases, it only enters the $A$ layers without disrupting the nanolaminated structure as in the $\mathrm{Ag}$ or $\mathrm{Cu}$ cases, where both $M$ and $A$ sites can be substituted [67,68]. 
Based on above results, I further investigated the post-deposition modification on the properties of Ga-containing MAX phases, $\left(\mathrm{Cr}_{0.5} \mathrm{Mn}_{0.5}\right)_{2} \mathrm{GaC}$ and $\mathrm{Mo}_{2} \mathrm{GaC}$. Due to the atomically defined layers, studies on magnetic MAX phases are motivated by the fundamental research on, e.g., interactions between magnetic layers and across non-magnetic layers, and quasi-2D magnetic materials. While the magnetic properties of MAX phases have been reported for $\left(M_{1-x} \mathrm{Mn}_{x}\right)_{2} A \mathrm{C}$ with $M=\mathrm{Cr}$, Mo, and $\mathrm{V}$, less is known about the effect of exchanging the $A$ element, due to the challenge in acquiring samples with very similar quality in the crystal structure and the $M$-layer composition. Therefore, I have applied the Au-substitution method on $\left(\mathrm{Cr}_{0.5} \mathrm{Mn}_{0.5}\right)_{2} \mathrm{GaC}$, a magnetic MAX phase, resulting in the formation of $\left(\mathrm{Cr}_{0.5} \mathrm{Mn}_{0.5}\right)_{2} \mathrm{AuC}$, where the retained structural and chemical properties of the $M$ layers allowed a more direct comparison on their magnetic properties. The magnetic measurement showed that the $\mathrm{Au}$ substitution for $\mathrm{Ga}$ reduced the Curie temperature of the Ga-containing phase from $\sim 220 \mathrm{~K}$ down to $\sim 100 \mathrm{~K}$, along with a reduced saturation magnetization, which were explained by a weaker exchange interaction across the Au monolayer. Beside changes in the properties, a single magnetic-phase behavior was measured, showing a complete Au substitution reaction throughout the thin film.

On the topic of magnetic MAX phases, I have also synthesized an Fe-containing MAX phase, $\mathrm{Mo}_{2} A \mathrm{C}$ with 50 at. $\%$ of $\mathrm{Fe}$ on the $A$ sites, through selective substitution of $\mathrm{Au}-\mathrm{Fe}$ alloy for the Ga layers in $\mathrm{Mo}_{2} \mathrm{GaC}$. This is the first report showing direct evidence on Fe in the MAX-phase structure, as well as indicating the feasibility of using Au-based alloying for modifying nanolaminated phases. I also showed that the substitution reaction of Fe did not take place in $\mathrm{Mo}_{2} \mathrm{GaC}$ in the same experimental setup but without participation of $\mathrm{Au}$, indicating the essential role of $\mathrm{Au}$ in catalyzing the Fe-substitution reaction. Through the last two studies, I showed that the properties of MAX phases can be tuned by the thermally-induced selective substitution method while retaining the nanolaminated structure.

The knowledge from this thesis work can be applied to depositions of thin films with desired nanolaminated TMCs, for controlling the phase composition, crystal quality, and properties, through direct-deposition and post-deposition approaches. In addition, the reports on the new nanolaminated phases may trigger further studies on the properties of their related 2D and quasi2D materials, e.g., the $\mathrm{Mo}_{2} \mathrm{C}$ MXenes from $\mathrm{Mo}_{2} \mathrm{Ga}_{2} \mathrm{C}$ and the $\mathrm{Fe}$ monatomic layers in $\mathrm{Mo}_{2} A \mathrm{C}$. 


\section{Bibliography}

[1] L. Toth, Transition Metal Carbides and Nitrides, Academic Press Inc., New York, USA, 1971.

[2] C. M. Fernandes and A. M. R. Senos, Cemented carbide phase diagrams: A review, Int. J. Refract. Met. H. 29 (2011) 405-418.

[3] D. Martínez-Martínez, C. López-Cartes, A. Fernández, and J. C. Sánchez-López, Influence of the microstructure on the mechanical and tribological behavior of TiC/a-C nanocomposite coatings, Thin Solid Films 517 (2009) 1662-1671.

[4] Å. Öberg, Å. Kassman, B. André, U. Wiklund, M. Lindquist, E. Lewin, U. Jansson, H. Högberg, T. Joelsson, and H. Ljungcrantz, Conductive nanocomposite ceramics as tribological and electrical contact materials, Eur. Phys. J. Appl. Phys. 49 (2010) 22902.

[5] W. S. Williams, Transition-Metal Carbides, Prog. Solid State Chem. 6 (1971) 57-118.

[6] F. Solymosi, A. Szöke, and J. Cserényi, Conversion of methane to benzene over $\mathrm{Mo}_{2} \mathrm{C}$ and $\mathrm{Mo}_{2} \mathrm{C} / \mathrm{ZSM}-5$ catalysts, Catal. Lett. 39 (1996) 157-161.

[7] W. F. Chen, J. T. Muckerman, and E. Fujita, Recent developments in transition metal carbides and nitrides as hydrogen evolution electrocatalysts, Chem. Commun. 49 (2013) 8896-8909.

[8] W.-F. Chen, C.-H. Wang, K. Sasaki, N. Marinkovic, W. Xu, J. T. Muckerman, Y. Zhu, and R. R. Adzic, Highly active and durable nanostructured molybdenum carbide electrocatalysts for hydrogen production, Energy Environ. Sci. 6 (2013) 943-951.

[9] Y. Xiao, J.-Y. Hwang, and Y.-K. Sun, Transition metal carbide-based materials: synthesis and applications in electrochemical energy storage, J. Mater. Chem. A 4 (2016) 10379-10393.

[10] Sir W. Ramsay, Moissan Memorial Lecture, J. Chem. Soc., Trans. 101 (1912) 477-488.

[11] G. V. Samsonov and V. A. Obolonchik, Frederic Henri Moissan, on the 120th Anniversary of His Birth, Sov. Powder Metall. Metal Ceram. 11 (1972) 766-768.

[12] Z. Yao, J. J. Stiglich, and T. S. Sudarshan, WC-Co enjoys proud history and bright future, Metal Pow. Rep. 53 (1998) 32-36.

[13] W. S. Williams, Physics of Transition Metal Carbides, Mater. Sci. Eng. A105/106 (1988) 1-10.

[14] J. C. Schuster and H. Nowotny, Investigations of the ternary systems (Zr, Hf, Nb, Ta)-Al-C and studies on complex carbides, Z. Metallkd. 71 (1980) 341-346.

[15] H. Nowotny, P. Rogl, and J. C. Schuster, Structural chemistry of complex carbides and related compounds, J. Solid State Chem. 44 (1982) 126-133.

[16] H. Holleck, Material selection for hard coatings, J. Vac. Sci. Technol. A 4 (1986) 2661-2669.

[17] T. M. Gesing, K. H. Wachtmann, and W. Jeitschko, The Perovskite Carbides $A_{3} \mathrm{MC}(A=\mathrm{Sc}, \mathrm{Y}, \mathrm{La}-\mathrm{Nd}$, Sm, Gd - Lu; $M=$ Al, Ga, In, Tl, Sn, Pb), Z. Naturforsch. 52 b (1997) 176-182.

[18] M. W. Barsoum, The $M_{N+1} A X_{N}$ Phases: A New Class of Solids; Thermodynamically Stable Nanolaminates, Prog. Solid St. Chem. 28 (2000) 201-281.

[19] M. W. Barsoum, MAX Phases: Properties of Machinable Carbides and Nitrides, Wiley VCH GmbH \& Co., Weinheim, 2013.

[20] M. Radovic and M. W. Barsoum, MAX phases: Bridging the gap between metals and ceramics, Am. Ceram. Soc. Bull. 92 (2013) 20-27.

[21] B. Anasori, M. R. Lukatskaya, and Y. Gogotsi, 2D metal carbides and nitrides (MXenes) for energy storage, Nat. Rev. Mater. 2 (2017) 16098. 
[22] M. Naguib, M. Kurtoglu, V. Presser, J. Lu, J. Niu, M. Heon, L. Hultman, Y. Gogotsi, and M. W. Barsoum, Two-dimensional nanocrystals produced by exfoliation of $\mathrm{Ti}_{3} \mathrm{AlC}_{2}$, Adv. Mater. 23 (2011) 4248-4253.

[23] M. Naguib, O. Mashtalir, J. Carle, V. Presser, J. Lu, L. Hultman, Y. Gogotsi, and M. W. Barsoum, Twodimensional transition metal carbides, ACS Nano 6 (2012) 1322-1331.

[24] R. Meshkian, L.-Å. Näslund, J. Halim, J. Lu, M. W. Barsoum, and J. Rosen, Synthesis of two-dimensional molybdenum carbide, $\mathrm{Mo}_{2} \mathrm{C}$, from the gallium based atomic laminate $\mathrm{Mo}_{2} \mathrm{Ga}_{2} \mathrm{C}$, Scripta Mater. 108 (2015) 147-150.

[25] J. Zhou, X. Zha, F. Y. Chen, Q. Ye, P. Eklund, S. Du, and Q. Huang, A Two-Dimensional Zirconium Carbide by Selective Etching of $\mathrm{Al}_{3} \mathrm{C}_{3}$ from Nanolaminated $\mathrm{Zr}_{3} \mathrm{Al}_{3} \mathrm{C}_{5}$, Angew. Chem. Int. Ed. 55 (2016) 5008-5013.

[26] J. Zhou, X. Zha, X. Zhou, F. Chen, G. Gao, S. Wang, C. Shen, T. Chen, C. Zhi, P. Eklund, S. Du, J. Xue, W. Shi, Z. Chai, and Q. Huang, Synthesis and electrochemical properties of two-dimensional hafnium carbide, ACS Nano (2017) doi: 10.1021/acsnano.7b00030.

[27] C. Xu, L. Wang, Z. Liu, L. Chen, J. Guo, N. Kang, X.-L. Ma, H.-M. Cheng, and W. Ren, Large-area highquality 2D ultrathin $\mathrm{Mo}_{2} \mathrm{C}$ superconducting crystals, Nat. Mater. (2015).

[28] V. M. H. Ng, H. Huang, K. Zhou, P. S. Lee, W. Que, J. Z. Xu, and L. B. Kong, Recent progress in layered transition metal carbides and/or nitrides (MXenes) and their composites: synthesis and applications, $J$. Mater. Chem. A 5 (2017) 3039-3068.

[29] P. Eklund, J. Rosen, and P. O. Å. Persson, Layered ternary $M_{n+1} A X_{n}$ phases and their 2D derivative MXene: an overview from a thin-film perspective, J. Phys. D: Appl. Phys. 50 (2017) 113001.

[30] M. Khazaei, M. Arai, T. Sasaki, M. Estili, and Y. Sakka, Two-dimensional molybdenum carbides: potential thermoelectric materials of the MXene family, Phys. Chem. Chem. Phys. 16 (2014) 7841-7849.

[31] M. Khazaei, A. Ranjbar, M. Arai, T. Sasaki, and S. Yunoki, Electronic properties and applications of MXenes: a theoretical review, J. Mater. Chem. C (2017) DOI: 10.1039/C7TC00140A.

[32] P. Eklund, M. Beckers, U. Jansson, H. Högberg, and L. Hultman, The $M_{n+1} A X_{n}$ phases: Materials science and thin-film processing, Thin Solid Films 518 (2010) 1851-1878.

[33] A. S. Ingason, A. Petruhins, and J. Rosen, Toward structural optimization of MAX phases as epitaxial thin films, Mater. Res. Lett. 4 (2016) 152-160.

[34] M. Magnuson, M. Mattesini, M. Bugnet, and P. Eklund, The origin of anisotropy and high density of states in the electronic structure of $\mathrm{Cr}_{2} \mathrm{GeC}$ by means of polarized soft x-ray spectroscopy and ab initio calculations, J. Phys. Cond. Matter 27 (2015) 415501.

[35] S. Salikhov, A. S. Semisalova, A. Petruhins, A. S. Ingason, J. Rosen, U. Wiedwald, and M. Farle, Magnetic anisotropy in the $\left(\mathrm{Cr}_{0.5} \mathrm{Mn}_{0.5}\right)_{2} \mathrm{GaC}$ MAX phase, Mater. Res. Lett. 3 (2015) 156-160.

[36] A. S. Ingason, M. Dahlqvist, and J. Rosen, Magnetic MAX phases from theory and experiments; a review, J. Phys. Condens. Matter 28 (2016) 433003.

[37] M. Dahlqvist, B. Alling, I. A. Abrikosov, and J. Rosen, Phase stability of $\mathrm{Ti}_{2} \mathrm{AlC}$ upon oxygen incorporation: a first-principles investigation, Phys. Rev. B 81 (2010) 024111.

[38] M. Dahlqvist, B. Alling, and J. Rosen, Stability trends of MAX phases from first principles, Phys. Rev. B 81 (2010) 220102.

[39] P. Eklund, M. Dahlqvist, O. Tengstrand, L. Hultman, J. Lu, N. Nedfors, U. Jansson, and J. Rosen, Discovery of the ternary nanolaminated compound $\mathrm{Nb}_{2} \mathrm{GeC}$ by a systematic theoretical-experimental approach, Phys. Rev. Lett. 109 (2012) 035502.

[40] A. Mockute, M. Dahlqvist, J. Emmerlich, L. Hultman, J. M. Schneider, P. O. Å. Persson, and J. Rosen, Synthesis and ab initio calculations of nanolaminated (Cr,Mn) ${ }_{2} \mathrm{AlC}$ compounds, Phys. Rev. B 87 (2013) 094113.

[41] A. Mockute, P. O. Å. Persson, F. Magnus, A. S. Ingason, S. Olafsson, L. Hultman, and J. Rosen, Synthesis and characterization of arc deposited magnetic (Cr,Mn) $)_{2}$ AlC MAX phase films, Phys. Status Solidi RRL 8 (2014) 420 . 
[42] J. Emmerlich, D. Music, P. Eklund, O. Wilhelmsson, U. Jansson, J. M. Schneider, H. Högberg, and L. Hultman, Thermal stability of $\mathrm{Ti}_{3} \mathrm{SiC}_{2}$ thin films, Acta Mater. 55 (2007) 1479-1488.

[43] J. Frodelius, J. Lu, J. Jensen, D. Paul, L. Hultman, and P. Eklund, Phase stability and initial low-temperature oxidation mechanism of $\mathrm{Ti}_{2} \mathrm{AlC}$ thin films, J. Euro. Ceram. Soc. 33 (2013) 375-382.

[44] A. Abdulkadhim, M. to Baben, T. Takahashi, V. Schnabel, M. Hans, C. Polzer, P. Polcik, and J. M. Schneider, Crystallization kinetics of amorphous $\mathrm{Cr}_{2} \mathrm{AlC}$ thin films, Surf. Coat. Technol. 206 (2011) 599603.

[45] A. Abdulkadhim, M. to Baben, V. Schnabel, M. Hans, N. Thieme, C. Polzer, P. Polcik, and J. M. Schneider, Crystallization kinetics of $\mathrm{V}_{2} \mathrm{AlC}$, Thin Solid Films 520 (2012) 1930-1933.

[46] V. Vishnyakov, O. Crisan, P. Dobrosz, and J. S. Colligon, Ion sputter-deposition and in-air crystallisation of $\mathrm{Cr}_{2} \mathrm{AlC}$ films, Vacuum 100 (2014) 61-65.

[47] C. Höglund, M. Beckers, N. Schell, J. v. Borany, J. Birch, and L. Hultman, Topotaxial growth of Ti ${ }_{2} \mathrm{AlN}$ by solid state reaction in AlN/Ti(0001) multilayer thin films, Appl. Phys. Lett. 90 (2007) 174106.

[48] V. Dolique, M. Jaouen, T. Cabioc'h, F. Pailloux, Ph. Guérin, and V. Pélosin, Formation of (Ti,Al)N/Ti 2 AlN multilayers after annealing of TiN/TiAl(N) multilayers deposited by ion beam sputtering, J. Appl. Phys. 103 (2008) 083527.

[49] A. Abdulkadhim, T. Takahashi, D. Music, F. Munnik, and J. M. Schneider, MAX phase formation by intercalation upon annealing of $\mathrm{TiC}_{x} / \mathrm{Al}(0.4<x<1)$ bilayer thin films, Acta Mater. 59 (2011) 6168-6175.

[50] R. Grieseler, B. Hähnlein, M. Stubenrauch, T. Kups, M. Wilke, M. Hopfeld, J. Pezoldt, and P. Schaaf, Nanostructured plasma etched, magnetron sputtered nanolaminar $\mathrm{Cr}_{2} \mathrm{AlC} \mathrm{MAX}$ phase thin films, Appl. Surf. Sci. 292 (2014) 997-1001.

[51] T. Cabioc'h, M. Alkazaz, M.-F. Beaufort, J. Nicolai, D. Eyidi, and P. Eklund, Ti 2 AlN thin films synthesized by annealing of (Ti+Al)/AlN multilayers, Mater. Res. Bull. 80 (2016) 58-63.

[52] C. Tang, M. Klimenkov, U. Jaentsch, H. Leiste, M. Rinke, S. Ulrich, M. Steinbrück, H. J. Seifert, and M. Stueber, Synthesis and characterization of $\mathrm{Ti}_{2} \mathrm{AlC}$ coatings by magnetron sputtering from three elemental targets and ex-situ annealing, Surf. Coat. Technol. 309 (2017) 445-455.

[53] H. Fashandi, M. Dahlqvist, J. Lu, J. Rosen, L. Hultman, M. Andersson, A. Lloyd Spetz, and P. Eklund, Synthesis of $\mathrm{Ti}_{3} \mathrm{AuC}_{2}, \mathrm{Ti}_{3} \mathrm{Au}_{2} \mathrm{C}_{2}$ and $\mathrm{Ti}_{3} \mathrm{IrC}_{2}$ by noble metal substitution reaction in $\mathrm{Ti}_{3} \mathrm{SiC}_{2}$ for hightemperature-stable Ohmic contacts to SiC, Nat. Mater. (2017) doi: 10.1038/nmat4896.

[54] L. E. Toth, High superconducting transition temperatures in the molybdenum carbide family of compounds, J. Less-Common Metals 13 (1967) 129-131.

[55] V. Sadagapan and H. C. Gatos, Superconductivity in the Transition Metal Carbides: $\mathrm{Mo}_{4.8} \mathrm{Si}_{3} \mathrm{C}_{0.6}$, $\mathrm{Mo}_{0.95} \mathrm{Hf}_{0.05} \mathrm{C}_{0.75}$ and $\mathrm{Mo}_{2} \mathrm{C}$, J. Phys. Chem. Solids 27 (1966) 235-238.

[56] W. O. Winer, Molybdenum disulfide as a lubricant: A review of the fundamental knowledge, Wear 10 (1967) 422-452.

[57] T. Spalvins, Morphological and frictional behavior of sputtered $\mathrm{MoS}_{2}$ films, Thin Solid Films 96 (1982) 17-24.

[58] T. He and J. Yao, Photochromism of molybdenum oxide, J. Photochem. Photobio. C: Photochem. Rev. 4 (2003) 125-143.

[59] G. Fu, X. Xu, X. Lu, and H. Wan, Mechanisms of methane activation and transformation on molybdenum oxide based catalysts, J. Am. Ceram. Soc. 127 (2005) 3989-3996.

[60] R. Meshkian, A. S. Ingason, M. Dahlqvist, A. Petruhins, U. B. Arnalds, F. Magnus, J. Lu, and J. Rosen, Theoretical stability, thin film synthesis and transport properties of the $\mathrm{Mo}_{n+1} \mathrm{GaC}_{n}$ MAX phase, Phys. Status Solidi RRL 9 (2015) 197-201.

[61] Y. C. Zhou, L. F. He, Z. J. Lin, and J. Y. Wang, Synthesis and structure-property relationships of a new family of layered carbides in $\mathrm{Zr}-\mathrm{Al}(\mathrm{Si})-\mathrm{C}$ and $\mathrm{Hf}-\mathrm{Al}(\mathrm{Si})-\mathrm{C}$ systems, J. Euro. Ceram. Soc. 33 (2013) 28312865 . 
[62] T. Lapauw, J. Halim, J. Lu, T. Cabioc'h, L. Hultman, M. W. Barsoum, K. Lambrinou, and J. Vleugels, Synthesis of the novel $\mathrm{Zr}_{3} \mathrm{AlC}_{2} \mathrm{MAX}$ phase, J. Euro. Ceram. Soc. 36 (2016) 943-947.

[63] T. Lapauw, K. Lambrinou, T. Cabioc'h, J. Halim, J. Lu, A. Pesach, O. Rivin, O. Ozeri, E. N. Caspi, L. Hultman, P. Eklund, J. Rosen, M. W. Barsoum, and J. Vleugels, Synthesis of the new MAX phase $\mathrm{Zr}_{2} \mathrm{AlC}_{\text {, }}$ J. Euro. Ceram. Soc. 36 (2016) 1847-1853.

[64] V. F. Sears, Neutron scattering lengths and cross sections, Neutron News 3 (1992) 26-37.

[65] K. Fukuda, S. Mori, and S. Hashimoto, Crystal Structure of $\mathrm{Zr}_{2} \mathrm{Al}_{3} \mathrm{C}_{4}$, J. Am. Ceram. Soc. 88 (2005) 35283530 .

[66] L. F. He, Y. C. Zhou, Y. W. Bao, Z. J. Lin, and J. Y. Wang, Synthesis, Physical, and Mechanical Properties of Bulk $\mathrm{Zr}_{3} \mathrm{Al}_{3} \mathrm{C}_{5}$ Ceramic, J. Am. Ceram. Soc. 90 (2007) 1164-1170.

[67] M. Nechiche, V. Gauthier-Brunet, V. Mauchamp, A. Joulain, T. Cabioc'h, X. Milhet, P. Chartier, and S. Dubois, Synthesis and characterization of a new $\left(\mathrm{Ti}_{1-\varepsilon}, \mathrm{Cu}_{\varepsilon}\right)_{3}(\mathrm{Al}, \mathrm{Cu}) \mathrm{C}_{2} \mathrm{MAX}$ phase solid solution, J. Euro. Ceram. Soc. 37 (2017) 459-466.

[68] C. Lu, G. Wang, G. Yang, G. Fan, J. Zhang, and X. Liu, Substitution behavior of Ag atoms in the $\mathrm{Ti}_{2} \mathrm{AlC}$ ceramic, J. Am. Ceram. Soc. 100 (2017) 732-738.

[69] M. W. Barsoum, T. El-Raghy, L. Farber, M. Amer, R. Christini, and A. Adams, The topotactic transformation of $\mathrm{Ti}_{3} \mathrm{SiC}_{2}$ into a partially ordered cubic $\mathrm{Ti}\left(\mathrm{C}_{0.67} \mathrm{Si}_{0.06}\right)$ phase by the diffusion of $\mathrm{Si}$ into molten cryolite, J. Electrochem. Soc. 146 (1999) 3919-3923.

[70] T. El-Raghy, M. W. Barsoum, and M. Sika, Reaction of $\mathrm{Al}$ with $\mathrm{Ti}_{3} \mathrm{SiC}_{2}$ in the $800-1000^{\circ} \mathrm{C}$ temperature range, Mater. Sci. Eng. A298 (2001) 174-178.

[71] W. L. Gu, C. K. Yan, and Y. C. Zhou, Reactions between $\mathrm{Al}$ and $\mathrm{Ti}_{3} \mathrm{SiC}_{2}$ in temperature range of 600 $650^{\circ} \mathrm{C}$, Scripta Mater. 49 (2003) 1075-1080.

[72] H. Guo, J. Zhang, F. Li, Y. Liu, J. Yin, and Y. Zhou, Surface strengthening of $\mathrm{Ti}_{3} \mathrm{SiC}_{2}$ through magnetron sputtering $\mathrm{Cu}$ and subsequent annealing, J. Euro. Ceram. Soc. 28 (2008) 2099-2107.

[73] D. V. Dulina, I. S. Batraev, V. Yu. Ulianitsky, M. A. Korchagin, G. V. Golubkova, S. Yu. Abramov, and O. I. Lomovsky, Control of interfacial interaction during detonation spraying of $\mathrm{Ti}_{3} \mathrm{SiC}_{2}-\mathrm{Cu}$ composites, Inorg. Mater. 50 (2014) 35-39.

[74] X.-Q. Chen, C. L. Fu, and C. Franchini, Polymeric forms of carbon in dense lithium carbide, J. Phys. Condens. Matter 22 (2010) 292201.

[75] T. Ya. Kosolapova, Carbides: Properties, Production, and Applications, Plenum Press, New York, USA, 1971.

[76] R. C. Vickery, R. Sedlacek, and A. Ruben, 103. Rare-earth carbides. Part I, J. Chem. Soc. (1959) 498-503.

[77] C. E. Holley Jr., Thermodynamic properties of actinide carbides, J. Nucl. Mater. 51 (1974) 36-46.

[78] H. O. Pierson, The Refractory Carbides in: Handbook of Refractory Carbides \& Nitrides: Properties, Characteristic, Processing and Applications, Noyes Publications, New Jersey, USA, 1996, pp. 8-16.

[79] U. Jansson and E. Lewin, Sputter deposition of transition-metal carbide films - A critical review from a chemical perspective, Thin Solid Films 536 (2013) 1-24.

[80] S. V. Meschel and O. J. Kleppa, Standard enthalpies of formation of some $3 d$ transition metal carbides by high temperature reaction calorimetry, J. Alloy. Compd. 257 (1997) 227-233.

[81] D. H. Jack and K. H. Jack, Invited Review: Carbides and Nitrides in Steel, Mater. Sci. Eng. 11 (1973) 1 27.

[82] J. Häglund, G. Grimvall, T. Jarlborg, and A. Fernández Guillermet, Band structure and cohesive properties of $3 d$-transition-metal carbides and nitrides with NaCl-type structure, Phys. Rev. B 43 (1991) 14400-14408

[83] J. Häglund, A. Fernández Guillermet, G. Grimvall, and M. Körling, Theory of bonding in transition-metal carbides and nitrides, Phys. Rev. B 48 (1993) 11685-11691.

[84] A. Fernández Guillermet and G. Grimvall, Cohesive properties and vibrational entropy of $3 d$-transition metal carbides, J. Phys. Chem. Solids 53 (1992) 105-125. 
[85] V. N. Lipatnikov, A. I. Gusev, P. Ettmayer, and W. Lengauer, Phase transformations in non-stoichiometric vanadium carbide, J. Phys.: Condens. Matter 11 (1999) 163-184.

[86] A. I. Gusev and A. A. Rempel, Order-disorder phase transition channel in niobium carbide, Phys. Stat. Sol. 93 (1986) 71-80.

[87] A. I. Gusev, A. A. Rempel, and V. N. Lipatnikov, Incommensurate ordered phase in non-stoichiometric tantalum carbide, J. Phys.: Condens. Matter 8 (1996) 8277-8293.

[88] H. W. Hugosson, O. Eriksson, L. Nordström, U. Jansson, L. Fast, A. Delin, J. M. Wills, and B. Johansson, Theory of phase stabilities and bonding mechanisms in stoichiometric and substoichiometric molybdenum carbide, J. Appl. Phys. 86 (1999) 3758-3767.

[89] A. S. Kurlov and A. I. Gusev, Phase equilibria in the W - C system and tungsten carbides, Russ. Chem. Rev. 75 (2006) 617-636.

[90] H. W. Hugosson, U. Jansson, B. Johansson, and O. Eriksson, Phase stability diagrams of transition metal carbides, a theoretical study, Chem. Phys. Lett. 333 (2001) 444-450.

[91] A. Inoeu and T. Matsumoto, Formation of nonequilibrium $\mathrm{Cr}_{3} \mathrm{C}$ carbide in $\mathrm{Cr}-\mathrm{C}$ binary alloys quenched rapidly from the melt, Scripta Metall. 13 (1979) 711-715.

[92] A. Fernández Guillermet, Predictive approach to thermodynamic properties of the metastable $\mathrm{Cr}_{3} \mathrm{C}$ carbide, Int. J. Thermophys. 12 (1991) 919-936.

[93] M. A. Konyaeva and N. I. Medvedeva, Electronic structure, magnetic properties, and stability of the binary and ternary carbides $(\mathrm{Fe}, \mathrm{Cr})_{3} \mathrm{C}$ and $(\mathrm{Fe}, \mathrm{Cr})_{7} \mathrm{C}_{3}$, Phys. Solid Sate 51 (2009) 2084-2089.

[94] S. J. Wang, H. Y. Tsai, and S. C. Sun, Characterization of Sputtered Titanium Carbide Film as Diffusion Barrier for Copper Metallization, J. Electrochem. Soc. 148 (2001) C563-C568.

[95] T. Laurila, K. Zeng, J. K. Kivilahti, J. Molarius, T. Riekkinen, and I. Suni, Tantalum carbide and nitride diffusion barriers for Cu metallisation, Microelectron. Eng. 60 (2002) 71-80.

[96] C. R. Wang, J.-M. Yang, and W. Hoffman, Thermal stability of refractory carbide/boride composites, Mater. Chem. Phys. 74 (2002) 272-281.

[97] P. Barnier and F. Thévenot, Synthesis and Hot-pressing of Single-phase $\mathrm{ZrC}_{x} \mathrm{O}_{y}$ and Two-phase $\mathrm{ZrC}_{x} \mathrm{O}_{y}$ $\mathrm{ZrO}_{2}$ Materials, Int. J. High Techno. Ceram. 2 (1986) 291-307.

[98] M. M. Opeka, I. G. Talmy, E. J. Wuchina, J. A. Zaykoski, and S. J. Causey, Mechanical, Thermal, and Oxidation Properties of Refractory Hafnium and Zirconium Compounds, J. Eur. Ceram. Soc. 19 (1999) 2405-2414.

[99] S. Zhang, Titanium carbonitride-based cermets: processes and properties, Mater. Sci. Eng. A163 (1993) 141-148.

[100] W. Lengauer, S. Binder, K. Aigner, P. Ettmayer, A. Guillou, J. Debuigne, and G. Groboth, Solid state properties of group IVb carbonitrides, J. Alloy Compd. 217 (1995) 137-147.

[101] A. L. Ivanovskii and G. P. Shveikin, The influence of inculcational and substitutional impurities on the electronic properties of transition metal refractory carbides and nitrides and their solid solutions, Phys. State Solidi 181 (1994) 251-289.

[102] T. F. Fedorov and E. I. Gladyshevskii, Phase equilibria in ternary systems of transition metals of groups IV and V and carbon, Sov. Powder Metall.+ 4 (1965) 27-29.

[103] T. Ya. Velikanova and V. N. Eremenko, Relationships governing phase equilibria in refractory carbidebearing systems of transition metals, Sov. Powder Metall. 27 (1988) 145-149.

[104] P. Duwez and F. Odell, Phase relationships in the binary systems of nitrides and carbides of zirconium, columbium, titanium, and vanadium, J. Electrochem. Soc. 97 (1950) 299-304.

[105] G. S. Upadhyaya, Material science of cemented carbides - an overview, Mater. Design 22 (2001) 483-489.

[106] J. Poetschke, V. Richter, and R. Holke, Influence and effectivity of $\mathrm{VC}$ and $\mathrm{Cr}_{3} \mathrm{C}_{2}$ grain growth inhibitors on sintering of binderless tungsten carbide, Int. J. Refract. Met. H. 31 (2012) 218-223. 
[107] H. Holleck, The effect of carbon on the occurrence of $\mathrm{Cu}_{3} \mathrm{Au}$-type phases in actinide and lanthanideplatinum metal systems, J. Nucl. Mater. 42 (1972) 278-284.

[108] A. I. Gusev, Phase equilibria in $M-X-X^{\prime}$ and $M$-Al- $X$ ternary systems $\left(M=\right.$ transition metal; $X, X^{\prime}-\mathrm{B}, \mathrm{C}$, N, Si) and the crystal chemistry of ternary compounds, Russ. Chem. Rev. 65 (1996) 379-419.

[109] H. H. Stadelmaier and L. J. Huetter, Ternary carbides of the transition metals nickel, cobalt, iron, manganese with zinc and tin, Acta Metall. 7 (1959) 415-419.

[110] F. Grandjean and A. Gérard, Study by Mossbauer spectroscopy of the series of perovskite carbides $M_{3} M^{\prime} \mathrm{C}$ with $M=\mathrm{Fe}$ or Mn, and $M^{\prime}=\mathrm{Al}, \mathrm{Ga}, \mathrm{Ge}, \mathrm{Zn}, \mathrm{Sn}, J$. Phys. F: Metal Phys. 6 (1976) 451-467.

[111] A. Hårsta, S. Rundqvist, and J. O. Thomas, A neutron powder diffraction study of the $\kappa$ phase in the Fe-WC system, J. Solid State Chem. 49 (1983) 118-122.

[112] A. Hårsta and S. Rundqvist, The crystal chemistry of $\kappa$-phases, J. Solid State Chem. 70 (1987) 210-218.

[113] K. Kuo, The formation of $\eta$ carbides, Acta Metall. 1 (1953) 301-304.

[114] J. M. Newsam, A. J. Jacobson, L. E. McCandlish, and R. S. Polizzotti, The structures of the $\eta$-carbides $\mathrm{Ni}_{6} \mathrm{Mo}_{6} \mathrm{C}, \mathrm{Co}_{6} \mathrm{Mo}_{6} \mathrm{C}$, and $\mathrm{Co}_{6} \mathrm{Mo}_{6} \mathrm{C}_{2}$, J. Solid Sate Chem. 75 (1988) 296-304.

[115] L. Faber, I. Levin, M. W. Barsoum, T. El-Raghy, and T. Tzenov, High-resolution transmission electron microscopy of some $\mathrm{Ti}_{n+1} A X_{n}$ compounds $(n=1,2 ; A=\mathrm{Al}$ or $\mathrm{Si} ; X=\mathrm{C}$ or N), J. Appl. Phys. 86 (1999) 25402543.

[116] R. Yu, Q. Zhan, L. L. He, Y. C. Zhou, and H. Q. Ye, Polymorphism of $\mathrm{Ti}_{3} \mathrm{SiC}_{2}$, J. Mater. Res. 17 (2002) 948-950.

[117] P. Eklund, J.-P. Palmquist, J. Höwing, D. H. Trinh, T. El-Raghy, H. Högberg, and L. Hultman, Ta $\mathrm{AlC}_{3}$ : Phase determination, polymorphism and deformation, Acta. Mater. 55 (2007) 4723-4729.

[118] J.-Y. Wang and Y.-C. Zhou, Polymorphism of $\mathrm{Ti}_{3} \mathrm{SiC}_{2}$ ceramic: First-principles investigations, Phys. Rev. B 69 (2004) 144108.

[119] Y. L. Du, Z. M. Sun, H. Hashimoto, and W. B. Tian, First-principles study of polymorphism in $\mathrm{Ta}_{4} \mathrm{AlC}_{3}$, Solid State Commun. 145 (2008) 461-464.

[120] N. J. Lane, P. Eklund, J. Lu, C. B. Spencer, L. Hultman, and M. W. Barsoum, High-temperature stability of $\alpha-\mathrm{Ta}_{4} \mathrm{AlC}_{3}$, Mater. Res. Bull. 46 (2011) 1088-1091.

[121] M. Naguib, G. W. Bentzel, J. Shah, J. Halim, E. N. Caspi, J. Lu, L. Hultman, and M. W. Barsoum, New solid solution MAX Phases: $\left(\mathrm{Ti}_{0.5}, \mathrm{~V}_{0.5}\right)_{3} \mathrm{AlC}_{2},\left(\mathrm{Nb}_{0.5}, \mathrm{~V}_{0.5}\right)_{2} \mathrm{AlC},\left(\mathrm{Nb}_{0.5}, \mathrm{~V}_{0.5}\right)_{4} \mathrm{AlC}_{3}$ and $\left(\mathrm{Nb}_{0.8}, \mathrm{Zr}_{0.2}\right)_{2} \mathrm{AlC}$, Mater. Res. Lett. 2 (2014) 233-240.

[122] H. Yang, B. Manoun, R. T. Downs, A. Ganguly, and M. W. Barsoum, Crystal chemistry of layered carbide, $\mathrm{Ti}_{3}\left(\mathrm{Si}_{0.43} \mathrm{Ge}_{0.57}\right) \mathrm{C}_{2}$, J. Phys. Chem. Solid. 67 (2006) 2512-2516.

[123] B. Manoun, S. K. Saxena, G. Hug, A. Ganguly, E. N. Hoffman, and M. W. Barsoum, Synthesis and compressibility of $\mathrm{Ti}_{3}\left(\mathrm{Al}_{1}, \mathrm{Sn}_{0.2}\right) \mathrm{C}_{2}$ and $\mathrm{Ti}_{3} \mathrm{Al}\left(\mathrm{C}_{0.5}, \mathrm{~N}_{0.5}\right)_{2}$, J. Appl. Phys. 101 (2007) 113523.

[124] J. Etzkorn, M. Ade, D. Kotzott, M. Kleczek, and H. Hillebrecht, $\mathrm{Ti}_{2} \mathrm{GaC}, \mathrm{Ti}_{4} \mathrm{GaC}_{3}$ and $\mathrm{Cr}_{2} \mathrm{GaC}-\mathrm{Synthesis}$, crystal growth and structure analysis of Ga-containing MAX-phases $M_{n+1} \mathrm{GaC}_{n}$ with $M=\mathrm{Ti}, \mathrm{Cr}$ and $n=1$, 3, J. Solid State Chem. 182 (2009) 995-1002.

[125] W. Yu, V. Gauthier-Brunet, T. Cabioc'h, and S. Dubois, Synthesis and microstructural characterization of substoichiometric $\mathrm{Ti}_{2} \mathrm{Al}\left(\mathrm{C}_{x} \mathrm{~N}_{y}\right)$ solid solutions and related $\mathrm{Ti}_{2} \mathrm{AlC}_{x}$ and $\mathrm{Ti}_{2} \mathrm{AlN}$ end-members, J. Am. Ceram. Soc. 97 (2014) 2308-2313.

[126] M. W. Barsoum, M. Ali, and T. El-Raghy, Processing and characterization of $\mathrm{Ti}_{2} \mathrm{AlC} \mathrm{Ti}_{2} \mathrm{AlN}$, and $\mathrm{Ti}_{2} \mathrm{AlC}_{0.5} \mathrm{~N}_{0.5}$, Metall. Mater. Trans. A 31A (2000) 1857-1865.

[127] F. L. Meng, Y. C. Zhou, and J. Y. Wang, Strengthening of $\mathrm{Ti}_{2} \mathrm{AlC}$ by substituting Ti with V, Scripta Mater. 53 (2005) 1369-1372.

[128] Y. C. Zhou, J. X. Chen, and J. Y. Wang, Strengthening of $\mathrm{Ti}_{3} \mathrm{AlC}_{2}$ by incorporation of $\mathrm{Si}$ to form $\mathrm{Ti}_{3} \mathrm{Al}_{1}$. ${ }_{x} \mathrm{Si}_{x} \mathrm{C}_{2}$ solid solutions, Acta Mater. 54 (2006) 1317-1322. 
[129] H. Guo, R. Benitez, W. Son, R. Arroyave, and M. Radovic, Structural, physical and mechanical properties of $\mathrm{Ti}_{3}\left(\mathrm{Al}_{1-x} \mathrm{Si}_{x}\right) \mathrm{C}_{2}$ solid solution with $x=0$-1, Mater. Sci. Eng. A 676 (2016) 197-208.

[130] A. S. Ingason, A. Mockute, M. Dahlqvist, F. Magnus, S. Olafsson, U. B. Arnalds, B. Alling, I. A. Abrikosov, B. Hjörvarsson, P. O. Å. Persson, and J. Rosen, Magnetic self-organized atomic laminate from first principles and thin film synthesis, Phys. Rev. Lett. 110 (2013) 195502.

[131] A. Mockute, J. Lu, E. J. Moon, M. Yan, B. Anasori, S. J. May, M. W. Barsoum, and J. Rosen, Solid solubility and magnetism upon $\mathrm{Mn}$ incorporation in the bulk ternary carbides $\mathrm{Cr}_{2} \mathrm{AlC}$ and $\mathrm{Cr}_{2} \mathrm{GaC}_{\text {, Mater }}$ Res. Lett. 3 (2015) 16-22.

[132] A. Petruhins, A. S. Ingason, J. Lu, F. Magnus, S. Olafsson, and J. Rosen, Synthesis and characterization of magnetic $\left(\mathrm{Cr}_{0.5} \mathrm{Mn}_{0.5}\right)_{2} \mathrm{GaC}$ thin films, J. Mater. Sci. 50 (2015) 4495-4502.

[133] R. Meshkian, A. S. Ingason, U. B. Arnalds, F. Magnus, J. Lu, and J. Rosen, A magnetic atomic laminate from thin film synthesis: (Mo0.5 $\left.\mathrm{Mn}_{0.5}\right)_{2} \mathrm{GaC}$, APL Mater. 3 (2015) 076102.

[134] R. Salikhov, A. S. Semisalova, A. Petruhins, A. S. Ingason, J. Rosen, U. Wiedwald, and M. Farle, Magnetic anisotropy in the $\left(\mathrm{Cr}_{0.5} \mathrm{Mn}_{0.5}\right)_{2} \mathrm{GaC}$ MAX phase, Mater. Res. Lett. 3 (2015) 156-160.

[135] Q. Tao, R. Salikhov, A. Mockute, J. Lu, M. Farle, U. Wiedwald, and J. Rosen, Thin film synthesis and characterization of a chemically ordered magnetic nanolaminate (V,Mn) ${ }_{3} \mathrm{GaC}_{2}$, APL Mater. 4 (2016) 086109.

[136] T. Cabioc'h, P. Eklund, V. Mauchamp, M. Jaouen, and M. W. Barsoum, Tailoring of the thermal expansion of $\mathrm{Cr}_{2}\left(\mathrm{Al}_{x}, \mathrm{Ge}_{1-x}\right)$ C phases, J. Euro. Ceram. Soc. 33 (2013) 897-904.

[137] H. Li, S. Li, H. Mao, and Y. Zhou, Synthesis and mechanical and thermal properties of (Cr,Mn) ${ }_{2} \mathrm{AlC}$ solid solutions, Adv. Appl. Ceram. 116 (2017) 165-172.

[138] J. Halim, P. Chartier, T. Basyuk, T. Prikhna, E. N. Caspi, M. W. Barsoum, and T. Cabioc'h, Structure and thermal expansion of $\left(\mathrm{Cr}_{x}, \mathrm{~V}_{1-x}\right)_{n+1} \mathrm{AlC}_{n}$ phases measured by X-ray diffraction, J. Euro. Ceram. Soc. 37 (2017) 15-21.

[139] L.-L. Zheng, L.-C. Sun, M.-S. Li, and Y.-C. Zhou, Improving the high-temperature oxidation resistance of $\mathrm{Ti}_{3}(\mathrm{SiAl}) \mathrm{C}_{2}$ by Nb-doping, J. Am. Ceram. Soc. 94 (2011) 3579-3586.

[140] H. B. Zhang, Y. C. Zhou, Y. W. Bao, and M. S. Li, Improving the oxidation resistance of $\mathrm{Ti}_{3} \mathrm{SiC}_{2}$ by forming a $\mathrm{Ti}_{3} \mathrm{Si}_{0.9} \mathrm{Al}_{0.1} \mathrm{C}_{2}$ solid solution, Acta Mater. 52 (2004) 3631-3637.

[141] I. Salama, T. El-Raghy, and M. W. Barsoum, Synthesis and mechanical properties of $\mathrm{Nb}_{2} \mathrm{AlC}_{\text {and }}$ (Ti,Nb) 2 AlC, J. Alloy Compd. 347 (2002) 271-278.

[142] A. Ganguly, T. Zhen, and M. W. Barsoum, Synthesis and mechanical properties of $\mathrm{Ti}_{3} \mathrm{GeC}_{2}$ and $\mathrm{Ti}_{3}\left(\mathrm{Si}_{x} \mathrm{Ge}_{1-}\right.$ ${ }_{x} \mathrm{C}_{2}(x=0.5,0.75)$ solid solutions, J. Alloy Compd. 376 (2004) 287-295.

[143] S. Dubois, G. P. Bei, C. Tromas, V. Gauthier-Brunet, and P. Gadaud, Synthesis, microstructure, and mechanical properties of $\mathrm{Ti}_{3} \mathrm{Sn}_{(1-x)} \mathrm{Al}_{x} \mathrm{C}_{2}$ MAX phase solid solutions, Int. J. Appl. Ceram. Technol. 7 (2010) 719-729.

[144] G. P. Bei, V. Gauthier-Brunet, C. Tromas, and S. Dubois, Synthesis, characterization, and intrinsic hardness of layered nanolaminate $\mathrm{Ti}_{3} \mathrm{AlC}_{2}$ and $\mathrm{Ti}_{3} \mathrm{Al}_{0.8} \mathrm{Sn}_{0.2} \mathrm{C}_{2}$ solid solution, J. Am. Ceram. Soc. 95 (2012) 102-107.

[145] M. W. Barsoum, I. Salama, T. El-Raghy, J. Golczewski, W. D. Porter, H. Wang, H. J. Seifert, and F. Aldinger, Thermal and electrical properties of $\mathrm{Nb}_{2} \mathrm{AlC},(\mathrm{Ti}, \mathrm{Nb})_{2} \mathrm{AlC}$ and $\mathrm{Ti}_{2} \mathrm{AlC}$, Metall. Mater. Trans. A 33A (2002) 2775-2779.

[146] M. W. Barsoum, J. Golczewski, H. J. Seifert, and F. Aldinger, Fabrication and electrical and thermal properties of $\mathrm{Ti}_{2} \mathrm{InC}, \mathrm{Hf}_{2} \mathrm{InC}$ and (Ti,Hf) ${ }_{2} \mathrm{InC}$, J. Alloy Compd. 340 (2002) 173-179.

[147] P. Finkel, B. Seaman, K. Harrell, J. Palma, J. D. Hettinger, S. E. Lofland, A. Ganguly, M. W. Barsoum, Z. Sun, S. Li, and R. Ahuja, Electronic, thermal, and elastic properties of $\mathrm{Ti}_{3} \mathrm{Si}_{1-x} \mathrm{Ge}_{x} \mathrm{C}_{2}$ solid solutions, Phys. Rev. B 70 (2004) 085104.

[148] W. Yu, V. Mauchamp, T. Cabioc'h, D. Magne, L. Gence, L. Piraux, V. Gauthier-Brunet, and S. Dubois, Solid solution effects in the $\operatorname{Ti}_{2} \mathrm{Al}\left(\mathrm{C}_{x} \mathrm{~N}_{y}\right)$ MAX phases: Synthesis, microstructure, electronic structure and transport properties, Acta Mater. 80 (2014) 421-434. 
[149] S. Kerdsongpanya, K. Buchholt, O. Tengstrand, J. Lu, J. Jensen, L. Hultman, and P. Eklund, Phasestabilization and substrate effects on nucleation and growth of $(\mathrm{Ti}, \mathrm{V})_{n+1} \mathrm{GeC}_{n}$ thin films, J. Appl. Phys. 110 (2011) 053516.

[150] L. Zheng, J. Wang, X. Lu, F. Li, J. Wang, and Y. Zhou, $\left(\mathrm{Ti}_{0.5} \mathrm{Nb}_{0.5}\right)_{5} \mathrm{AlC}_{4}$ : A new-layered compound belonging to MAX phases, J. Am. Ceram. Soc. 93 (2010) 3068-3071.

[151] D. Horlait, S. Grasso, A. Chroneos, and W. E. Lee, Attempts to synthesise quaternary MAX phases $(\mathrm{Zr}, M)_{2} \mathrm{AlC}$ and $\mathrm{Zr}_{2}(\mathrm{Al}, A) \mathrm{C}$ as a way to approach $\mathrm{Zr}_{2} \mathrm{AlC}$, Mater. Res. Lett. 4 (2016) 137-144.

[152] D. Horlait, S. C. Middleburgh, A. Chroneos, and W. E. Lee, Synthesis and DFT investigation of new bismuth-containing MAX phases, Sci. Report 6 (2016) 18829.

[153] N. J. Lane, S. C. Vogel, E. N. Caspi, and M. W. Barsoum, High-temperature neutron diffraction and firstprinciples study of temperature-dependent crystal structures and atomic vibrations in $\mathrm{Ti}_{3} \mathrm{AlC}_{2}, \mathrm{Ti}_{2} \mathrm{AlC}_{\mathrm{C}}$, and $\mathrm{Ti}_{5} \mathrm{Al}_{2} \mathrm{C}_{3}$, J. Appl. Phys. 113 (2013) 183519.

[154] J.-P. Palmquist, S. Li, P. O. Å. Persson, J. Emmerlich, O. Wilhelmsson, H. Högberg, M. I. Katsnelson, B. Johansson, R. Ahuja, O. Eriksson, L. Hultman, and U. Jansson, $M_{n+1} A X_{n}$ phases in the Ti-Si-C system studied by thin-film synthesis and ab initio calculations, Phys. Rev. B 70 (2004) 165401.

[155] H. Högberg, P. Eklund, J. Emmerlich, J. Birch, and L. Hultman, Epitaxial $\mathrm{Ti}_{2} \mathrm{GeC}_{2} \mathrm{Ti}_{3} \mathrm{GeC}_{2}$, and $\mathrm{Ti}_{4} \mathrm{GeC}_{3}$ MAX-phase thin films grown by magnetron sputtering, J. Mater. Res. 20 (2005) 779-782.

[156] T. H. Scabarozi, J. D. Hettinger, S. E. Lofland, J. Lu, L. Hultman, J. Jensen, and P. Eklund, Epitaxial growth and electrical-transport properties of $\mathrm{Ti}_{7} \mathrm{Si}_{2} \mathrm{C}_{5}$ thin films synthesized by reactive sputter-deposition, Scripta Mater. 65 (2011) 811-814.

[157] Y. Zhou, F. Meng, and J. Zhang, New MAX-phase compounds in the V-Cr-Al-C system, J. Am. Ceram. Soc. 91 (2008) 1357-1360.

[158] Z. Liu, L. Zheng, L. Sun, Y. Qian, J. Wang, and M. Li, $\left(\mathrm{Cr}_{2 / 3} \mathrm{Ti}_{1 / 3}\right)_{3} \mathrm{AlC}_{2}$ and $\left(\mathrm{Cr}_{5 / 8} \mathrm{Ti}_{3 / 8}\right)_{4} \mathrm{AlC}_{3}$ : New MAXphase Compounds in Ti-Cr-Al-C System, J. Am. Ceram. Soc. 97 (2014) 67-69.

[159] E. N. Caspi, P. Chartier, F. Porcher, F. Damay, and T. Cabioc'h, Ordering of (Cr,V) Layers in Nanolamellar $\left(\mathrm{Cr}_{0.5} \mathrm{~V}_{0.5}\right)_{n+1} \mathrm{AlC}_{n}$ Compounds, Mater. Res. Lett. 3 (2015) 100-106.

[160] B. Anasori, J. Halim, J. Lu, C. A. Voigt, L. Hultman, and M. W. Barsoum, Mo2 TiAlC2: A new ordered layered ternary carbide, Scripta Mater. 101 (2015) 5-7.

[161] R. Meshkian, Q. Tao, M. Dahlqvist, J. Lu, L. Hultman, and J. Rosen, Theoretical stability and materials synthesis of a chemically ordered $\mathrm{MAX}$ phase, $\mathrm{Mo}_{2} \mathrm{ScAlC}_{2}$, and its two-dimensional derivate $\mathrm{Mo}_{2} \mathrm{ScC}_{2}$ MXene, Acta Mater. 125 (2017) 476-480.

[162] B. Anasori, Y. Xie, M. Beidaghi, J. Lu, B. C. Hosler, L. Hultman, P. R. C. Kent, Y. Gogotsi, and M. W. Barsoum, Two-dimensional, ordered, double transition metal carbides (MXenes), ACS Nano 9 (2015) 9507-9516.

[163] B. Anasori, M. Dahlqvist, J. Halim, E. J. Moon, J. Lu, B. C. Hosler, E. N. Caspi, S. J. May, L. Hultman, P. Eklund, J. Rosen, and M. W. Barsoum, Experimental and theoretical characterization of ordered MAX phases $\mathrm{Mo}_{2} \mathrm{TiAlC}_{2}$ and $\mathrm{Mo}_{2} \mathrm{Ti}_{2} \mathrm{AlC}_{3}$, J. Appl. Phys. 118 (2015) 094304.

[164] C. Hu, C.-C. Lai, Q. Tao, J. Lu, J. Halim, L. Sun, J. Zhang, J. Yang, B. Anasori, J. Wang, Y. Sakka, L. Hultman, P. Eklund, J. Rosen, and M. W. Barsoum, $\mathrm{Mo}_{2} \mathrm{Ga}_{2} \mathrm{C}$ : A new ternary nanolaminated carbide, Chem. Commun. 51 (2015) 6560.

[165] C.-C. Lai, R. Meshkian, M. Dahlqvist, J. Lu, L.-Å. Näslund, O. Rivin, E. N. Caspi, O. Ozeri, L. Hultman, P. Eklund, M. W. Barsoum, and J. Rosen, Structural and chemical determination of the new nanolaminated carbide $\mathrm{Mo}_{2} \mathrm{Ga}_{2} \mathrm{C}$ from first principles and materials analysis, Acta Mater. 99 (2015) 157-164.

[166] R.Tonner and N. Gaston, The dimeric nature of bonding in gallium: from small clusters to the $\alpha$-gallium phase, Phys. Chem. Chem. Phys. 16 (2014) 24244-24249.

[167] K. Fukuda and M. Hisamura, Cr ystal structure and thermoelectric properties of $\mathrm{YAl}_{3} \mathrm{C}_{3}, \mathrm{~J}$. Am. Ceram. Soc. 90 (2007) 3299-3302. 
[168] K. Sugiura, T. Iwata, H. Yoshida, S. Hashimoto, and K. Fukuda, Syntheses, crystal structures and Si solubilities of new layered carbides $\mathrm{Zr}_{2} \mathrm{Al}_{4} \mathrm{C}_{5}$ and $\mathrm{Zr}_{3} \mathrm{Al}_{4} \mathrm{C}_{6}$, J. Solid State Chem. 181 (2008) 2864-2868.

[169] T. M. Gesing and W. Jeitschko, The crystal structures of $\mathrm{Zr}_{3} \mathrm{Al}_{3} \mathrm{C}_{5}, \mathrm{ScAl}_{3} \mathrm{C}_{3}$, and $\mathrm{UAl}_{3} \mathrm{C}_{3}$ and their relation to the structures of $\mathrm{U}_{2} \mathrm{Al}_{3} \mathrm{C}_{4}$ and $\mathrm{Al}_{4} \mathrm{C}_{3}$, J. Solid State Chem. 140 (1998) 396-401.

[170] T. M. Gesing, R. Pöttgen, W. Jeitschko, and U. Wortmann, Crystal structure and physical properties of the carbides $\mathrm{UAl}_{3} \mathrm{C}_{3}$ and $\mathrm{YbAl}_{3} \mathrm{C}_{3}$, J. Alloy. Compd. 186 (1992) 321-331.

[171] T. Iwata, E. Hattori, S. Hashimoto, and K. Fukuda, Synthesis and crystal structure of a new layered carbide $\mathrm{ZrAl}_{4} \mathrm{C}_{4}$, J. Am. Ceram. Soc. 91 (2008) 2713-2715.

[172] H. Nian, L. He, F. Li, J. Wang, and Y. Zhou, Crystal structure and theoretical elastic property of a new ternary ceramic $\mathrm{HfAl}_{4} \mathrm{C}_{4}$, J. Am. Ceram. Soc. 93 (2010) 1164-1168.

[173] T. Lapauw, B. Tunca, T. Cabioc'h, J. Lu, P. O. Å. Persson, K. Lambrinou, and J. Vleugels, Synthesis of MAX phases in the Hf-Al-C system, Inorg. Chem. 55 (2016) 10922-10927.

[174] J. Emmerlich, D. Music, M. Braun, P. Fayek, F. Munnik, and J. M. Schneider, A proposal for an unusually stiff and moderately ductile hard coating material: $\mathrm{Mo}_{2} \mathrm{BC}$, J. Phys. D: Appl. Phys. 42 (2009) 185406.

[175] P. Lejay, B. Chevalier, J. Etourneau, P. Hagenmuller, and P. Peshev, The boroncarbides $\mathrm{Mo}_{2-x} \mathrm{~W}_{x} \mathrm{BC}(0 \leq$ $x \leq 1.1$ ), a new family of refractory superconducting materials, Synthetic Met. 4 (1981) 139-145.

[176] J. Travaglini, M. W. Barsoum, V. Jovic, and T. El-Raghy, The corrosion behavior of $\mathrm{Ti}_{3} \mathrm{SiC}_{2}$ in common acids and dilute $\mathrm{NaOH}$, Corros. Sci. 45 (2003) 1313-1327.

[177] V. D. Jovic, B. M. Jovic, S. Gupta, T. El-Raghy, and M. W. Barsoum, Corrosion behavior of select MAX phases in $\mathrm{NaOH}, \mathrm{HCl}$ and $\mathrm{H}_{2} \mathrm{SO}_{4}$, Corros. Sci. 48 (2006) 4274-4282.

[178] V. D. Jovic, M. W. Barsoum, B. M. Jovic, A. Ganguly, and T. El-Raghy, Corrosion behavior of $\mathrm{Ti}_{3} \mathrm{GeC}_{2}$ and $\mathrm{Ti}_{2} \mathrm{AlN}$ in $1 \mathrm{M} \mathrm{NaOH}$, J. Electrochem. Soc. 153 (2006) B238-B243.

[179] V. D. Jovic, Corrosion of $\mathrm{Ti}_{3} \mathrm{SiC}_{2}$ and $\mathrm{Ti}_{4} \mathrm{AlN}_{3}$ in concentrated $\mathrm{HCl}$ solutions, Mater. Sci. Forum 453-454 (2004) 127-132.

[180] D. Li, Y. Liang, X. Liu, and Y. Zhou, Corrosion behavior of $\mathrm{Ti}_{3} \mathrm{AlC}_{2}$ in $\mathrm{NaOH}$ and $\mathrm{H}_{2} \mathrm{SO}_{4}$, J. Euro. Ceram. Soc. 30 (2010) 3227-3234.

[181] V. D. Jovic and M. W. Barsoum, Corrosion Behavior and passive film characteristics formed on Ti, $\mathrm{Ti}_{3} \mathrm{SiC}_{2}$, and $\mathrm{Ti}_{4} \mathrm{AlN}_{3}$ in $\mathrm{H}_{2} \mathrm{SO}_{4}$ and $\mathrm{HCl}$, J. Electrochem. Soc. 151 (2004) B71-B76.

[182] J. Xie, X. Wang, A. Li, F. Li, and Y. Zhou, Corrosion behavior of selected $M_{n+1} A X_{n}$ phases in hot concentrated HCl solution: Effect of A element and MX layer, Corros. Sci. 60 (2012) 129-135.

[183] M. Zhu, R. Wang, C. Chen, H. B. Zhang, and G. J. Zhang, Comparison of corrosion behavior of $\mathrm{Ti}_{3} \mathrm{SiC}_{2}$ and $\mathrm{Ti}_{3} \mathrm{AlC}_{2}$ in $\mathrm{NaCl}$ solutions with Ti, Ceram. Int. 43 (2017) 5708-5714.

[184] J. Halim, M. R. Lukatskaya, K. M. Cook, J. Lu, C. R. Smith, L.-Å. Näslund, S. J. May, L. Hultman, Y. Gogotsi, P. Eklund, and M. W. Barsoum, Transparent conductive two-dimensional titanium carbide epitaxial thin films, Chem. Mater. 26 (2014) 2374-2381.

[185] J. Halim, K. M. Cook, M. Naguib, P. Eklund, Y. Gogotsi, J. Rosen, and M. W. Barsoum, X-ray photoelectron spectroscopy of select multi-layered transitionmetal carbides (MXenes), Appl. Surf. Sci. 362 (2016) 406-417.

[186] O. Mashtalir, M. Naguib, V. N. Mochalin, Y. Dall'Agnese, M. Heon, M. W. Barsoum, and Y. Gogotsi, Intercalation and delamination of layered carbides and carbonitrides, Nat. Commun. 4 (2013) 1716.

[187] M. Ghidiu, M. R. Lukatskaya, M.-Q. Zhao, Y. Gogotsi, and M. W. Barsoum, Conductive two-dimensional titaniumcarbide 'clay' with high volumetric capacitance, Nature 516 (2014) 78-81.

[188] J. Halim, S. Kota, M. R. Lukatskaya, M. Naguib, M.-Q. Zhao, E. J. Moon, J. Pitock, J. Nanda, S. J. May, Y. Gogotsi, and M. W. Barsoum, Synthesis and characterization of 2D molybdenum carbide (MXene), Adv. Funct. Mater. 26 (2016) 3118-3127.

[189] M. Naguib, V. N. Mochalin, M. W. Barsoum, and Y. Gogotsi, 25th anniversary article: MXenes: A new family of two-dimensional materials, Adv. Mater. 26 (2014) 992-1005. 
[190] P. Urbankowski, B. Anasori, T. Makaryan, D. Er, S. Kota, P. L. Walsh, M. Zhao, V. B. Shenoy, M. W. Barsoum, and Y. Gogotsi, Synthesis of two-dimensional titanium nitride $\mathrm{Ti}_{4} \mathrm{~N}_{3}$ (MXene), Nanoscale 8 (2016) 11385-11391.

[191] I. R. Shein and A. L. Ivanovskii, Graphene-like titanium carbides and nitrides $\mathrm{Ti}_{n+1} \mathrm{C}_{n}, \mathrm{Ti}_{n+1} \mathrm{~N}_{n}(n=1,2$, and 3) from de-intercalated MAX phases: First-principles probing of their structural, electronic properties and relative stability, Comput. Mater. Sci. 65 (2012) 104-114.

[192] M. W. Barsoum and T. El-Raghy, Synthesis and characterization of a remarkable ceramic: $\mathrm{Ti}_{3} \mathrm{SiC}_{2}, J . A m$. Ceram. Soc. 79 (1996) 1953-56.

[193] M. W. Barsoum, T. El-Raghy, and L. U. J. T. Ogbuji, Oxidation of Ti ${ }_{3} \mathrm{SiC}_{2}$ in air, J. Electrochem. Soc. 144 (1997) 2508-2516.

[194] S. Gupta, A. Ganguly, D. Filimonov, and M. W. Barsoum, High-temperature oxidation of $\mathrm{Ti}_{3} \mathrm{GeC}_{2}$ and $\mathrm{Ti}_{3} \mathrm{Ge}_{0.5} \mathrm{Si}_{0.5} \mathrm{C}_{2}$ in air, J. Electrochem. Soc. 153 (2006) J61-J68.

[195] B. Anasori, E. N. Caspi, Y. Elraheb, and M. W. Barsoum, On the oxidation of $\mathrm{Ti}_{2} \mathrm{GeC}_{\text {in }}$ air, J. Alloy Compd. 580 (2013) 550-557.

[196] M. W. Barsoum, L. H. Ho-Duc, M. Radovic, and T. El-Raghy, Long time oxidation study of $\mathrm{Ti}_{3} \mathrm{SiC}_{2}$, $\mathrm{Ti}_{3} \mathrm{SiC}_{2} / \mathrm{SiC}$, and $\mathrm{Ti}_{3} \mathrm{SiC}_{2} / \mathrm{TiC}$ composites in air, J. Electrochem. Soc. 150 (2003) B166-B175.

[197] Z. Zhang, J. Chai, H. Jin, J. Pan, L. M. Wong, S. H. Lim, M. B. Sullivan, and S. J. Wang, Oxidation of single crystalline $\mathrm{Ti}_{2} \mathrm{AlN}$ thin films between 300 and $900{ }^{\circ} \mathrm{C}$ : A perspective from surface analysis, J. Phys. Chem. C 120 (2016) 18520-18528.

[198] I. Samala, T. El-Raghy, and M. W. Barsoum, Oxidation of $\mathrm{Nb}_{2} \mathrm{AlC}$ and (Ti,Nb) ${ }_{2} \mathrm{AlC}$ in Air, J. Electrochem. Soc. 150 (2003) C152-C158.

[199] S. Gupta, D. Filimonov, and M. W. Barsoum, Isothermal oxidation of Ta ${ }_{2} \mathrm{AlC}$ in air, J. Am. Ceram. Soc. 89 (2006) 2974-2976.

[200] S. Gupta, E. N. Hoffman, and M. W. Barsoum, Synthesis and oxidation of $\mathrm{Ti}_{2} \mathrm{InC}_{2} \mathrm{Zr}_{2} \mathrm{InC}_{2}\left(\mathrm{Ti}_{0.5}, \mathrm{Zr}_{0.5}\right)_{2} \mathrm{InC}$ and $\left(\mathrm{Ti}_{0.5}, \mathrm{Hf}_{0.5}\right)_{2} \mathrm{InC}$ in air, J. Alloy. Compd. 426 (2006) 168-175.

[201] S. Chakraborty, T. El-Raghy, and M. W. Barsoum, Oxidation of $\mathrm{Hf}_{2} \mathrm{SnC}$ and $\mathrm{Nb}_{2} \mathrm{SnC}$ in air in the $400{ }^{\circ} \mathrm{C}$ - $600{ }^{\circ} \mathrm{C}$ temperature range, Oxid. Met. 59 (2003) 83-96.

[202] S. Amini, A. R. McGhie, and M. W. Barsoum, Isothermal oxidation of $\mathrm{Ti}_{2} \mathrm{SC}$ in air, J. Electrochem. Soc. 156 (2009) P101-P106.

[203] X. H. Wang and Y. C. Zhou, Intermediate-temperature oxidation behavior of $\mathrm{Ti}_{2} \mathrm{AlC}$ in air, J. Mater. Res. 17 (2002) 2974-2981.

[204] X. H. Wang and Y. C. Zhou, High-temperature oxidation behavior of Ti ${ }_{2} \mathrm{AlC}$ in air, Oxid. Met. 59 (2003) 303-320.

[205] X. H. Wang, F. Z. Li, J. X. Chen, and Y. C. Zhou, Insights into high temperature oxidation of $\mathrm{Al}_{2} \mathrm{O}_{3}-$ forming $\mathrm{Ti}_{3} \mathrm{AlC}_{2}$, Corros. Sci. 58 (2012) 95-103.

[206] D. J. Tallman, B. Anasori, and M. W. Barsoum, A critical review of the oxidation of $\mathrm{Ti}_{2} \mathrm{AlC} \mathrm{Ti}_{3} \mathrm{AlC}$ and $\mathrm{Cr}_{2} \mathrm{AlC}$ in air, Mater. Res. Lett. 1 (2013) 115-125.

[207] G. M. Song, Y. T. Pei, W. G. Sloof, S. B. Li, J. Th. M. De Hosson, and S. van der Zwaag, Oxidationinduced crack healing in $\mathrm{Ti}_{3} \mathrm{AlC}_{2}$ ceramics, Scripta Mater. 58 (2008) 13-16.

[208] H. J. Yang, Y. T. Pei, J. C. Rao, J. Th. M. De Hosson, S. B. Li, and G. M. Song, High temperature healing of $\mathrm{Ti}_{2} \mathrm{AlC}$ : On the origin of inhomogeneous oxide scale, Scripta Mater. 65 (2011) 135-138.

[209] S. Li, G. Song, K. Kwakernaak, S. van der Zwaag, and W. G. Sloof, Multiple crack healing of a $\mathrm{Ti}_{2} \mathrm{AlC}$ ceramic, J. Euro. Ceram. Soc. 32 (2012) 1813-1820.

[210] H. J. Yang, Y. T. Pei, G. M. Song, and J. Th. M. De Hosson, Healing performance of Ti ${ }_{2} \mathrm{AlC}_{\text {ceramic }}$ studied with in situ microcantilever bending, J. Euro. Ceram. Soc. 33 (2013) 383-391. 
[211] W. G. Sloof, R. Pei, S. A. McDonald, J. L. Fife, L. Shen, L. Boatemaa, A.-S. Farle, K. Yan, X. Zhang, S. van der Zwaag, P. D. Lee, and P. J. Withers, Repeated crack healing in MAX-phase ceramics revealed by 4D in situ synchrotron X-ray tomographic microscopy, Sci. Report 6 (2016) 23040.

[212] S. Li, L. Xiao, G. Song, X. Wu, W. G. Sloof, and S. van der Zwaag, Oxidation and crack healing behavior of a fine-grained $\mathrm{Cr}_{2} \mathrm{AlC}$ ceramic, J. Am. Ceram. Soc. 96 (2013) 892-899.

[213] L. Shen, D. Eichner, S. van der Zwaag, C. Leyens, and W. G. Sloof, Reducing the erosive wear rate of $\mathrm{Cr}_{2} \mathrm{AlC}$ MAX phase ceramic by oxidative healing of local impact damage, Wear 358-359 (2016) 1-6.

[214] R. Pei, S. A. McDonald, L. Shen, S. van der Zwaag, W. G. Sloof, P. J. Withers, and P. M. Mummery, Crack healing behaviour of $\mathrm{Cr}_{2} \mathrm{AlC}$ MAX phase studied by X-ray tomography, J. Euro. Ceram. Soc. 37 (2017) 441-450.

[215] G. B. Pei, B. J. Pedimonte, T. Fey, and P. Greil, Oxidation behavior of MAX phase $\operatorname{Ti}_{2} \mathrm{Al}_{(1-x)} \operatorname{Sn}_{x} \mathrm{C}$ solid solution, J. Am. Ceram. Soc. 96 (2013) 1359-1362.

[216] S. Li, G. Bei, X. Chen, L. Zhang, Y. Zhou, M. Mackovic, E. Spiecker, and P. Greil, Crack healing induced electrical and mechanical properties recoveryin a $\mathrm{Ti}_{2} \mathrm{SnC}$ ceramic, J. Euro. Ceram. Soc. 36 (2015) 25-32.

[217] D. B. Lee, T. D. Nguyen, J. H. Han, and S. W. Park, Oxidation of $\mathrm{Cr}_{2} \mathrm{AlC}$ at $1300{ }^{\circ} \mathrm{C}$ in air, Corros. Sci. 49 (2007) 3926-3934.

[218] J. Wang, Y. Zhou, T. Liao, J. Zhang, and Z. Lin, A first-principles investigation of the phase stability of $\mathrm{Ti}_{2} \mathrm{AlC}$ with Al vacancies, Scripta Mater. 58 (2008) 227-230.

[219] J. Zhang, B. Liu, J. Y. Wang, and Y. C. Zhou, Low-temperature instability of Ti2 SnC: A combined transmission electron microscopy, differential scanning calorimetry, and $\mathrm{x}$-ray diffraction investigations, J. Mater. Res. 24 (2009) 39-49.

[220] A.-S. Farle, C. Kwakernaak, S. van der Zwaag, and W. G. Sloof, A conceptual study into the potential of $M_{n+1} A X_{n}$-phase ceramics forself-healing of crack damage, J. Euro. Ceram. Soc. 35 (2015) 37-45.

[221] A.-S. M. Farle, J. Stikkelman, S. van der Zwaag, and W. G. Sloof, Oxidation and self-healing behaviour of spark plasma sintered Ta 2 AlC, J. Euro. Ceram. Soc. 37 (2017) 1969-1974.

[222] Y. Zhou and W. Gu, Chemical reaction and stability of $\mathrm{Ti}_{3} \mathrm{SiC}_{2}$ in $\mathrm{Cu}$ during high-temperature processing of $\mathrm{Cu} / \mathrm{Ti}_{3} \mathrm{SiC}_{2}$ composites, Z. Metallkd. 95 (2004) 50-56.

[223] J. Wu, Y. Zhou, J. Wang, W. Wang, and C. Yan, Interfacial reaction between $\mathrm{Cu}$ and $\mathrm{Ti}_{2} \mathrm{SnC}$ during processing of $\mathrm{Cu}-\mathrm{Ti}_{2} \mathrm{SnC}$ composite, Z. Metallkd. 96 (2005) 1314-1320.

[224] J. Zhang and Y. C. Zhou, Microstructure, mechanical, and electrical properties of $\mathrm{Cu}-\mathrm{Ti}_{3} \mathrm{AlC}_{2}$ and in situ $\mathrm{Cu}-\mathrm{TiC}_{x}$ composites, J. Mater. Res. 23 (2008) 924-932.

[225] W. J. Wang, V. Gauthier-Brunet, G. P. Bei, G. Laplanche, J. Bonneville, A. Joulain, and S. Dubois, Powder metallurgy processing and compressive properties of $\mathrm{Ti}_{3} \mathrm{AlC}_{2} / \mathrm{Al}$ composites, Mater. Sci. Eng. A 530 (2011) 168-173.

[226] M. T. Agne, M. Radovic, G. W. Bentzel, and M. W. Barsoum, Stability of $\mathrm{V}_{2} \mathrm{AlC}$ with $\mathrm{Al}$ in $800-1000{ }^{\circ} \mathrm{C}$ temperature range and in situ synthesis of $\mathrm{V}_{2} \mathrm{AlC} / \mathrm{Al}$ composites, J. Alloy Compd. 666 (2016) 279-286.

[227] X. Shi, M. Wang, W. Zhai, Z. Xu, Q. Zhang, and Y. Chen, Influence of $\mathrm{Ti}_{3} \mathrm{SiC}_{2}$ content on tribological properties of NiAl matrix self-lubricating composites, Mater. Design 45 (2013) 179-189.

[228] X. Shi, M. Wang, W. Zhai, Z. Zhu, Z. Xu, Q. Zhang, S. Song, J. Yao, and A. Q. ud Din, Friction and wear behavior of NiAl-10 wt\% $\mathrm{Ti}_{3} \mathrm{SiC}_{2}$ composites, Wear 303 (2013) 9-20.

[229] X. Shi, W. Zhai, M. Wang, Z. Xu, J. Yao, S. Song, A. Q. ud Din, and Q. Zhang, Tribological performance of $\mathrm{Ni}_{3} \mathrm{Al}-15 \mathrm{wt} \% \mathrm{Ti}_{3} \mathrm{SiC}_{2}$ composites against $\mathrm{Al}_{2} \mathrm{O}_{3}, \mathrm{Si}_{3} \mathrm{~N}_{4}$ and WC-6Co from 25 to $800{ }^{\circ} \mathrm{C}$, Wear 303 (2013) 244-254.

[230] L. Hu, A. Kothalkar, G. Proust, I. Karaman, and M. Radovic, Fabrication and characterization of $\mathrm{NiTi} / \mathrm{Ti}_{3} \mathrm{SiC}_{2}$ and $\mathrm{NiTi} / \mathrm{Ti}_{2} \mathrm{AlC}$ composites, J. Alloy Compd. 610 (2014) 635-644.

[231] S. Amini, C. Ni, and M. W. Barsoum, Processing, microstructural characterization and mechanical properties of a $\mathrm{Ti}_{2} \mathrm{AlC} /$ nanocrystalline Mg-matrix composite, Compos. Sci. Technol. 69 (2009) 414-420. 
[232] B. Anasori, E. N. Caspi, and M. W. Barsoum, Fabrication and mechanical properties of pressureless melt infiltrated magnesium alloy composites reinforced with $\mathrm{TiC}$ and $\mathrm{Ti}_{2} \mathrm{AlC}$ particles, Mater. Sci. Eng. A 618 (2014) 511-522.

[233] N. F. Gao and Y. Miyamoto, Joining of $\mathrm{Ti}_{3} \mathrm{SiC}_{2}$ with Ti-6Al-4V alloy, J. Mater. Res. 17 (2002) 52-59.

[234] D. J. Tallman, J. Yang, L. Pan, B. Anasori, and M. W. Barsoum, Reactivity of Zircaloy-4 with $\mathrm{Ti}_{3} \mathrm{SiC}_{2}$ and $\mathrm{Ti}_{2} \mathrm{AlC}$ in the $1100-1300{ }^{\circ} \mathrm{C}$ temperature range, J. Nucl. Mater. 460 (2015) 122-129.

[235] X. H. Yin, M. S. Li, and Y. C. Zhou, Microstructure and mechanical strength of transient liquid phase bonded $\mathrm{Ti}_{3} \mathrm{SiC}_{2}$ joints using Al interlayer, J. Euro. Ceram. Soc. 27 (2007) 3539-3544.

[236] Y. Hadji, A. Haddad, M. Yahi, M. E. A. Benamar, D. Miroud, T. Sahraoui, M. Hadji, and M. W. Barsoum, Joining $\mathrm{Ti}_{3} \mathrm{SiC}_{2} \mathrm{MAX}$ phase with 308 stainless steel and aluminum fillers by tungsten inert gas (TIG)brazing process, Ceram. Inter. 42 (2016) 1026-1035.

[237] X. H. Yin, M. S. Li, and Y. C. Zhou, Microstructure and mechanical strength of diffusion-bonded $\mathrm{Ti}_{3} \mathrm{SiC}_{2} / \mathrm{Ni}$ joints, J. Mater. Res. 21 (2006) 2415-2421.

[238] S. Basu, M. F. Ozaydin, A. Kothalkar, I. Karaman, and M. Radovic, Phase and morphology evolution in high-temperature $\mathrm{Ti}_{3} \mathrm{SiC}_{2}$-NiTi diffusion-bonded joints, Scripta Mater. 65 (2011) 237-240.

[239] A. Kothalkar, A. Cerit, G. Proust, S. Basu, M. Radovic, and I. Karaman, Interfacial study of NiTi-Ti $\mathrm{SiC}_{2}$ solid state diffusion bonded joints, Mater. Sci. Eng. A 622 (2015) 168-177.

[240] C. Lu, J. Zhang, T. Duan, and C. Liu, Microstructure evolution and brazing mechanisms of the $\mathrm{Ti} \mathrm{A}_{2} \mathrm{AlC} / \mathrm{Ni}$ joints using nickel based filler alloy, J. Euro. Ceram. Soc. 36 (2016) 3319-3327.

[241] X. Yin, M. Li, J. Xu, J. Zhang, and Y. Zhou, Direct diffusion bonding of $\mathrm{Ti}_{3} \mathrm{SiC}_{2}$ and $\mathrm{Ti}_{3} \mathrm{AlC}_{2}$, Mater. Res. Bull. 44 (2009) 1379-1384.

[242] S. Tsukimoto, K. Nitta, T. Sakai, M. Moriyama, and M. Murakami, Correlation between the electrical properties and the interfacial microstructures of TiAl-based ohmic contacts to $p$-type $4 \mathrm{H}$-SiC, J. Electro. Mater. 33 (2004) 460-466.

[243] S. Tsukimoto, K. Ito, Z. Wang, M. Saito, Y. Ikuhara, and M. Murakami, Growth and microstructure of epitaxial $\mathrm{Ti}_{3} \mathrm{SiC}_{2}$ contact, Mater. Trans. 50 (2009) 1071-1075.

[244] Z. Wang, S. Tsukimoto, M. Saito, K. Ito, M. Murakami, and Y. Ikuhara, Ohmic contacts on silicon carbide: The first monolayer and its, Phys. Rev. B 80 (2009) 245303.

[245] K. Buchholt, R. Ghandi, M. Domeji, C.-M. Zetterling, J. Lu, P. Eklund, L. Hultman, and A. Lloyd Spetz, Ohmic contact properties of magnetron sputtered $\mathrm{Ti}_{3} \mathrm{SiC}_{2}$ on $n$ - and $p$-type $4 \mathrm{H}$-silicon carbide, Appl. Phys. Lett. 98 (2011) 042108.

[246] K. Buchholt, P. Eklund, J. Jensen, J. Lu, R. Ghandi, M. Domeji, C. M. Zetterling, G. Behan, H. Zhang, A. Lloyd Spetz, and L. Hultman, Growth and characterization of epitaxial $\mathrm{Ti}_{3} \mathrm{GeC}_{2}$ thin films on $4 \mathrm{H}$ SiC(0001), J. Cryst. Growth 343 (2012) 133-137.

[247] H. Fashandi, M. Andersson, J. Eriksson, J. Lu, K. Smedfors, C.-M. Zetterling, A. Lloyd Spetz, and P. Eklund, Single-step synthesis process of $\mathrm{Ti}_{3} \mathrm{SiC}_{2}$ ohmic contacts on $4 \mathrm{H}-\mathrm{SiC}$ by sputter-deposition of $\mathrm{Ti}$, Scripta Mater. 99 (2015) 53-56.

[248] M. Ohring, The materials science of thin films, Academic Press, California, USA, 1992.

[249] A. C. Jones and M. L. Hitchman, Chapter 1 Overview of Chemical Vapour Deposition in: Chemical Vapour Deposition: Precursors, Processes and Applications, A. C. Jones and M. L. Hitchman, Eds., The Royal Society of Chemistry, Cambridge, UK, 2009, p. 1.

[250] R. Gago, L. Vázquez, R. Cuerno, M. Varela, C. Ballesteros, and J. M. Albella, Nanopatterning of silicon surfaces by low-energy ion-beam sputtering: dependence on the angle of ion incidence, Nanotechnol. 13 (2002) 304-308.

[251] H. Adachi and K. Wasa, Part I Fundamentals of Sputtering in: Handbook of Sputter Deposition Technology 2nd ed., Elsevier, Oxford, UK, 2012, pp. 1-140.

[252] D. W. Hoffman and J. A. Thornton, Compressive stress and inert gas in Mo films sputtered from a cylindrical-post magnetron with Ne, Ar, Kr, and Xe, J. Vac. Sci. Technol. 17 (1980) 380-383. 
[253] I. Petrov, I. Ivanov, V. Orlinov, and J.-E. Sundgren, Comparison of magnetron sputter deposition conditions in neon, argon, krypton, and xenon discharges, J. Vac. Sci. Technol. A 11 (1993) 2733-2741.

[254] P.J.Kelly and R.D.Arnell, Magnetron sputtering: a review of recent developments and applications, Vacuum 56 (2000) 159-172.

[255] J. A. Thornton and A. S. Penfold, II-2 Cylindrical Magnetron Sputtering in: Thin Film Processes, J. L. Vossen and W. Kern, Eds., Academic Press, New York, USA, 1978, pp. 76-114.

[256] S. Schiller, K. Goedicke, J. Reschke, V. Kirchhoff, S. Schneider, and F. Milde, Pulsed magnetron sputter technology, Surf. Coat. Technol. 61 (1993) 331-337.

[257] K. Sarakinos, J. Alami, and S. Konstantinidis, High power pulsed magnetron sputtering: A review on scientific and engineering state of the art, Surf. Coat. Technol. 204 (2010) 1661-1684.

[258] A. Anders, Unfiltered and filtered cathodic arc deposition in: Handbook of Deposition Technologies for Films and Coatings 3rd ed., P. M. Martin, Ed., Elsevier, Oxford, UK, 2010, pp. 466-531.

[259] A. Anders, 3 The Physics of Cathode Processes in: Cathodic Arcs: From Fractal Spots to Energetic Condensation, Springer Science + Business Media, New York, USA, 2008, pp. 75-174.

[260] B. Jütter, Characaterization of the Cathode Spot, IEEE Trans. Plasma Sci. PS-15 (1987) 474-480.

[261] D. M. Sanders and A. Anders, Review of cathodic arc deposition technology at the start of the new millennium, Surf. Coat. Technol. 133-134 (2000) 78-90.

[262] R. L. Boxman and V. N. Zhitomirsky, Vacuum arc deposition devices, Rev. Sci. Instrum. 77 (2006) 021101.

[263] L. Ryves, M. M. M. Bilek, T. W. H. Oates, R. N. Tarrant, D. R. McKenzie, F. A. Burgmann, and D. G. McCulloch, Synthesis and in-situ ellipsometric monitoring of Ti/C nanostructured multilayers using a highcurrent, dual source pulsed cathodic arc, Thin Solid Films 482 (2005) 133-137.

[264] P. Siemroth, T. Schülke, and T. Witke, High-current arc - a new source for high-rate deposition, Surf. Coat. Technol. 68/69 (1994) 314-319.

[265] B. K. Gan, M. M. M. Bilek, D. R. McKenzie, P. D. Swift, and G. McCredie, Optimizing the triggering mode for stable operation of a pulsed cathodic arc deposition system, Plasma Sources Sci. Technol. 12 (2003) 508-512.

[266] A. Anders, Approaches to rid cathodic arc plasma of macro- and nanoparticles: a review, Surf. Coat. Technol. 120-121 (1999) 319-330.

[267] E. Bauer, Phänomenologische Theorie der Kristallabscheidung an Oberflächen. I (in German), Z. Kristallogr. 110 (1958) 372-394.

[268] H. Holleck, Metastable coatings - Predection of composition and structure, Surf. Coat. Technol. 36 (1988) 151-159.

[269] I. Petrov, P. B. Barna, L. Hultman, and J. E. Greene, Microstructural evolution during film growth, J. Vac. Sci. Technol. A 21 (2003) S117-S128.

[270] I. Petrov, L. Hultman, U. Helmersson, J.-E. Sundgren, and J. E. Greene, Microstructure modification of TiN by ion bombardment during reactive sputter deposition, Thin Solid Films 169 (1989) 299-314.

[271] U. Helmersson, M. Lattemann, J. Bohlmark, A. P. Ehiasarian, and J. T. Gudmundsson, Ionized physical vapor deposition (IPVD): A review of technology and applications, Thin Solid Films 513 (2006) 1-24.

[272] A. Anders, A review comparing cathodic arcs and high power impulse magnetron sputtering (HiPIMS), Surf. Coat. Technol. 257 (2014) 308-325.

[273] A. Anders, A structure zone diagram including plasma-based deposition and ion etching, Thin Solid Films 518 (2010) 4087-4090.

[274] J. L. Schroeder, A. S. Ingason, J. Rosen, and J. Birch, Beware of poor-quality MgO substrates: A study of $\mathrm{MgO}$ substrate quality and its effect on thin film quality, J. Cryst. Growth 420 (2015) 22-31. 


\section{Papers}

The articles associated with this thesis have been removed for copyright reasons. For more details about these see:

http://urn.kb.se/resolve? urn:nbn:se:liu:diva-137367 